\title{
DEVELOPMENT OF CONTINUOUS SOLVENT EXTRACTION PROCESSES FOR COAL DERIVED CARBON PRODUCTS
} DE-FC26-03NT41873

\author{
Quarterly Report \\ PERIOD OF PERFORMANCE: \\ January 1, 2005 - March 31, 2005 \\ Resubmission date: \\ June 8, 2005 \\ Principal Investigator: \\ Elliot B. Kennel
}

Co-Investigators:

Stephen P. Carpenter, Dady Dadyburjor, Manoj Katakdaunde, Liviu Magean, Peter G. Stansberry, Alfred H. Stiller, John W. Zondlo

\author{
West Virginia University \\ Department of Chemical Engineering \\ PO Box 6102 \\ Morgantown WV 26506 \\ Subcontractors: \\ GrafTech International \\ 12900 Snow Road \\ Parma, OH 44130 \\ Koppers Inc. \\ 1005 William Pitt Way \\ Pittsburgh, PA 15238
}

College of Engineering and Mineral Resources 


\section{DISCLAIMER:}

"This report was prepared as an account of work sponsored by an agency of the United States Government. Neither the United States Government nor any agency thereof, nor any of their employees, makes any warranty, express or implied, or assumes any legal liability or responsibility for the accuracy, completeness, or usefulness of any information, apparatus, product, or process disclosed, or represents that its use would not infringe privately owned rights. Reference herein to any specific commercial product, process, or service by trade name, trademark, manufacturer, or otherwise does not necessarily constitute or imply its endorsement, recommendation, or favoring by the United States Government or any agency thereof. The views and opinions of authors expressed herein do not necessarily state or reflect those of the United States Government or any agency thereof." 


\begin{abstract}
The purpose of this DOE-funded effort is to develop continuous processes for solvent extraction of coal for the production of carbon products. These carbon products include materials used in metals smelting, especially in the aluminum and steel industries, as well as porous carbon structural material referred to as "carbon foam" and carbon fibers.

During this reporting period, efforts have focused on the development of continuous processes for hydrogenation as well as continuous production of carbon foam and coke.
\end{abstract}




\section{TABLE OF CONTENTS}

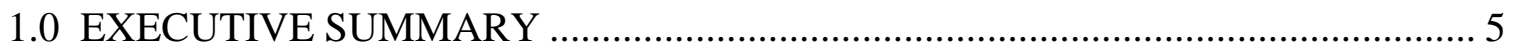

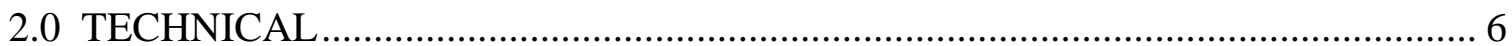

2.1 Development of a Continuous Process for Pitch ................................................ 6

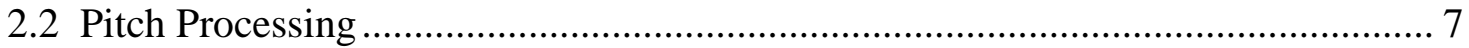

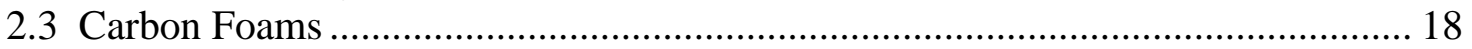

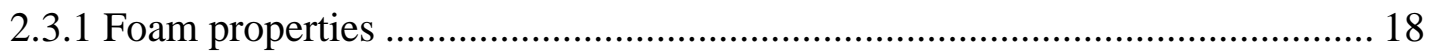

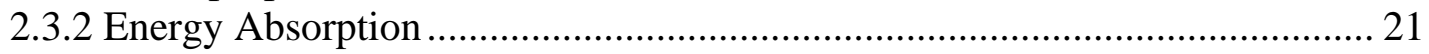

2.3.3 ASTM Experimental Methods ............................................................... 21

2.3.4 A New Experimental Method for Carbon Foam.............................................. 23

2.3.5 Experimental Tests on Carbon Foams ....................................................... 30

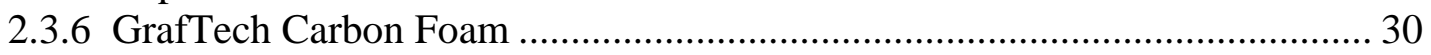

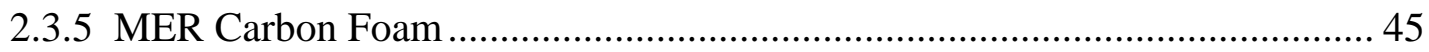

2.3.8 WVU Carbon Foams................................................................................... 46

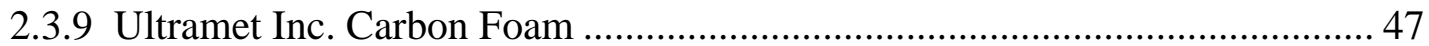

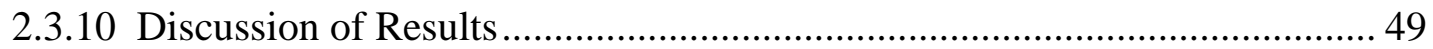

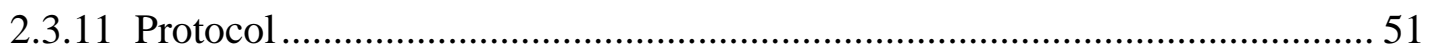

APPENDIX A. Proposed Test Protocol................................................................. 53

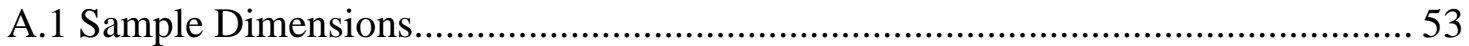

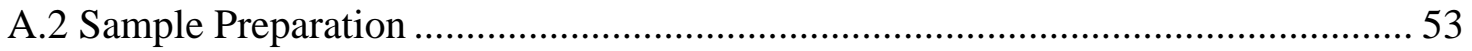

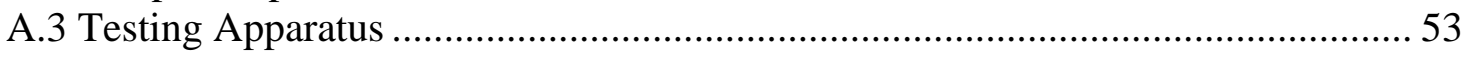

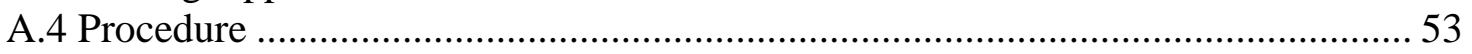

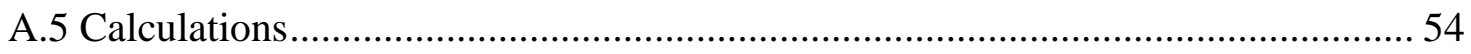

Appendix B. Stress-Strain Plots............................................................................. 55 


\subsection{EXECUTIVE SUMMARY}

The purpose of this DOE-funded effort is to develop continuous processes for solvent extraction of coal for the production of carbon products. These carbon products include materials used in metals smelting, especially in the aluminum and steel industries, as well as porous carbon structural material referred to as "carbon foam" and carbon fibers.

During this reporting period, efforts have focused on the development of continuous processes for hydrogenation as well as continuous production of carbon foam and coke.

Hydrotreatment of coal in the presence of hydrogen donor solvents is considered to be a potential route for developing value-added carbon products. Coal-derived solvents were investigated as replacements for expensive hydrogen-donor solvents like tetralin, in the production of hydrogen rich precursors to commercial carbon products. Three coalderived solvents from the metallurgical coke ovens, namely Heavy Creosote Oil (HCO), Carbon Black Base (CBB) and Refined Chemical Oil (RCO), were utilized as hydrogen donor solvents in the hydrotreatment/extraction process. The conversion to produce THF solubles were observed to decrease in the order as $\mathrm{CBB}>\mathrm{HCO}>\mathrm{RCO}$. Process-derived (recovered) solvents were isolated as vacuum distillation overheads. The residue from the distillation, i.e. the pitch, was characterized by measuring the softening point, ash content, elemental analysis and optical texture. The coke yield and softening point of the pitch followed a linear dependence on the amount of solvent distilled from the product mixture. The effect of temperature and reaction atmosphere was studied on the hydrotreatment process. The coal-alone conversion increased with higher temperature and a hydrogen atmosphere was found to be crucial. The optimum process temperature was found to be $450{ }^{\circ} \mathrm{C}$ under 500 psig (cold) hydrogen pressure. The ash content of the pitches was found to be low, on the order of $0.2 \%$. The optical texture of the cokes exhibited anisotropic structure which might be suitable for use as anode coke or a graphite precursor. The elemental composition of the pitches showed higher hydrogen-tocarbon ratio than the feed coal and was found to be similar irrespective of reaction conditions.

Specific accomplishments for this period include the following:

a. A new condenser for the coking furnace has been constructed.

b. A new stainless steel tank has been fitted for pilot plant centrifuge

c. A new column heat exchanger has been fabricated for the hydrogenation plant

d. A fill tank has been constructed for the hydrogenation plant reactor

e. Work has begun on the modified calcination furnace interface. 


\subsection{TECHNICAL}

\subsection{Development of a Continuous Process for Pitch}

The Hydro Treatment Facility has required extensive minor equipment modifications to be fabricated or modified such as fabrication of a fill tank for the digestion reactor, fabrication of a heat exchanger to condense vapors.

A major concern was that the centrifugation of coal digests resulted in ash content of 0.7 mass percent or even higher, which exceeds the specification of 0.5 maximum mass percent ash for binder pitch. Initial trials of large scale coal digests were centrifuged at a very low mass throughput rate (or as slow as the pump in the pilot plant would allow) and the ash content was over $1 \%$ mass percent after vacuum distillation. The initial concern was that the product was picking up ash from the carbon steel containers that was being used to transport the mixtures. To solve this concern carbon steel tanks were replaced with stainless steel tanks which were modified to fit both the bunker and pilot plant. This involved cutting new larger ports and then welding stainless steel nipples in the newly cut ports. These tanks will serve as feed tanks and receiving vessels for the materials in the processing.

After another run through the centrifuge with the new tanks, the ash content was reduced to the $0.7 \%$ level, still in excess of the specification. Hot filtration, combined with WFE distillation produced a pitch of approximately $110^{\circ} \mathrm{C}$ softening point and ash content of $0.5 \%$ to $0.6 \%$ and is considered marginally acceptable.

A full scale production plant may well require the use of centrifugation from the standpoint of economics. Hence this option needs to be developed in parallel with the hot filtration technique. The decanter type centrifuge operated in the Solvent Extraction Pilot Plant was originally manufactured by Sharples Pennwalt, now Pennwalt India, Ltd. Pennwalt was consulted to determine whether the centrifugation process might be enhanced. Pennwalt's response was that decreasing the solids content by more than a decade generally requires two centrifuges to be run in series. The downstream unit might be a high speed disc bowl centrifuge, which might succeed in "clarifying" the output to well below the 0.5 mass percent requirement. This is considered to be a viable option; however thus far it has not been pursued further due to schedule, cost and laboratory space constraints.

The wiped film evaporator has been reconnected to the pilot plant and new stainless steel tanks have been added. A stand was constructed for the product collection vessel so it could be mounted vertically. Also all piping and valves to and from the vessels were replaced with stainless steel.

Although organic vapor emission from the apparatus is quite low, below 1 ppm even during operations, it is necessary to further reduce odors that are emitted from the process. Although this might not be a problem at a pitch plant (say Follansbee or Clairton), it is a problem given the proximity of the facilities to offices at the National Research Center for Coal and Energy (NRCCE). Activated carbon will be used in an odor and vapor collection vessel to further mitigate odors. This unit will be installed in a 
manner that will allow all vapors produced by any part of the pilot plant to pass through this vessel before going out the exhaust vents.

\subsection{Pitch Processing}

Efforts on pitch processing protocols are summarized below, based upon Katakdaunde's Master's thesis. ${ }^{1}$ Coal-derived pitches have been obtained by combining coal hydrogenation with solvent extraction. In these experiments, coal is hydrogenated in the presence of tetralin, which has been proven to be a very effective hydrogen donor. However, during liquefaction reactions, tetralin is converted into naphthalene and cannot be reused without external separation and rehydrogenation. Also tetralin is an expensive solvent and cannot be employed for commercial production of pitches because its cost far exceeds the cost of the final carbon product.

Coal-derived liquids could replace tetralin as the liquefaction solvent. Making this substitution would have several advantages: (1) the possibility of producing a recyclable solvent during the product separation steps thus eliminating the need to supply an external solvent except for makeup; (2) the process would employ only coal and coal products as starting materials, thus generating a completely coal-derived carbon product precursor; (3) the coal-derived liquids are by-products from the coal tar industry and their low cost compared to tetralin would significantly bring down the overall process cost, making it economically viable. As mentioned earlier, these coal-derived liquids come from the by-product coke oven industry and since the coke industry is on a decline, the availability of these coal-derived liquids may become a problem. Nevertheless the nearterm advantages seem to promise a future for these liquids, so it is worthwhile to study these coal-derived liquids as hydrogen-donor solvents. The evaluation of several coalderived liquids as solvents for the production of carbon-product precursors is studied in this paper.

A high-volatile bituminous coal, Lower War Eagle (LWE), was obtained from the southern West Virginia coal fields. The coal had fixed carbon, volatile matter and ash content of $63.3 \%, 31 \%$ and $5.7 \%$ respectively. The coal was ground to -20 mesh and dried overnight in a vacuum oven. Three coal-derived solvents referred to as refined chemical oil (RCO), heavy creosote oil (HCO), and carbon black base (CBB) were obtained from Koppers Industries Inc. HCO is a pasty material that needed to be heated in order to process easily. RCO is fluid at ambient temperatures but contains some solid like matter entrained in the fluid. Therefore, it was also heated before processing. CBB is a homogenous liquid at room temperature and is used as received. The following table shows the ultimate analysis of the LWE coal and the three coal-derived liquids. 
Table 1. Ultimate analysis of LWE coal and the three coal derived solvents.

\begin{tabular}{|l|l|l|l|l|}
\hline Elements (\%) & LWE & CBB & HCO & RCO \\
\hline $\mathrm{C}$ & 88.7 & 91.6 & 92.4 & 91.8 \\
\hline $\mathrm{H}$ & 4.68 & 5.7 & 5.7 & 6.9 \\
\hline $\mathrm{N}$ & 0.9 & 0.0 & 0.7 & 0.6 \\
\hline $\mathrm{S}$ & 0.6 & 0.5 & 0.6 & 0.7 \\
\hline $\mathrm{O}^{\mathrm{a}}$ & 5.12 & 2.2 & 0.6 & 0.0 \\
\hline $\mathrm{H} /$ C Atomic Ratio & 0.63 & 0.75 & 0.74 & 0.90 \\
\hline
\end{tabular}

a determined by difference

The hydrogenation reactions were run in tube bomb microreactors (TBMR) made of 316 stainless steel and having $50 \mathrm{cc}$ body volume. A Techne SBL-2 fluidized sand bath was used to heat the TBMR. A Techne TL-8D temperature controller regulated the sand bath temperature. The sand bath is filled three-quarters full with a -100 aluminum oxide powder.

The hydrogenations were run with the three coal-derived solvents under hydrogen pressure of $500 \mathrm{psig}$ (cold), temperature of $400{ }^{\circ} \mathrm{C}$, solvent-to-coal ratio of 5:1 and a reaction time of 1 hour. To investigate the effect of temperature and reaction atmosphere, the temperature was varied from $350{ }^{\circ} \mathrm{C}$ to $450{ }^{\circ} \mathrm{C}$ in increments of $50{ }^{\circ} \mathrm{C}$. In some runs nitrogen replaced hydrogen to affect the change of reaction atmosphere.

Two TBMR were prepared to run each reaction condition in duplicate. Once the reactor was thoroughly cleaned, one end of TBMR was sealed and the reactants weighed and charged into the TBMR according to the desired ratio. The solvent weight was determined by difference. Three stainless steel ball bearings were weighed and added to the TBMR to aid in the mixing of the charge. Once charged the other end of TBMR was sealed. Air was removed from the sealed TBMR by pressure purge cycling using the desired reaction gas. Finally, the TBMR was pressurized to the desired cold reaction pressure and the purge valve was sealed. Once charged, the TBMRs were placed in the holder above the fluidized sand bath which has been already preheated to a temperature slightly above the desired reaction temperature. The TBMR was agitated by a shaking mechanism at $400 \mathrm{rpm}$ with a vertical stroke of 1.5 inches. The TBMR was rapidly heated by immersion into the sand bath by raising the sand bath using a winch-and-pulley system. The time of reaction was counted from this time onwards. After being at temperature for one hour, the sand bath was quickly lowered and the TBMR was quenched rapidly by immersion in cold water.

Once quenched completely, the gas in the TBMR was vented off. The pasty TBMR products were then washed quantitatively into a flask with the solvent tetrahydrofuran (THF). A heat gun was necessary to facilitate this process. The flask containing coal/solvent/THF solution was filled with fresh THF until three-quarters full, placed in a heating mantle and fitted with a simple water-cooled condenser. The solution was allowed to boil for about 12-16 hours. After cooling, the contents were centrifuged at $4000 \mathrm{rpm}$ for 30 mins and the liquid portion was decanted into a Buchner funnel under 
vacuum. The filtering funnel was fitted with a preweighted filter paper to collect the solids. The residue remaining in the centrifuge bottles was washed with fresh THF to separate any entrapped soluble products. This mixture was again centrifuged at $4000 \mathrm{rpm}$ for 15 mins. and the liquid portion again vacuum filtered. Finally the solids from the filter paper and the centrifuge bottles were combined and upon subsequent drying in the vacuum oven gave the THF insoluble fraction of the product. This fraction was used to calculate the overall and the coal-alone conversion. The overall conversion is based on quantities of feed coal and solvent while the coal-alone conversion is based only on the weight of feed coal.

The filtrate was stripped of THF by rotary evaporation. The remaining coal liquid containing only the converted coal and the coal-derived solvent was further separated by vacuum distillation into the two main products, the soluble product pitch and the recovered solvent. The vacuum distillation was a simple separation set-up with the heated flask fitted with a thermometer and the product collection system immersed in a dry ice bath and connected to a vacuum pump. The typical distillation conditions were 270-280 ${ }^{\circ} \mathrm{C}$ temperature and close to $30 \mathrm{~mm} \mathrm{Hg}$ vacuum. These conditions were employed so as to maximize the recovery of the solvent from the process; however a temperature of $300{ }^{\circ} \mathrm{C}$ was not exceeded to avoid coking of the pitch. The recovered solvent was then recycled to assess its utility as a hydrogenation solvent.

Standard characterization techniques for cokes and pitches such as softening point, ash content, coke yield, elemental analysis and optical microscopy were performed on these products so that they might be compared to their typical commercial analogs.

Each of the three coal liquids was used as a hydrogenation solvent under the same conditions of temperature, pressure, reaction time and solvent-to-coal ratio so that a quantitative comparison of the conversion yields could be performed. The overall and coal-alone conversions for the three solvents at $400{ }^{\circ} \mathrm{C}$ and 500 psig cold $\mathrm{H}_{2}$ pressure are shown in the figure below. $\mathrm{CBB}$ was found to be the most effective solvent while RCO was least effective towards solubilizing coal to THF solubles. The complete solubility of coal liquids in THF and the use of high 5:1 solvent-to-coal ratio explain the large difference between the overall conversion (which involves the quantity of solvent) and the coal-alone conversion. Therefore, the effect of changing solvents on coal conversion was swamped by the large amount of solvent that was included in the overall conversion calculation. So, the coal-alone conversion gives a more definitive comparison between the solvents as it does not include any solvent in the calculation.

A mass balance was performed on each hydrogenation run with the three solvents being tested. The next table shows the results of the mass balance for a representative run of all the trials for each of the three solvents. The results showed an average mass loss of 7-10\%. Three routes were identified which could account for the observed mass loss. THF rotovaporization, vacuum distillation and solubles trapped in the THF insolubles from the centrifuge bottles. Negligible mass loss was found through the first and last route and was minimized by careful operation. The vacuum distillation accounted for maximum mass loss and was unavoidable. 


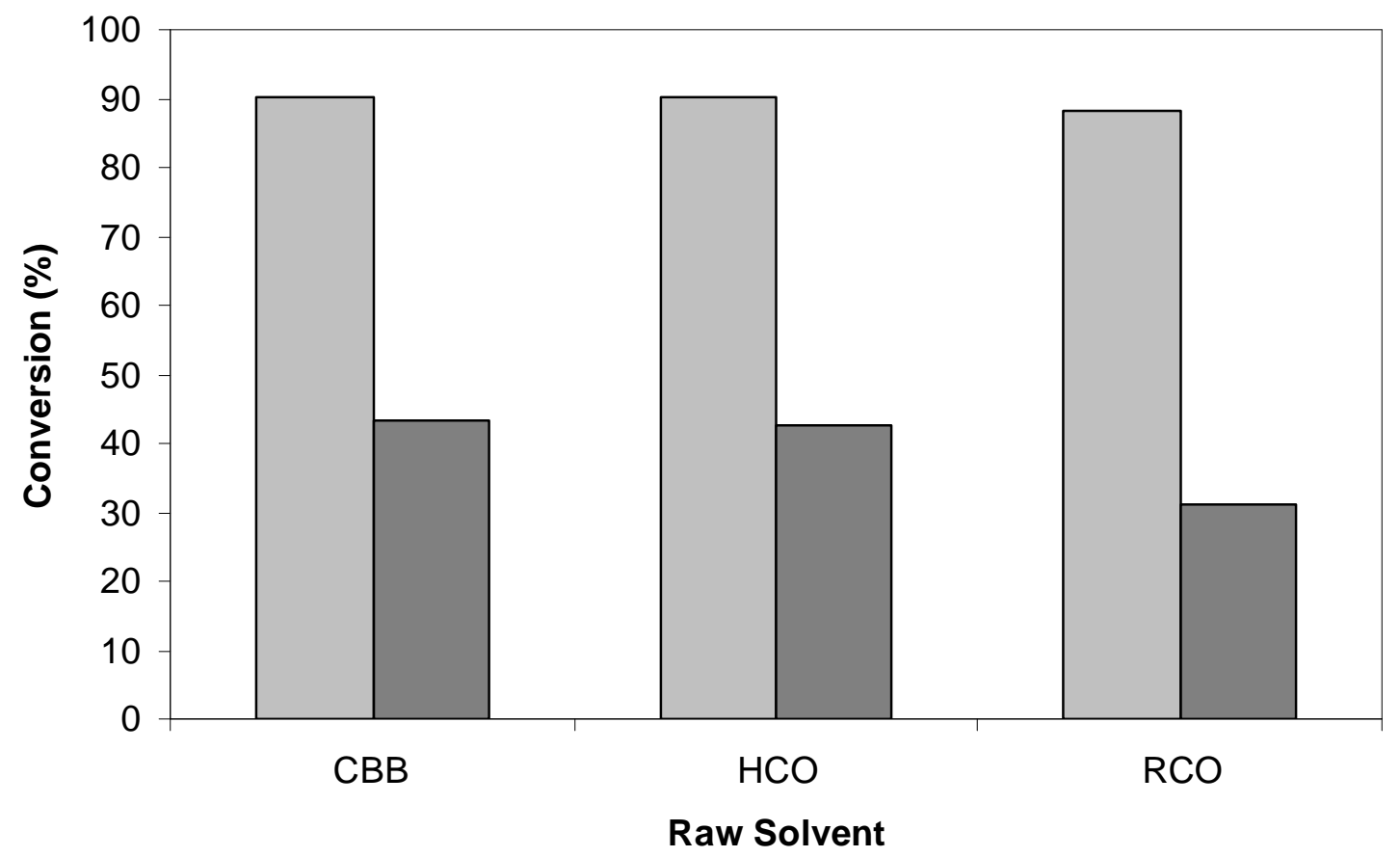

$\square$ Overall Conversion $\square$ Coal-Alone Conversion

Figure 1. Overall and Coal-alone conversion yields for LWE coal with fresh HCO, CBB and $\mathrm{RCO}$ at $400{ }^{\circ} \mathrm{C}, 500 \mathrm{psig}$ cold hydrogen and one hour reaction time.

Table 2. Mass Balances of the Coal Digestion Reactions with Fresh Solvents.

\begin{tabular}{|l|l|l|l|l|l|l|l|l|}
\hline $\begin{array}{l}\text { Coal } \\
(\mathbf{g})\end{array}$ & $\begin{array}{l}\text { Fresh } \\
\text { Solvent } \\
(\mathbf{g})\end{array}$ & $\begin{array}{l}\text { Total } \\
\text { Input }(\mathbf{g})\end{array}$ & $\begin{array}{l}\text { Pitch } \\
\text { (g) }\end{array}$ & $\begin{array}{l}\text { THF Ins. } \\
\text { (g) } \\
\text { Solv. }(\mathbf{g})\end{array}$ & $\begin{array}{l}\text { Total } \\
\text { Output (g) }\end{array}$ & $\begin{array}{l}\text { Input } \\
\text { Output (g) }\end{array}$ & $\begin{array}{l}\text { Loss } \\
(\%)\end{array}$ \\
\hline 4.0021 & 20.2 & 24.2021 & 2.88 & 2.3566 & 17.1 & 22.3366 & 1.8655 & 7.7 \\
\hline 4.0031 & 20.2 & 24.2031 & 3.05 & 2.4198 & 16.41 & 21.8798 & 2.3233 & 9.6 \\
\hline 4.0032 & 20.1 & 24.1032 & 3.98 & 2.8156 & 15.1 & 21.8956 & 2.2076 & 9.1 \\
\hline
\end{tabular}

The pressure profiles during the course of the reaction and after quenching proved to be of value. Information such as maximum pressure under high temperature conditions, the average rate of rise/fall during the reaction and the cold pressure at the end of the quenching can be determined from tracing pressure with time. The rate of pressure fall under a hydrogen atmosphere gives an indication of how fast hydrogen is being consumed and the rate of pressure rise under a nitrogen atmosphere gives an indication how fast the volatiles are coming off the reacting mixture. The final cold pressure suggests the quantity of hydrogen consumption or the amount of volatiles generated during reaction.

Reaction pressure profiles were traced during the course of reaction and following quenching. The next figure shows the pressure profiles for all the three solvents. The 
sudden rise in pressure occurs when the reactors were inserted into the hot sand bath while the steep drop indicates quenching in the water bath following the reaction. After the initial pressure rise there is a steady drop in the pressure indicating consumption of hydrogen gas when the reaction mixture is at temperature. This is further confirmed by the final cold pressure which is found to be less than the initial cold pressure. This difference in pressure can be used to estimate the moles of hydrogen consumed during the course of reaction with the assumption that the gas products from the reaction are minimal. In fact the hydrogen consumption using the ideal gas law was estimated at approximately $0.5 \%$ of the total feed weight.

The product distributions for reactions with the three solvents are shown in an Figure 3. The mass loss was found to be on the order of $7-10 \%$ for reactions with raw solvents. It can also be observed that the dominant fraction among the three products is the distilled solvent which accounts for $60-70 \%$ of the original feed including the coal and the solvent. The other two product fractions depend upon the coal-alone conversion and the amount of solvent distilled in the vacuum distillation step.

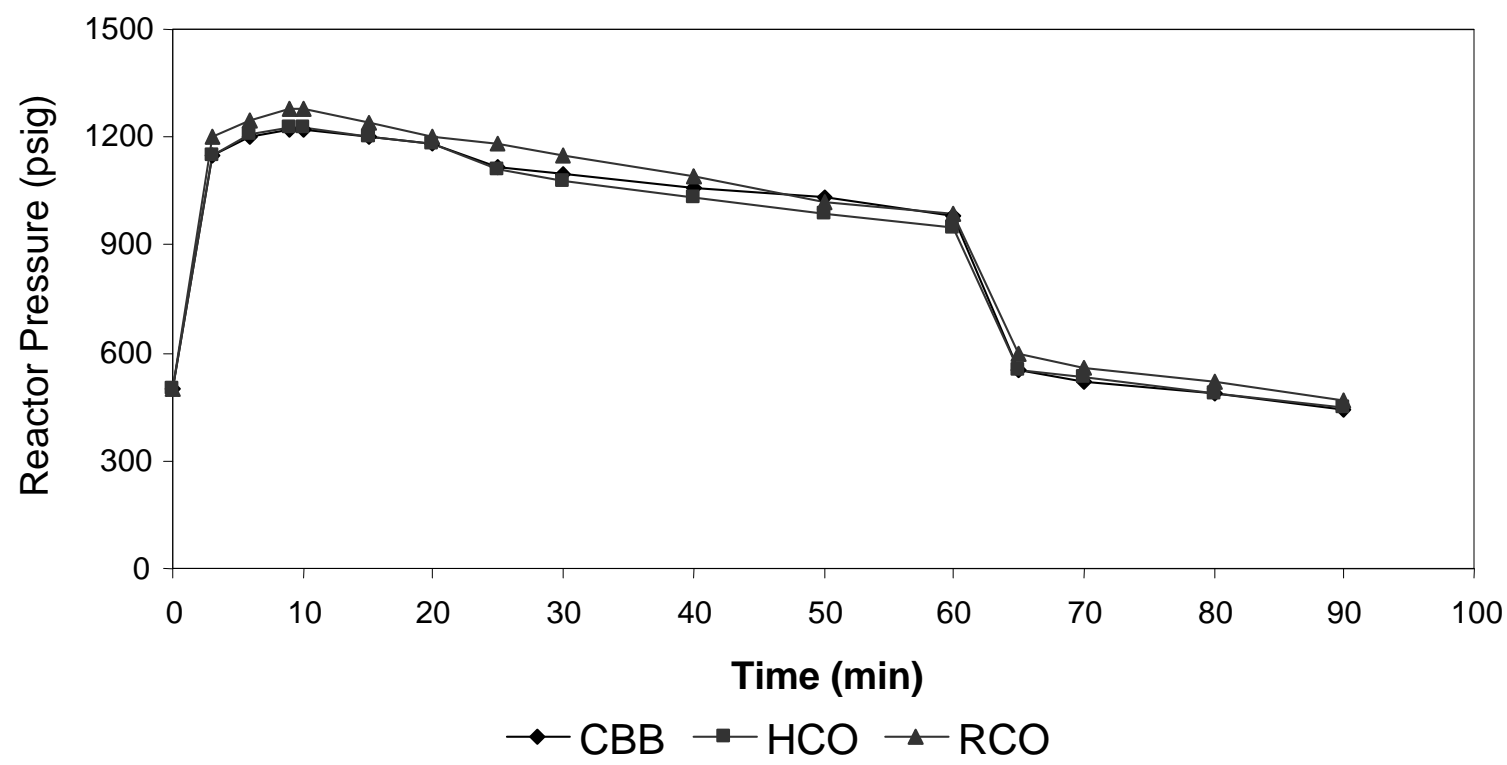

Figure 2. Pressure profiles for fresh solvents $\mathrm{CBB}, \mathrm{HCO}$ and $\mathrm{RCO}$ at $400{ }^{\circ} \mathrm{C}, 500$ psig cold hydrogen and one hour reaction time. 


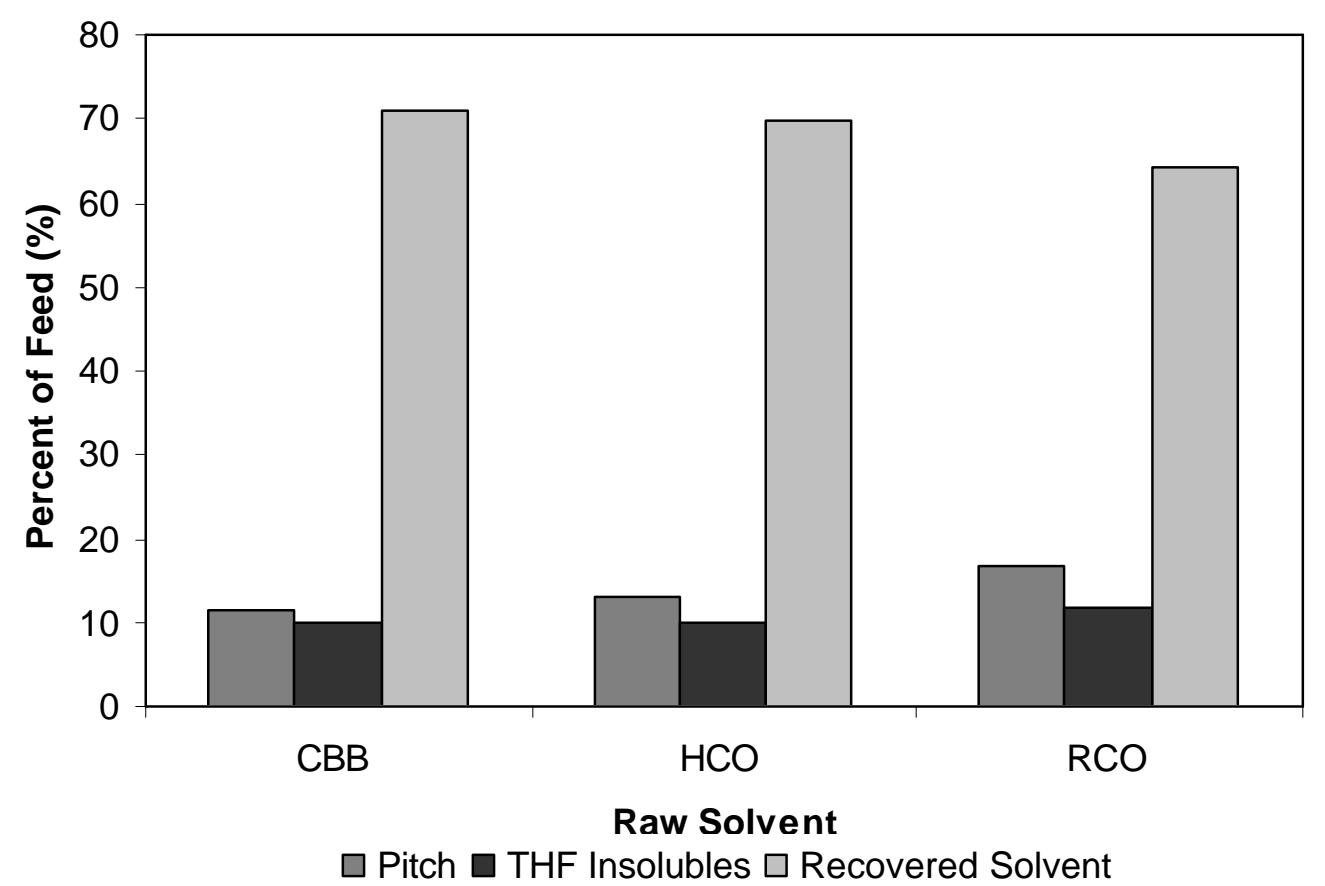

Figure 3. Hydrogenation product distribution for LWE coal using raw solvents CBB, $\mathrm{HCO}$ and $\mathrm{RCO}$ at $400{ }^{\circ} \mathrm{C}, 500$ psig cold hydrogen and one hour reaction time.

The pitch product (defined as the residue from the vacuum distillation step) for all the three solvents was characterized for ash content, softening point and the coke yield. The results are shown in the table below. The pitch products in general showed low ash, moderate softening point and very high coke yields. The optical micrographs of the raw pitches show some development of mesophase. This is due to the rather high temperature the pitch sees in the distillation pot - sometimes around $300{ }^{\circ} \mathrm{C}$. Thus the high coke yield is a consequence of the high temperature the material had seen in the distillation. Pitches obtained from this process might be useful for applications such as fiber spinning or coke making which require moderate softening point and high coke yield.

Table 3. Characteristics of the hydrogenation products using raw solvent.

\begin{tabular}{|l|l|l|l|l|}
\hline \multirow{2}{*}{ Raw Solvent } & THF Insolubles & \multicolumn{3}{|l|}{ Pitch } \\
\cline { 2 - 5 } & $\begin{array}{l}\text { Ash } \\
(\mathbf{\%})\end{array}$ & $\begin{array}{l}\text { Ash } \\
(\mathbf{\%})\end{array}$ & $\begin{array}{l}\text { Coke Yield } \\
(\boldsymbol{\%})\end{array}$ & $\begin{array}{l}\text { Softening Point } \\
\left({ }^{\mathbf{O}} \mathbf{C}\right)\end{array}$ \\
\hline CBB & 9.2 & 0.16 & 81.4 & 129 \\
\hline HCO & 9.1 & 0.25 & 79.1 & 122 \\
\hline RCO & 8.2 & 0.28 & 84.1 & 158 \\
\hline
\end{tabular}

During the vacuum distillation step variable amounts of recovered solvent were distilled from the pitch to determine the relationship between the softening point and the coke yield. These results are shown in the figure below, where solvent removal via distillation was targeted for 40,60, and $80 \%$ of the feed solvent amount. Both these properties were found to yield a linear relationship with the amount of solvent distilled. 
Moreover, reactions with the three different solvents showed identical behavior. A later figure shows the same linear relationship between the softening point and the coke yield. This can be important commercially, where a variety of tailor-made pitches are required based on the end applications.

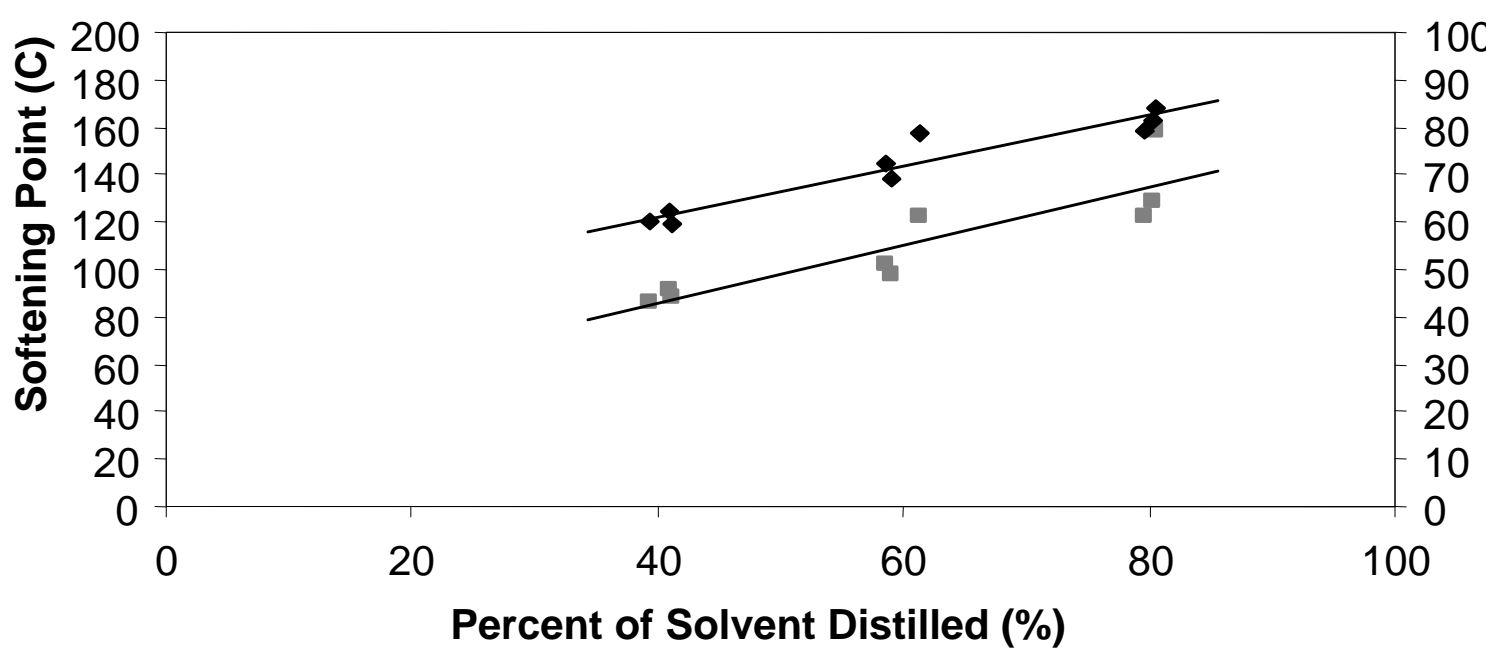

- Softening Point $(\mathrm{C})$ - Coke yield (\%)

Figure 4. Relation between coke yield and softening point for the pitch product from reactions using solvents $\mathrm{CBB}, \mathrm{HCO}$ and $\mathrm{RCO}$ with $\mathrm{LWE}$ coal at $400{ }^{\circ} \mathrm{C}, 500$ psig cold hydrogen and one hour reaction time.

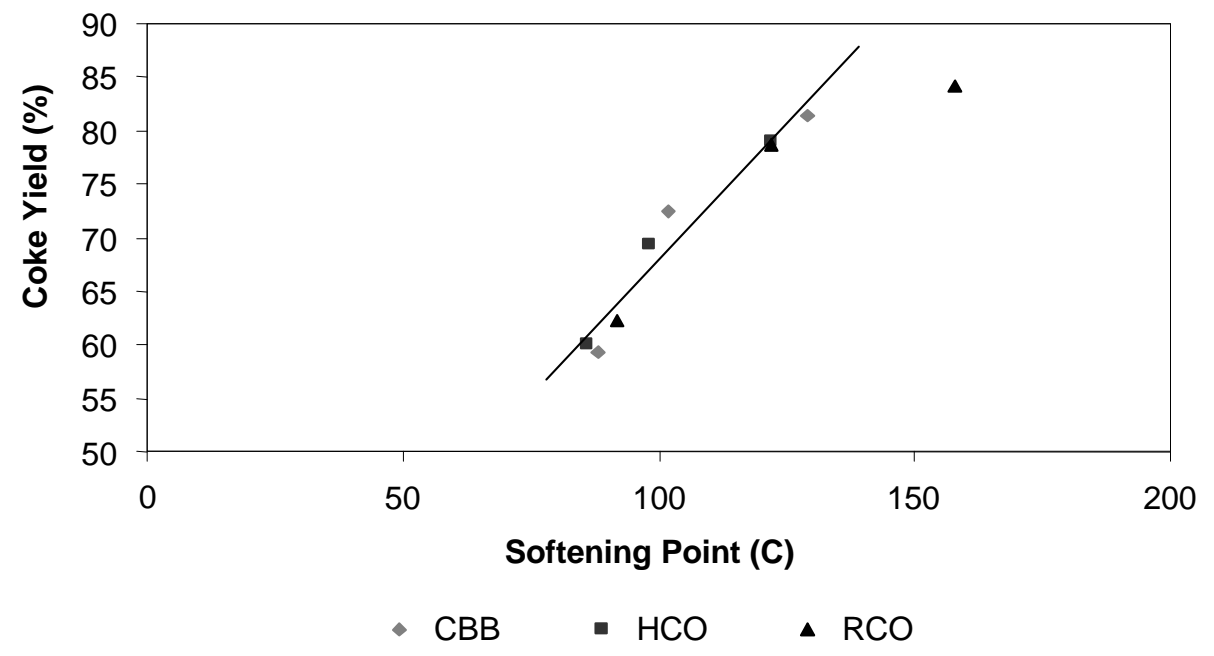

Figure 5. Relation between coke yield and softening point for the pitch product from LWE coal using solvents $\mathrm{CBB}, \mathrm{HCO}$ and $\mathrm{RCO}$ at $400{ }^{\circ} \mathrm{C}, 500$ psig cold hydrogen and one hour reaction time. 
Elemental analysis was done on the pitch and the recovered solvent for the purpose of assessing the $\mathrm{H} / \mathrm{C}$ ratio. This ratio gives an idea of the aromaticity/aliphaticity of the products. Data for the freshly recovered solvents are presented in the table below. The more effective solvents were found to be primarily aromatic in nature as suggested by the lower $\mathrm{H} / \mathrm{C}$ ratio for $\mathrm{CBB}$ and $\mathrm{HCO}$ as compared to $\mathrm{RCO}$. Also the $\mathrm{H} / \mathrm{C}$ ratio for the recovered solvents was found to be similar to the raw solvents indicating that the recovered solvents should behave comparable to the fresh solvents. It was found that the pitch showed a higher $\mathrm{H} / \mathrm{C}$ ratio than the feed coal, which means that hydrogen has been added to the organic coal matrix by hydrotreatment.

Table 4. Elemental composition of the hydrogenation reactions for three solvents.

\begin{tabular}{|l|l|l|l|l|}
\hline \multirow{2}{*}{ Solvent } & Element & $\begin{array}{l}\text { Fresh } \\
\text { Solvent } \\
(\boldsymbol{\%})\end{array}$ & $\begin{array}{l}\text { Pitch } \\
(\boldsymbol{\%})\end{array}$ & $\begin{array}{l}\text { Recovered } \\
\text { Solvent } \\
(\boldsymbol{\%})\end{array}$ \\
\hline \multirow{3}{*}{$\mathrm{CBB}$} & $\mathrm{C}$ & 91.66 & 92.24 & 91.79 \\
\cline { 2 - 5 } & $\mathrm{H}$ & 5.78 & 5.46 & 5.85 \\
\cline { 2 - 5 } & $\mathrm{H} / \mathrm{C}$ & 0.75 & 0.71 & 0.77 \\
\hline \multirow{3}{*}{$\mathrm{HCO}$} & $\mathrm{C}$ & 92.46 & 92.59 & 93.16 \\
\cline { 2 - 5 } & $\mathrm{H}$ & 5.76 & 5.66 & 5.95 \\
\cline { 2 - 5 } & $\mathrm{H} / \mathrm{C}$ & 0.75 & 0.73 & 0.77 \\
\hline \multirow{3}{*}{$\mathrm{RCO}$} & $\mathrm{C}$ & 91.81 & 92.15 & 89.90 \\
\cline { 2 - 5 } & $\mathrm{H}$ & 6.9 & 6.23 & 7.25 \\
\cline { 2 - 5 } & $\mathrm{H} / \mathrm{C}$ & 0.90 & 0.81 & 0.96 \\
\hline
\end{tabular}

Pitch samples were coked by soaking at $600{ }^{\circ} \mathrm{C}$ for an hour in an inert atmosphere. The cokes were observed under the polarized-light microscope. The nature of optical texture determines the end use of the material. Figure 6 below shows the structures of the cokes obtained from the three solvents. All the cokes produced from the hydrogenation reactions with $\mathrm{CBB}$ and $\mathrm{HCO}$ were found to have large flow domains, which indicate an anisotropic texture. For the RCO samples, the domains appear to be smaller and more uniformly distributed suggesting a lesser degree of anisotropy as compared to the samples from CBB and HCO. Anisotropic cokes such as these may be suitable for the production of graphite electrodes or anodes whereas isotropic coke from RCO may be more suitable for the production of graphite.
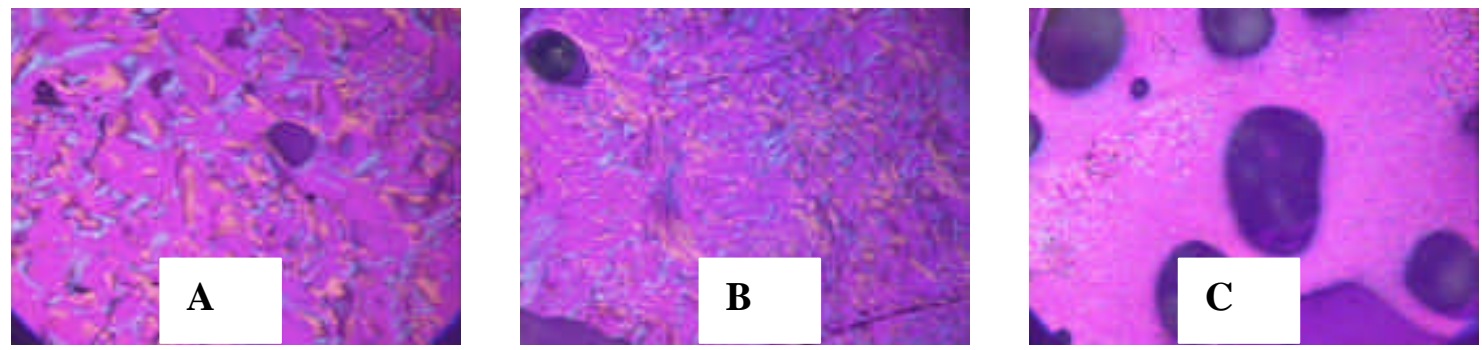

Figure 6. Optical Micrographs of coke samples: (A) Coke with CBB. (B) Coke with HCO. (C) Coke with RCO. 
To understand the influence of the reaction parameters on the hydrotreatment, two important parameters, temperature and the reaction atmosphere, were varied. Three different temperatures 350,400 and $450{ }^{\circ} \mathrm{C}$ were looked at under hydrogen while nitrogen was used as the other reaction atmosphere only at $400{ }^{\circ} \mathrm{C}$. Temperature was not increased beyond $450{ }^{\circ} \mathrm{C}$ as higher temperature led to excessive gas formation, thus decreasing the liquid yield. Solvent $\mathrm{CBB}$ was chosen as the solvent of choice to investigate these changes as it gave the highest conversion and also is readily available commercially. The figure below shows the results of coal-alone conversion with temperature. Coal-alone conversion was found to increase substantially with an increase in temperature.

Figure 8 shows the coal-alone conversion under a nitrogen atmosphere as compared with the conversion under hydrogen at identical processing conditions. The conversion decreased by around $10 \%$ when the atmosphere was changed to nitrogen. This suggests that hydrogen is critical during these hydrogenation runs. There is also one more important thing to notice here. The conversion with nitrogen at $400{ }^{\circ} \mathrm{C}$ is higher than at $350{ }^{\circ} \mathrm{C}$ with hydrogen. This means that though the hydrogen atmosphere is crucial, it is the temperature which plays a major role in these types of reactions. Also it is unexpected to see that even under nitrogen the conversion did not decrease appreciably. This is because of the polyaromatic hydrocarbons (PAH's) present in the solvents which have been known to be good extractors for coal.

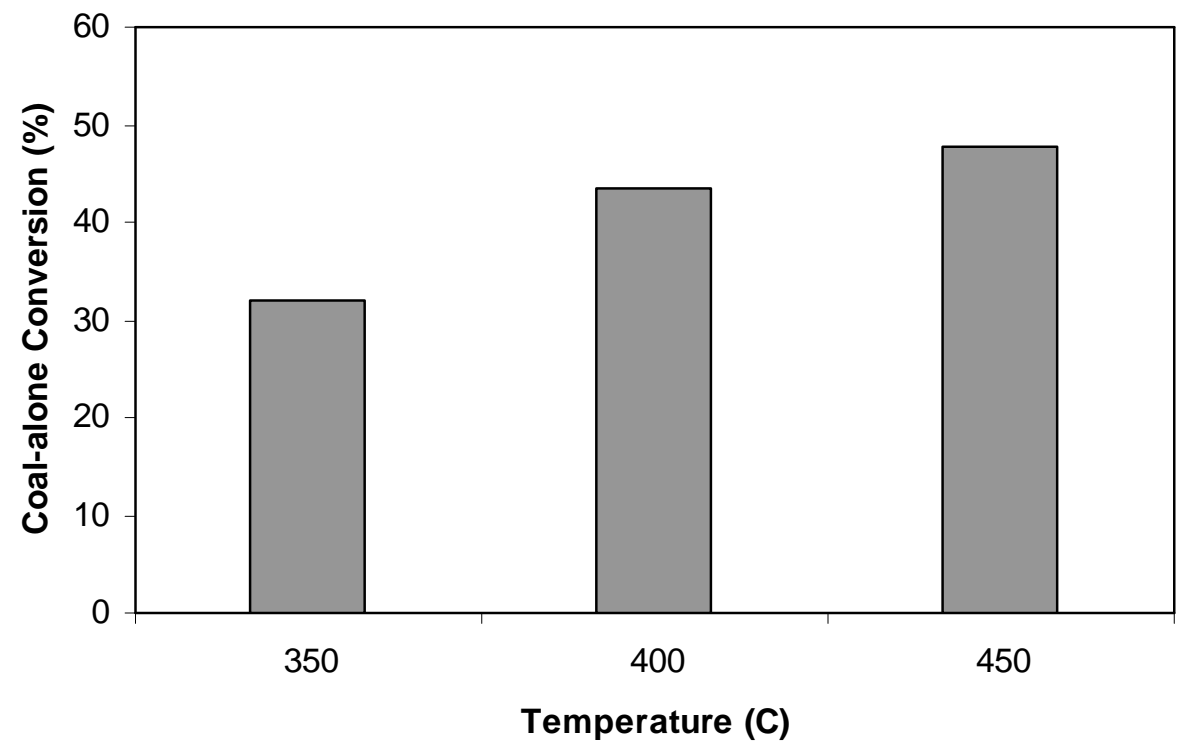

Figure 7. Coal-alone conversion for LWE coal at different temperature using raw CBB at 500 psig cold hydrogen and one hour reaction time.

In reactions such as these, where there is deficiency of hydrogen either by absence of gas phase hydrogen or by absence of hydroaromatic structures in the solvent, the shuttling effect (rearrangement of hydrogen radicals within the coal matrix) becomes the main mechanism for hydrogen transfer. 
Figure 9 shows the pressure profile for reactions under hydrogen and nitrogen atmosphere. Unlike hydrogen, the nitrogen atmosphere shows an increase in pressure during the course of reaction and also a higher final cold pressure than the initial cold pressure. This demonstrates the fact that some non-condensable species are being produced in the reaction and that hydrogen is indeed being consumed.

The microstructure of the cokes obtained at different temperature and with reaction under nitrogen atmosphere was also looked into. The coke structure for these samples showed anisotropy similar as those exhibited by the samples obtained under the standard conditions. However the degree of anisotropy was different. No attempt was made to quantify the degree of anisotropy within different samples. Relatively lower temperature or nitrogen atmosphere samples showed less degree of anisotropy compared to their counterparts at higher temperature or hydrogen atmosphere.

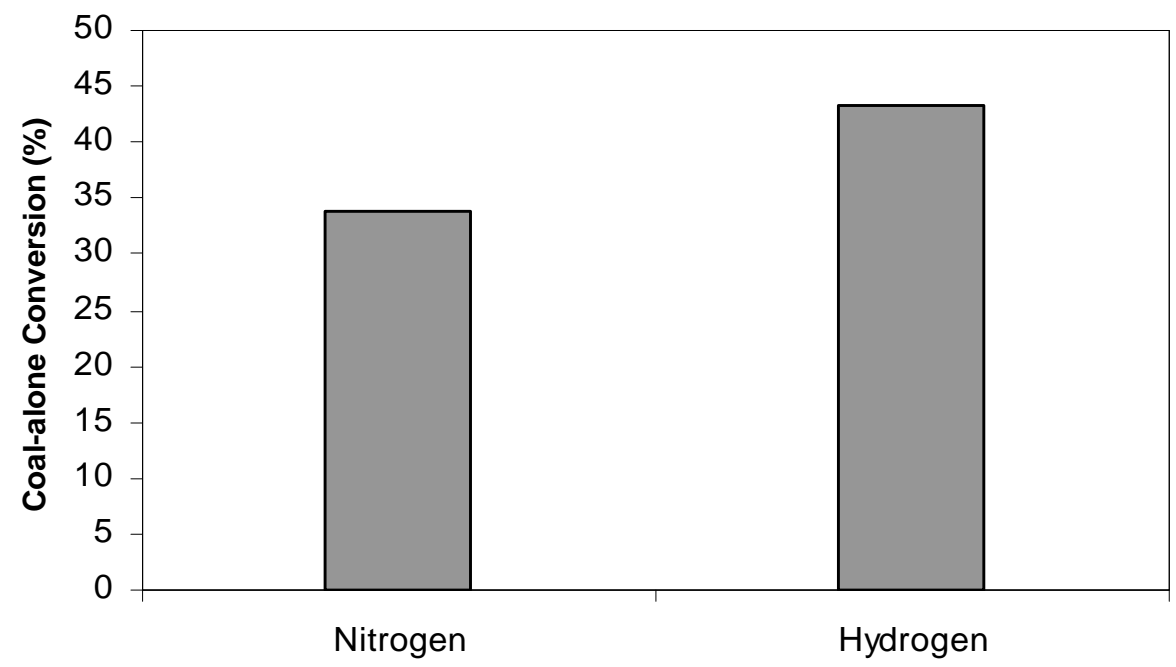

Figure 8. Coal-alone conversion for LWE coal using raw CBB under different reaction atmospheres and $400{ }^{\circ} \mathrm{C}, 500 \mathrm{psig}$ cold pressure and a reaction time of one hour. 


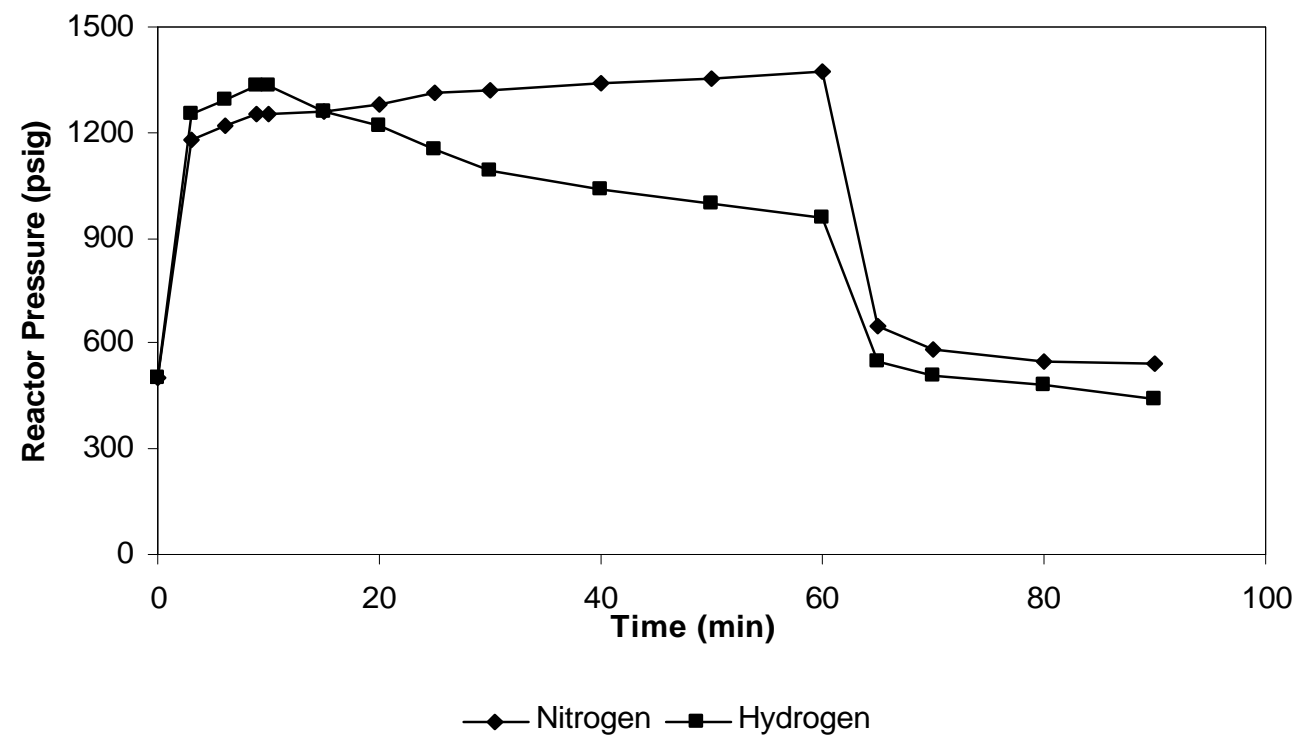

Figure 9. Pressure profiles for LWE coal reaction with raw CBB at $400{ }^{\circ} \mathrm{C}, 500$ psig cold hydrogen/nitrogen and one hour reaction time.

The coal-alone conversion was a reasonable quantifying measure over overall conversion in such hydrotreatment studies involving higher solvent-to-coal ratios. Good coal extractor solvents were found to be primarily aromatic. Higher coal-alone conversion values were found at higher temperature and in a hydrogen atmosphere. The pitch products at high $(\sim 80 \%)$ recovery of the solvent were found to exhibit low ash, moderate softening point and high coke yields. The softening point and the coke yield showed linear dependence. The optical texture of the cokes exhibited anisotropic structure. 


\subsection{Carbon Foams}

Some of the most sought after properties of carbon foams are their mechanical properties: yield strength, Young's Modulus, and energy absorption. These particular properties are essential to determine specific uses for different types of carbon foams. However, different carbon foam manufacturers are using different techniques to obtain these properties. Compression and tensile testing are both done for stress analysis, different samples are prepared in different ways, and different instruments are used by different labs to test these mechanical properties of vastly different carbon foams. These variances in compression testing result in inconsistent properties reported by carbon foam manufacturers. $^{2}$

Several items must be addressed before a test can be administered. The most important issue is to determine which results can be gathered and what conclusions can be made as a result of a particular test. Other items include studying the influence of variables that may come from the material being tested, sample preparation, and experimental parameters of the test itself.

\subsubsection{Foam properties}

The crucial foam properties to be measured are bulk density, the Young's Modulus, the yield strength, and fracture strength. Young's Modulus is the initial slope of the stress-strain compression curve that is linear. The yield strength corresponds to the plateau of the stress-strain curve during compressive loading and is associated with the collapse of the cells. This collapse can occur by elastic buckling (as in elastomeric foam such as rubber), by the formation of plastic hinges in a foam that yield (such as a metallic

foam), and by brittle crushing of cells within a brittle foam (such as carbon foam). The stress at which the compressive load reaches a point where the cell walls begin to physically break apart and fracture is called the fracture strength. The fracture strength and the yield strength are basically the same for brittle foams in which the cell walls do not bend much, but fracture under a compressive load. When the cells have almost completely collapsed, opposing cell walls touch and further strain compresses the solid itself. This gives a final region at the end of the stress-strain plateau of rapidly increasing stress known as the densification region. These properties and areas of an actual stressstrain plot can be seen in Figure 10. 


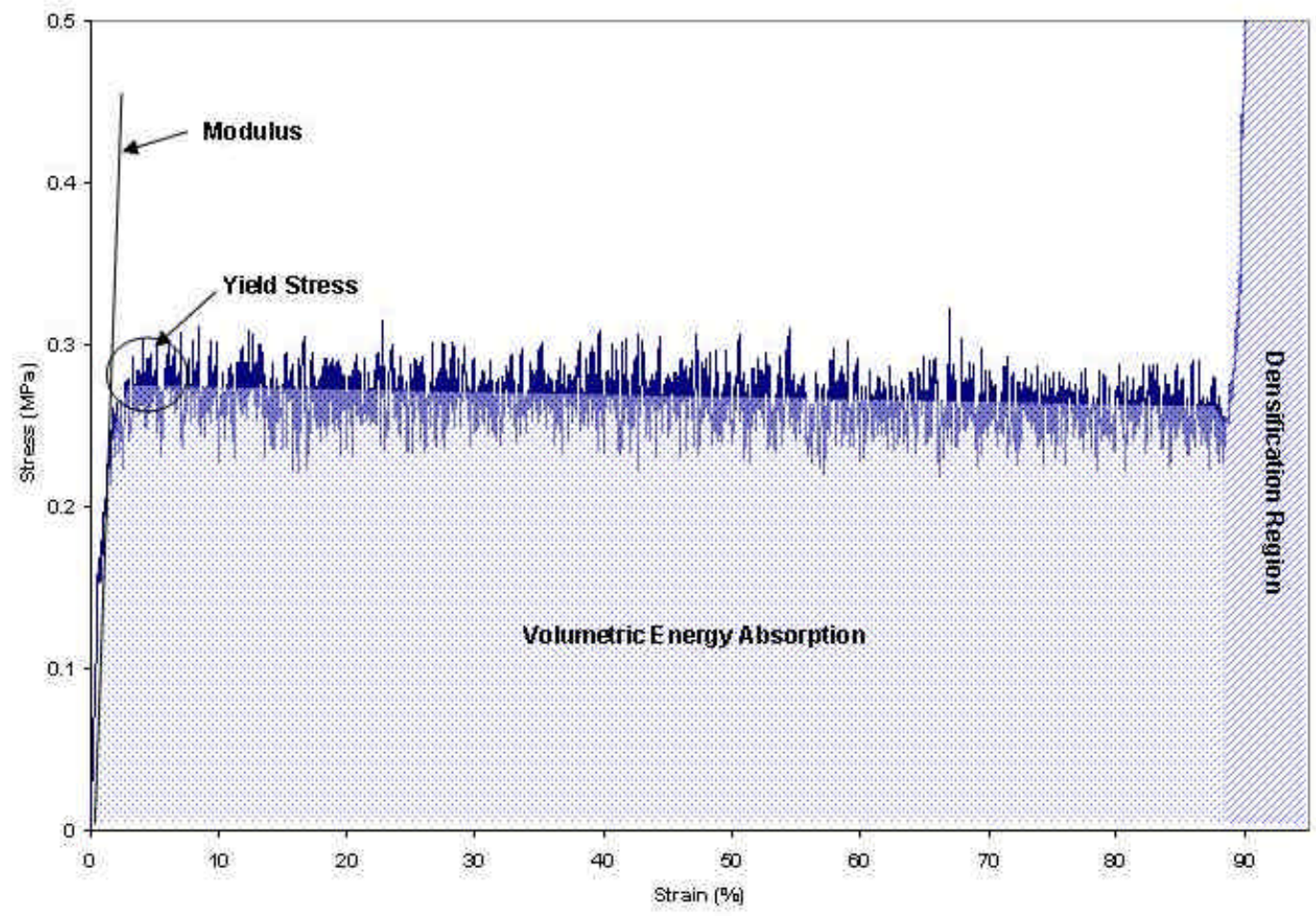

Figure 10. Typical Compressive Stress vs. Strain plot for a foam sample.

The most important structural features of any foam that can impact its mechanical properties are its relative density, the degree to which the cells are opened or closed, and the cells' shape anisotropy within the foam. The relative density is defined as the ratio of the bulk density of the foam divided by the density of the solid from which the foam was made. The higher a foam's relative density, the stronger the foam will be due to an increase of solid material within the foam matrix. Closed cell foams are generally stronger than open cell foams because of the increase of surface area of solid material surrounding each cell that must be fractured. Instead of having cells partially surrounded by solid material as is the case in open cells, the cells are completely encased in solid carbon material. However, surface tension usually forces the bulk of the material to accumulate in the outer edges or corners of the cells themselves, leaving little more than a thin membrane of solid material that closes the cell structures. Cell anisotropy also has a large effect on foam strength. Most foams are anisotropic. Polymer foams, made by pouring the polymer plus a hardener and a foaming agent into an open mold, usually have cells that are elongated in the rise direction. Anisotropy can arise in two different ways. The more obvious is structural anisotropy. This is a directional dependence of the foam properties directly attributed to the shape of the cells, as in the open mold foaming mentioned. The other arises from material anisotropy in the properties of the cell walls. Anisotropy in the modulus, strength, and toughness of foams is a common observation. In polymer foams, there is a general agreement that the Young's Modulus is greatest in the rise direction; that is, the direction of greatest elongation of the cells, and an 
agreement that the plastic collapse strength of a rigid plastic foam, too, is greatest in this direction. However, despite the frequent reports of anisotropy, there are very few which contain enough information on cell shape and on properties in the three principle directions to allow a critical comparison with the theory. ${ }^{3}$

There are a few controllable variables that have an impact on the results of a compression test. Temperature of the sample can be a major factor, especially when working with thermoplastic polymer-based foams. As the temperature rises and approaches the softening point of the material, the yield strength decreases due to the inherent softening of the material. However, for the case of carbon foams, this is not an issue since these foams are usually calcined to over $1000{ }^{\circ} \mathrm{C}$ and hence can withstand very high temperatures without softening.

The ratio of the cross-sectional areas of the compressive device and the foam sample being compressed can also have an impact on test results for brittle foams such as carbon foam. Indentation tests of brittle foams with open cells, in which the compressive device has a smaller cross-section than the foam sample, show a surprising effect. The indentation pressure is not always equal to the compressive strength, but is strongly dependant on the size of the indenter face. It has been discovered that the maximum indentation pressure $P_{i}$ is inversely proportional to the square root of facial area of the indenter $A_{s}$, such that

$$
P_{i} \propto \frac{1}{\sqrt{A_{s}}}
$$

This size effect is valid for values of $A_{s}$ which are much greater than the area of a single cell. Therefore, as the area of the compressive device gets smaller (compared to the area of the sample), the resultant compressive strength reading gets higher. However, if all the cell edges contact the indenter surface, the true yield stress can be determined from the test. That is to say, if the facial area of the indenter is equal to the apparent crosssectional area of the foam sample, the resultant compressive strength reading is equal to the actual yield strength of the foam.

The strain rate of the compression test can influence the results as well. At high strain rates, inertial effects drive the compression strength upwards. There are three features of dynamic crushing that influence the overall force displacement response. Localization is the concentration of deformation at a given instant into a thin layer, often adjacent to the loading force. Caused by geometric softening, localization leads to local strain rates which are much larger than the apparent nominal strain-rate. Micro-inertia is associated with rotation and lateral motion of cell walls when they buckle. This tends to suppress the more compliant buckling modes, thus increasing the crushing stress. Densification causes the stress to rise steeply when cell walls come into contact. This leads to "shock" enhancement at very high strain rates because the cell collapse is overdriven during densification. These three phenomena will inflate the real results of yield strength for brittle foams thus causing increased energy absorption behavior. 


\subsubsection{Energy Absorption}

Foams are especially promising for applications requiring high energy adsorption. Compared to the solid from which it is made, the foam always generates a lower peak force for the same energy absorption. Energy is absorbed as cell walls bend plastically, buckle, or fracture, but the stress is limited by the long, flat plateau of the stress-strain curve.

When the foam is loaded, work is done by the forces applied to it. The work per unit volume in deforming the foam to a strain $E$ is simply the area under the stress-strain curve up to the strain $E$. Very little energy is absorbed in the short, linear-elastic portion of the curve. It is the long plateau of the curve, arising from cell collapse by buckling, yielding, or crushing, which allows large energy absorption at near-constant load. The level of this plateau depends on the material and density of the foam, and on the rate of strain. Ordinary laboratory compressive testing equipment provide low strain rates, $10^{-8}$ to $10^{-2} / \mathrm{s}$. Converted to an impact velocity on a compressible foam $100 \mathrm{~mm}$ thick is $10^{-9}$ to $10^{-3} \mathrm{~m} / \mathrm{s}$. Free fall from a height of 1 meter gives an impact-velocity of just over $4 \mathrm{~m} / \mathrm{s}$, with associated strain rates (same $100 \mathrm{~mm}$ thickness) of around 40/s. These intermediate strain rates are reproduced in the laboratory with high-speed servo-hydraulic testing equipment and drop hammer tests. Automotive applications require protection against impacts up to 40/s and ballistic impacts can be 50 times faster than that, corresponding to velocities up to $10^{4} \mathrm{~m} / \mathrm{s}$. Dynamic loading devices, gas guns, and explosive loading equipment allow this high strain rate to be investigated. The upper end of this range lies above the sound velocity in all foams, and here inertial effects drive the plateau levels upward rapidly. However, dynamic loading of foams is rarely relevant for the kind of packaging applications in which foams excel. ${ }^{3}$

\subsubsection{ASTM Experimental Methods}

In order to find the best testing method for compressing carbon foam, ASTM standard testing methods were researched for similar tests on similar materials. Five ASTM testing methods were referenced for sample preparation, testing apparatus and protocol, and for data acquisition and processing:

a. C 67-99a Standard Test Methods for Sampling and Testing Brick and Structural Clay Tile. ${ }^{4}$

b. C 695-91(95) Standard Test Method for Compressive Strength of Carbon and Graphite. $^{5}$

c. D 1621-00 Standard Test Method for Compressive Properties of Rigid Cellular Plastics. ${ }^{6}$ Plastics. ${ }^{7}$

d. D 696-96 Standard Test Method for Compressive Properties of Rigid 
e. F 414-96 Standard Test Method for Energy Absorbed by a Tire When Deformed by a Slow-Moving Plunger. ${ }^{8}$

The first four methods deal directly with measuring the yield strength of the material. Each test is stopped when the yield stress has been reached and the sample being tested has failed. The final test (F 414-96) measures only the energy absorbed by a tire from a plunger that is forced into its treads.

The four compressive testing methods each have very small variations in test specimen requirements. However, all agree that at least five specimens must be tested to yield reliable, statistical results.

Each test requires a right-angled volume with a circular cross-section. Some of the tests leave the option for a square cross-section, but all tests mention a right cylinder. The measurements of each specimen depend on particle sizes or cell sizes within each material being tested. For example, the carbon and graphite test requests a diameter greater than ten times the size of the largest particle. The rigid cellular plastic foam test, on the other hand, specifies a cross-section between $4-36 \mathrm{in}^{2}$. The specimen height requirement of each test varies slightly as well. Carbon and graphite testing requires a height-to-diameter ratio between $1.9-2.1$ to 1.0. The cellular plastic foam test specifies a minimum height of 1 inch and a maximum of no greater than the specimen diameter.

Each test also requires some conditioning of the samples before they are tested. These instructions vary, but all agree that the specimens must be dry and well conditioned to the humidity and temperature of the room in which the specimen shall be tested.

Each of the ASTM methods contains similar instructions. Specimen dimensions are to be recorded as an average of three measurements for each diameter and height by a caliper to \pm 0.001 in. Measurements should be taken when specimen and caliper faces come in contact. The caliper should not compress the specimen for any measurements. The specimen should be centered in testing apparatus within $5 \%$ of the specimen diameter.

Each test describes platen movement differently, according to the requirements and expectations of each material being tested. Brick and clay tile testing defines testing speed by applying half of the expected maximum load at any rate and the remainder of the load must be applied within 1-2 minutes. The carbon and graphite test requires continuous load to be applied so that specimen rupture time is greater than 30 seconds. Rigid cellular plastic foam testing specifies platen movement at $2.5 \pm 0.25 \mathrm{~mm} / \mathrm{min}$ and the solid rigid plastic test specifies $1.3 \pm 0.3 \mathrm{~mm} / \mathrm{min}$. Finally, the energy absorption test for a tire requires a plunger speed of $50 \mathrm{~mm} / \mathrm{min}$.

The tests described here are all of an unconstrained method. That is to say that the sample being compressed is not contained within or constrained by any physical apparatus or sample holder. In the case of very dense foams, this usually results in multidirectional volume change. When failure occurs at the yield stress, the sample usually breaks apart causing the cross-section to change as pieces of foam break off. Most carbon foams are currently tested using some type of unconstrained method to gather modulus and yield stress. When failure occurs, the test is ended. However, the total energy absorption cannot be assessed by these techniques. Therefore, an alternate procedure must be developed so that the entire stress/strain curve can be measured. The 
development of this new test is the focus of the present research proposal. Details of the test and the apparatus are described below.

Each of the current ASTM tests record the same information when it comes to gathering and calculating the final results. Compressive strength (also yield strength in the case of brittle foams) $C$ is defined as the load $F_{f}$ at the time of sample failure divided by the cross-sectional area $A$ of the sample.

$$
C=\frac{F_{f}}{A}
$$

Apparent modulus $E_{c}$ is defined as the change in stress divided by the change in strain for the linear portion of the stress-strain curve.

$$
\begin{aligned}
& E_{c}=\frac{\Delta \text { stress }}{\Delta \text { strain }}=\frac{d S}{d x} \\
& \text { stress }=\frac{F}{A}=S \\
& \text { strain }=\frac{\Delta D}{H}(100 \%)=x
\end{aligned}
$$

where $\Delta D$ is deformation of the specimen, $H$ is the initial height of the specimen, and $F$ is the load at any point during the test during the linear portion of the test. Finally, the energy absorbed per unit volume $W$ by the specimen is defined as the area under the plateau region of the stress-strain curve $T(L)$ up to a any desired strain $x$.

$$
W=\int_{0}^{x} T(L) d L
$$

Equation 2.6 can only be used if the cross-section of the sample being compressed stays constant throughout the compression test. In the event that the cross-section changes, Equation 2.6 can no longer be used because the area $A$ in Equation 2.2 is no longer constant. This results in false stress values in the stress-strain curve $T(L)$.

\subsubsection{A New Experimental Method for Carbon Foam}

After consulting the aformentioned ASTM methods and general theory of foam compression, it was noted that none of the methods are strictly applicable to carbon foam. Thus, the following experimental procedure has been proposed as a compression test 
method for carbon foams. This single test method provides results for yield strength, Young's Modulus, as well as energy absorption.

a. Specimens shall be a right cylinder. Great care must be taken to insure that the faces of the right cylinder are parallel to each other and perpendicular to the cylindrical sides. The diameter of each cylinder shall be $25 \mathrm{~mm}$ (1in) and the height shall be between 25-50mm (1-2 inches).

b. The specimens should be conditioned in the room in which the test shall be performed for 24 hours.

Compression tests on the carbon foam have been successfully performed using an Instron 5869 load frame fitted with a $50 \mathrm{kN}$ load cell. A piston assembly has been constructed out of stainless steel in order to control the sample cross-section during compression testing. This defines a one-dimensional volume change as the samples are compressed.

A hollow, stainless steel cylinder has been turned on a lathe with an inside diameter of $25.4254 \mathrm{~mm} \pm 0.0254 \mathrm{~mm}(1.001 \pm 0.001 \mathrm{in})$. An $88.9 \mathrm{~mm}$ (3.50in) long solid plunger and a $12.7 \mathrm{~mm}(0.50 \mathrm{in})$ long solid plug were also constructed with an outside diameter of $25.3746 \mathrm{~mm} \pm 0.0254 \mathrm{~mm}(0.999 \pm 0.001 \mathrm{in})$. The plug is employed as a false bottom for the sample chamber cavity to provide a stable base for the specimen and to ensure that the crushed specimen can be removed. A photograph of the complete assembly can be seen in Figure 11 below and a schematic of the piston assembly crushing a carbon foam sample along with its resulting stress-strain plot can be seen in Figure 12 . The foam is compressed between the solid plunger and the solid plug to ensure a onedimensional volume change between two parallel surfaces.

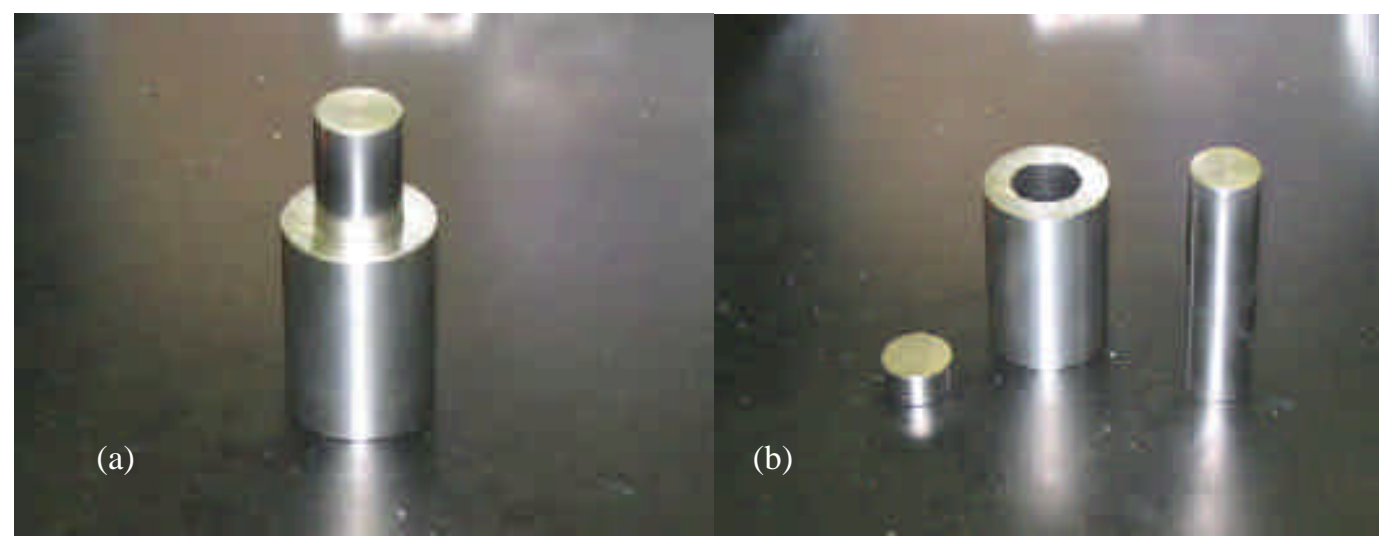

Figure 11. Photographs of piston-assembly used in compression tests as a complete assembly (a), and its individual parts (b). 


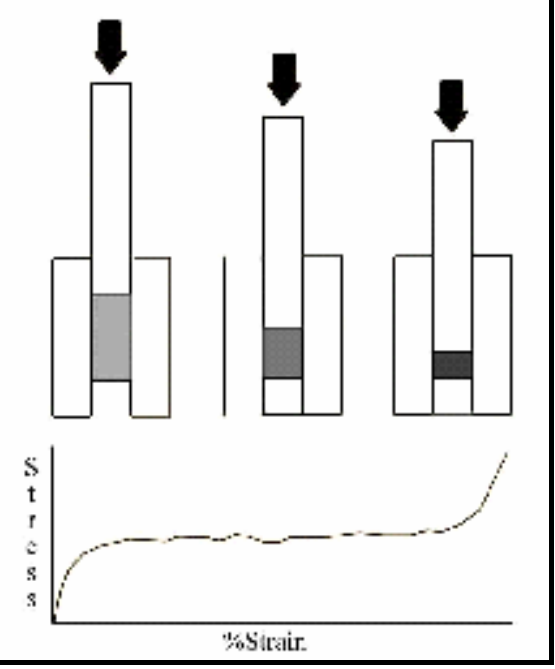

Figure 12. Schematic of piston assembly and corresponding Stress vs. Strain plot.

The height and diameter of each specimen are recorded as an average of 3 different measurements using a caliper to the nearest \pm 0.001 in $( \pm 0.0254 \mathrm{~mm})$. The measurement shall be taken when the faces of the caliper first come into contact with the specimen, there should be no force from the caliper applied to the specimen. The specimen weight $( \pm 0.01 \mathrm{~g})$ shall also be taken so that bulk density can be calculated. The specimen shall be placed in the piston assembly, assuring that the loaded ends are parallel and no binding can occur between the piston and the cylinder. The piston assembly is placed between the platens, being sure that the assembly is centered on the lower platen. The platens shall compress at $1 \mathrm{~mm} / \mathrm{min}$ to assure that there is no air resistace being recorded as air escapes the cylinder.

The yield strength (or compressive strength) $C(\mathrm{MPa})$ is defined as the maximum load $F_{m}(\mathrm{~N})$ of the linear portion of the stress-strain curve divided by the apparent crosssectional area $A_{c}\left(\mathrm{~mm}^{2}\right)$ of the foam sample being tested.

$$
C=\frac{F_{m}}{A_{c}}
$$

The Young's Modulus $E_{c}(\mathrm{MPa})$ is the slope of the linear portion of the plot and is defined as the change in stress divided by the change in strain.

$$
E_{c}=\frac{y_{1}-y_{2}}{\left(\frac{x_{1}-x_{2}}{100}\right)}
$$

where $x_{1}, y_{1}$ is a set of data for strain and stress at an instant, and $x_{2}, y_{2}$ is a set of data for strain and stress at another instant (both are on the linear portion of the curve). 
The total energy absorbed per unit volume is found by integrating the area under the Stress vs. Strain plot. Integration can be carried out using the Newton-Cotes closed integration formula where:

$$
\begin{gathered}
x_{i}=\frac{x_{n+1}-x_{n}}{100} \\
y_{i}=\frac{y_{n}+y_{n+1}}{2} \\
A=\sum_{1}^{i} x_{i} y_{i}
\end{gathered}
$$

The total area $A$ under the stress-strain plot, which is the total energy absorbed by the foam, is calculated by the summation of the products of each individual piece of area. The individual pieces are defined as the product of $x_{i}$ and $y_{i}$. The term, $x_{i}$, is defined as the difference between two consecutive data points of strain (\%), where the $y_{i}$ term is the arithmetic mean of two consecutive data points of stress (MPa). The area under the plot is the total energy absorbed per unit volume expressed in $\mathrm{MJ} / \mathrm{m}^{3}$, and dividing the total energy by the sample density results in specific energy $(\mathrm{kJ} / \mathrm{kg})$.

Several tests have been successfully performed using the proposed compression test method for compressing carbon foams. Tests have been performed on various types of carbon foams using this method. These foams have differed greatly in bulk density, cell size and shape, as well as the material from which the foam was produced. There have been many specific testing sessions in which the constrained test was used to obtain data for different carbon foams. Two of the most recent were done as part of a round robin test for the United States Air Force Research Laboratory. The first session was comprised of testing foams from Poco Graphite, Incorporated; Touchstone Research Laboratories (TRL); and Materials and Electrochemical Research (MER) Corporation. The second such session included carbon foams from Ultramet and Fiber Materials, Incorporated (FMI). No further information was supplied concerning the manufacturing processes used for any of these carbon foam samples. It should also be noted that complete information regarding other laboratories involved in the round robin test, their testing procedures, and their results are not available at this time. However, they will be described when the report from the United States Air Force is released.

The foam blocks, which varied in size from manufacturer to manufacturer, were taken from a large piece of foam for each individual foam sample. The large foam pieces were cut into smaller blocks and distributed by the Air Force to the different laboratories involved in the round robin test. Therefore all labs received a similar block of foam, which ultimately came from the same parent piece of carbon foam from each manufacturer. However, the blocks of foam received by WVU for testing were small and did not allow for more than two samples to be prepared and compressed due to physical size limitations.

The results from the first session, shown in Table 4, reveal that the Poco graphitized carbon foam sample is much softer and pliable than that from MER or TRL, 
making it behave differently in the crushing test. The crushed Poco samples did not break apart, nor did they crack or fracture in any way. The volumes of the soft, graphitized samples were simply reduced, while their cross section remained intact. MER Corporation also included a graphitized carbon foam sample (labeled MERG) that behaved in a very similar manner.

The sample from Touchstone Research Laboratories was a much lighter, brittle foam and behaved as such. The stress-strain plot was very jagged, and not constant. This behavior suggests non-uniformity in the cell structure of the foam. The foam matrices of the samples were completely destroyed in the compression tests, leaving behind nothing more than carbon dust in the chamber.

The MER sample proved to be very difficult to cut, and as a consequence only one useful crush specimen could be obtained. However, the one sample that was compressed yielded a successful compression test. It also behaved as a brittle foam, in that the stress-strain curve was not smooth, and the foam matrix was completely destroyed in the test. The results of this compression testing session can be seen in the following table.

Table 4. Compression Performance of Carbon Foam Samples.

\begin{tabular}{|c|c|c|c|c|c|c|c|}
\hline Specimen & $\begin{array}{l}\text { Bulk } \\
\text { Density }\end{array}$ & $\begin{array}{l}\text { Volumetric } \\
\text { Energy } \\
\text { Absorption } \\
\end{array}$ & $\begin{array}{l}\text { Specific } \\
\text { Energy } \\
\text { Absorption } \\
\end{array}$ & Modulus & $\begin{array}{l}\text { Yield } \\
\text { Strength }\end{array}$ & $\begin{array}{l}\text { Specific } \\
\text { Modulus }\end{array}$ & $\begin{array}{l}\text { Specific } \\
\text { Yield } \\
\text { Strength } \\
\end{array}$ \\
\hline & $\left(\mathrm{g} / \mathrm{cm}^{3}\right)$ & $\left(\mathrm{MJ} / \mathrm{m}^{3}\right)$ & $(\mathrm{kJ} / \mathrm{kg})$ & (MPa) & (MPa) & $\begin{array}{l}\left(\mathrm{kPa}^{\prime} \mathrm{m}^{3} / \mathrm{k}\right. \\
\mathrm{g})\end{array}$ & $\begin{array}{l}\left(\mathrm{kPa} \mathrm{m}^{3} / \mathrm{k}\right. \\
\mathrm{g})\end{array}$ \\
\hline POCO 1 & 0.62 & 1.31 & 2.1 & 160 & 2.25 & 260 & 3.6 \\
\hline POCO 2 & 0.62 & 1.41 & 2.3 & 124 & 2.06 & 200 & 3.3 \\
\hline $\begin{array}{l}\text { POCO } \\
\text { Average }\end{array}$ & 0.62 & 1.36 & 2.2 & 142 & 2.16 & 230 & 3.5 \\
\hline TRL 1 & 0.30 & 2.93 & 9.8 & 136 & 6.23 & 450 & 20.8 \\
\hline TRL 2 & 0.30 & 3.18 & 10.6 & 147 & 6.15 & 490 & 20.5 \\
\hline $\begin{array}{l}\text { TRL } \\
\text { Average }\end{array}$ & 0.30 & 3.06 & 10.2 & 142 & 6.19 & 470 & 20.6 \\
\hline MER & 0.71 & 22.51 & 31.7 & 541 & 26.36 & 760 & 37.1 \\
\hline MERG 1 & 0.48 & 0.86 & 1.79 & 74 & 1.40 & 154 & 2.9 \\
\hline MERG 2 & 0.51 & 1.04 & 2.04 & 88 & 1.58 & 173 & 3.1 \\
\hline $\begin{array}{l}\text { MERG } \\
\text { Average }\end{array}$ & 0.50 & 0.95 & 1.92 & 81 & 1.49 & 164 & 3.0 \\
\hline
\end{tabular}

The Touchstone foam had the lowest apparent or bulk density, yet was surprisingly strong. The bulk density of the POCO, MER, and MERG foams were comparable, but the ungraphitized MER foam was much stronger and absorbed nearly 20 times more energy per unit volume. This is due, in part, to the fact that the graphitized POCO and MERG foams were soft and pliable.

During the second compression testing session, all three samples, from both FMI and Ultramet, behaved as brittle foams when crushed. The FMI foam was much stronger 
than that of Ultramet. These results are shown in the table below. This was expected since the FMI had a bulk density over three times greater than the Ultramet foam.

Due to the small dimensions of the FMI foam block, limitations only allowed one sample to be cut from the original block, but the single compression test performed extremely well. Unfortunately some problems arose while testing both Ultramet samples. Neither of the Ultramet compression tests ran completely to the densification range of the stress-strain plot. The first test was not completed due to equipment failure caused by a power outage. The resulting plot can be seen in the Figure 13. The second test was incomplete due to operator error in estimating the approximate strain for densification. These problems prevented the complete energy absorption calculations to be carried out for either sample. However, all three samples allowed for modulus and yield stress observations shown in Table 5.

Table 5. Compression Performance of Carbon Foam Samples.

\begin{tabular}{|l|l|l|l|l|l|l|l|}
\hline Specimen & $\begin{array}{l}\text { Bulk } \\
\text { Density }\end{array}$ & $\begin{array}{l}\text { Volumetric } \\
\text { Energy } \\
\text { Absorption }\end{array}$ & $\begin{array}{l}\text { Specific } \\
\text { Energy } \\
\text { Absorption }\end{array}$ & Modulus & $\begin{array}{l}\text { Yield } \\
\text { Stress }\end{array}$ & $\begin{array}{l}\text { Specific } \\
\text { Modulus }\end{array}$ & $\begin{array}{l}\text { Specific } \\
\text { Yield } \\
\text { Stress }\end{array}$ \\
\hline & $\left(\mathbf{g} / \mathbf{c m}^{3}\right)$ & $\left(\mathbf{M J} / \mathbf{m}^{3}\right)$ & $(\mathbf{k J} / \mathbf{k g})$ & $(\mathbf{M P a})$ & $(\mathbf{M P a})$ & $\begin{array}{l}\left(\mathbf{k P a} \mathbf{m}^{3} / \mathbf{k}\right. \\
\mathbf{g})\end{array}$ & $\begin{array}{l}\left(\mathbf{k P a} \mathbf{m}^{3} / \mathbf{k}\right. \\
\mathbf{g})\end{array}$ \\
\hline FMI & 0.50 & 4.04 & 8.08 & 326 & 4.32 & 652 & 8.64 \\
\hline & & & & & & & \\
\hline Ultramet 1 & 0.16 & - & - & 46.7 & 0.71 & 292 & 4.44 \\
\hline Ultramet 2 & 0.16 & - & - & 35.7 & 0.68 & 223 & 4.25 \\
\hline $\begin{array}{l}\text { Ultramet } \\
\text { Average }\end{array}$ & $\mathbf{0 . 1 6}$ & - & - & $\mathbf{4 1 . 2}$ & $\mathbf{0 . 7 0}$ & $\mathbf{2 5 8}$ & $\mathbf{4 . 3 5}$ \\
\hline
\end{tabular}

Due to the extreme bulk density differences of these two foams, it is not valid to compare them directly. However, all foam samples did behave as expected, with the FMI sample having a much higher yield stress and modulus. The total energy absorption was not calculated for either Ultramet foam sample because of the problems that occurred during the test, which did not allow either test to be completed. 


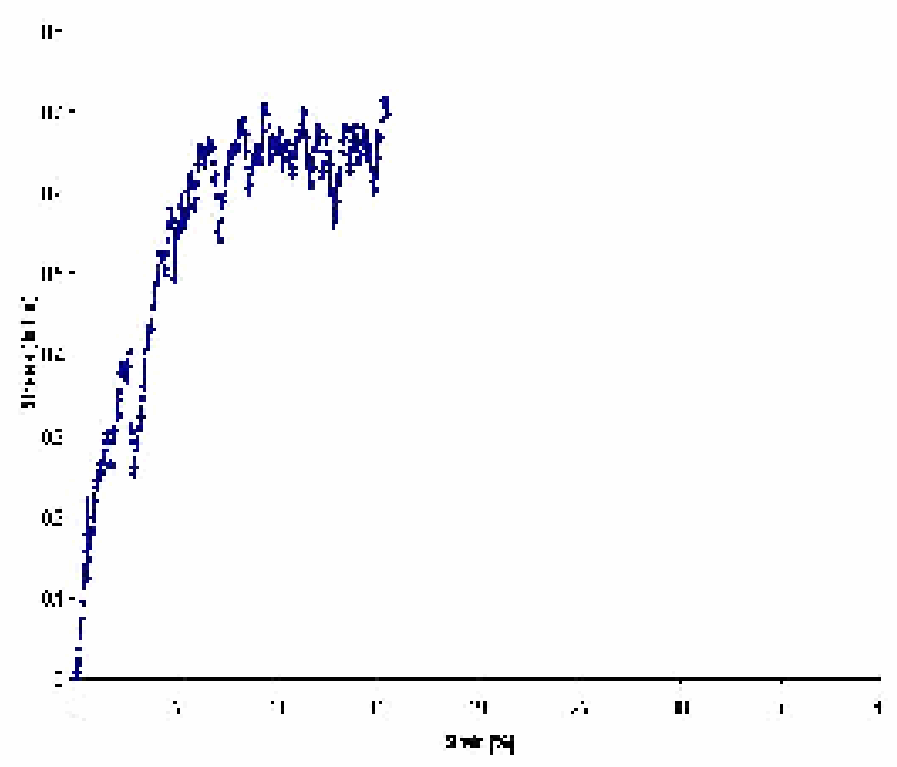

Figure 13. Plot Showing Incomplete Stress/Strain Data of Ultramet Foam Sample 1.

The data in the previous tables show that, indeed, yield strength, modulus, and total absorbed energy can be calculated using the single compression testing method proposed. However, the amount of data is not sufficient to support a statistical analysis comprising standard deviation, variance, or reproducibility due to the small amounts of material that were tested.

Statistical analysis is needed to validate this compression testing method. This method must produce dependable yield strength results that are reproducible. Also, the results from the compression method described here must be compared to those from the more conventional unconstrained test. There will be a slight discrepancy in the numbers between any number of samples, even of the same foam, due to the anisotropy of both the matrix of the foam and the carbon material itself, thus solid statistical evaluations must be completed. Finally, comparison between yield strength results from conventional unconstrained testing without the piston compression assembly and constrained testing using the piston compression assembly must be done in order to assess the utility of the constrained piston compression test.

Unconstrained compression tests are performed to allow statistical information to be gathered about carbon foam compression testing. This step provides information about the reproducibility, standard deviation, and averages of the properties being reported. The proper number of samples that must be tested during a single session can also be determined. In addition to statistical analysis, the unconstrained compression test is performed on the foam samples in order to determine what influences the piston assembly may have on the compression test results. It is imperative to determine if the piston compression assembly adds any significant forces that would in any way influence the results. These tests were performed using large pieces of foam that have been received from GrafTech. GrafTech has supplied foams with densities between 2 and 35 $\mathrm{lb} / \mathrm{ft}^{3}$. 
In order to perform the unconstrained test, foam samples are cut using the same sample preparation techniques. These samples are compressed alone, without the use of the piston compression assembly. The samples are centered on the lower platen of the Instron 5869 load frame and compressed. These results will not give total energy absorption for most samples because if a sample breaks, or changes its cross-sectional area, the resulting stress calculations will not correspond to the force applied to an already specified area. However, accurate yield strength and modulus results are obtained.

These yield strength and modulus results are compared to the same results of the constrained piston compression assembly test to determine if the constrained piston test is giving accurate results.

\subsubsection{Experimental Tests on Carbon Foams}

Compression tests were performed on carbon foams from different manufacturers. Carbon foams from GrafTech International, Ltd., Materials and Electrochemical Research (MER) Corporation, Ultramet, and West Virginia University were tested in order to gather information and data from carbon foams of different precursor material, different manufacturing processes, and with different physical properties. A wide range of carbon foams were chosen in order to show that the proposed compression test can, in fact, be used on any type of carbon foam, regardless of bulk density or precursor material.

Statistical analyses were also successfully performed on three GrafTech foams with different bulk densities $\left(2,10\right.$, and $\left.20 \mathrm{lb} / \mathrm{ft}^{3}\right)$. These analyses were performed on the yield stress, modulus, and energy absorption results for each of the three foams. The group of GrafTech foams allowed enough material for 20 to 50 specimens to be tested at

each density level. This insured that confidence intervals could be determined and reported. The other foams did not provide enough material for confidence intervals, however, sample means, and sample standard deviations were calculated. The results showed that the yield stress and modulus numbers for the foams followed a normal distribution and that the energy absorption followed a chi-square distribution. These results help to confirm that, indeed, the energy absorbed by carbon foams resembles more of a lower limit value instead of an average value supported by a normal distribution.

The foams from Ultramet, MER Corporation, and WVU were tested to verify that the compression test could, in fact, be completed on foams with different densities that were manufactured from different precursor material. There was not enough material to complete a statistical analysis on the data, but a mean and standard deviation was calculated for each set of tests.

\subsubsection{GrafTech Carbon Foam}

GrafTech International Ltd. provided several commercial foams of different density to be used for a statistical analysis. The three foams chosen had densities of 2 , 10, and $20 \mathrm{lb} / \mathrm{ft}^{3}$. Each of these foams was tested using both unconstrained and constrained methods in order to compare the results from each technique. Specifically, 
the yield stress and modulus were compared to determine if the piston assembly influenced the results of the compression test. The results of these tests are presented below.

The $2-\mathrm{lb} / \mathrm{ft}^{3}\left(0.032 \mathrm{~g} / \mathrm{cm}^{3}\right)$ bulk density GrafTech foam, also known as FPA-02, was used the most frequently because the foam is extremely lightweight and very easy to prepare. Therefore, five different sets of compression tests (each set contains 10 samples) were performed using this foam. Variables that were compared included sample height, testing speed (speed of platens), and the difference between constrained and unconstrained tests. The five sets of compression tests are summarized in Table 6, and the results of the compression tests are shown in Figure 15. As seen in Figure 14, the FPA-02 foam is an open-cell structure with relatively large cells of nearly uniform dimension. The foam shows a noticeable cell elongation in the foaming direction.

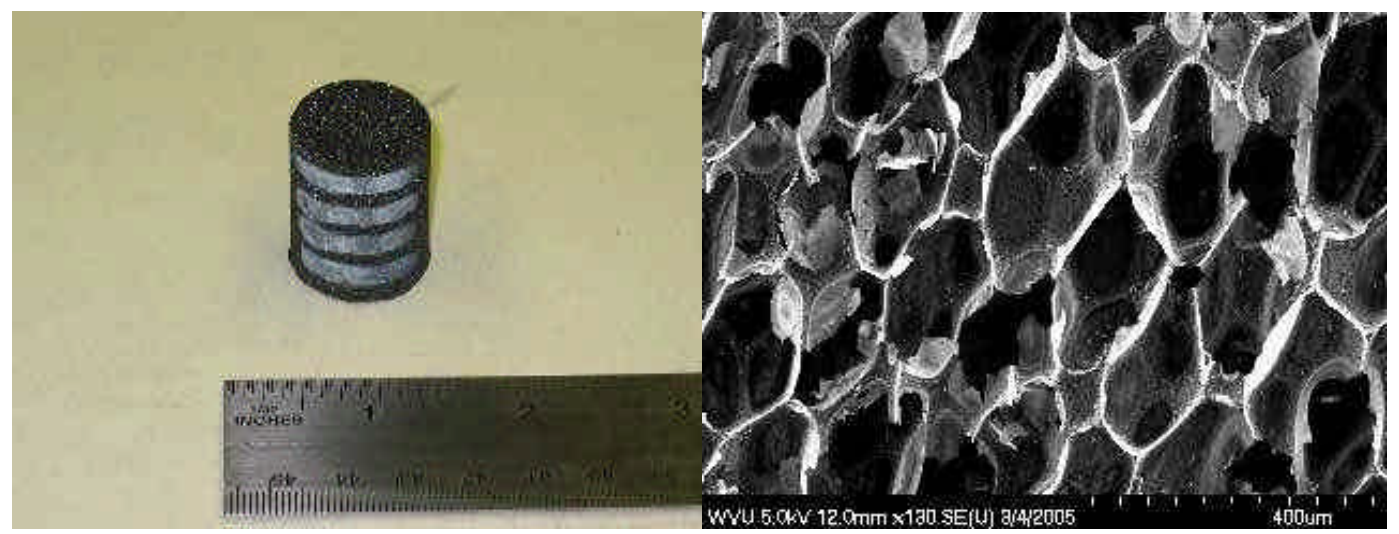

Figure 14. Image of FPA-02 with white lines drawn on for reference during testing (a), and (b) SEM micrograph of FPA-02.

Table 6. Parameters for Compression Tests of FPA-02 Carbon Foam.

\begin{tabular}{|l|lll|}
\hline & $\begin{array}{l}\text { Test } \\
\text { Type }\end{array}$ & $\begin{array}{l}\text { Sample } \\
\text { Height }(\mathbf{c m})\end{array}$ & $\begin{array}{l}\text { Platen Speed } \\
(\mathbf{m m} / \mathbf{m i n})\end{array}$ \\
\hline Test 2.1 & Unconstrained & 2.54 & 1 \\
Test 2.2 & Unconstrained & 2.54 & 2 \\
Test 2.3 & Constrained & 2.54 & 1 \\
Test 2.4 & Constrained & 2.54 & 2 \\
Test 2.5 & Constrained & 5.08 & 2 \\
\hline
\end{tabular}

A rough population mean, along with unbiased standard deviation and variance were calculated using all available data from FPA-02 since all values were extremely close together. These values are labeled in Table 7 under "combined." These 50 values were combined together and provided a histogram which followed a normal distribution. Using a normal distribution, various confidence intervals were calculated (see Table 8). The same procedure was performed on modulus values as well. 

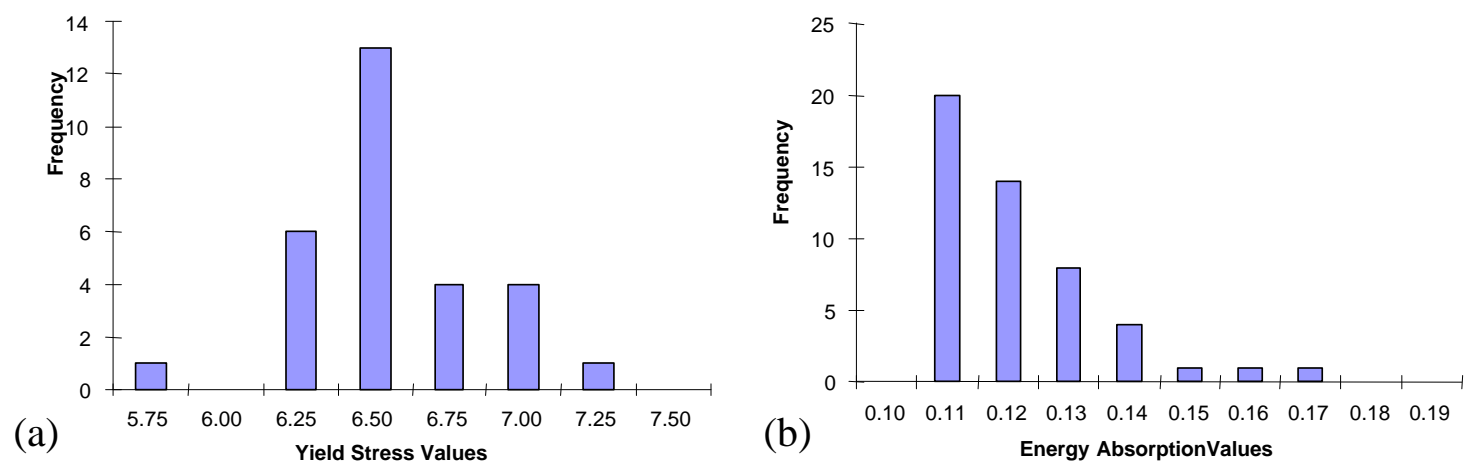

Figure 15. Histograms Showing Shape of Distributions for Yield Stress (a) and Energy Absorption Values(b) for all Foams Tested.

The histogram for energy absorption, however, did not follow a normal distribution, but resembled a chi-square distribution. The chi-square distribution gives confidence intervals about the variance of the set of samples, not the mean value. Therefore, the confidence interval was calculated and a range was found for the unbiased variance of the 50 samples. The confidence interval was found to be $50 \%$ and the variance $\sigma^{2}$ was found to be between $0.00010=\sigma^{2}=0.00013\left(\mathrm{MJ} / \mathrm{m}^{3}\right)^{2}$. The standard deviation $(\sigma)$ is the square root of the variance. Both of these values give an indication of how much spread is in the data, in other words, how much the data vary from the mean value. The smaller these values, the closer the individual measurements are to each other and to the corresponding mean.

Compression tests were also documented using photos taken at normal intervals during unconstrained compression tests. These photos were taken to observe differences in failure between foams of different density. The photos from FPA-02 are shown in Figure 16.

Table 7. Mean Results from Each Set of Compression Tests for FPA-02 Foam.

\begin{tabular}{|l|llll|}
\hline 10 samples/test & $\begin{array}{l}\text { Measured Bulk } \\
\text { Density }\left(\mathbf{g} / \mathbf{c m}^{\mathbf{3}}\right)\end{array}$ & $\begin{array}{l}\text { Yield } \\
\text { Stress }(\mathbf{M P a})\end{array}$ & $\begin{array}{l}\text { Modulus } \\
(\mathbf{M P a})\end{array}$ & $\begin{array}{l}\text { Energy } \\
\text { Absorption }\left(\mathbf{M J} / \mathbf{m}^{3}\right)\end{array}$ \\
\hline Test 2.1 & $\mathbf{0 . 0 2 4}$ & $\mathbf{0 . 1 4 2}$ & $\mathbf{2 . 8 3}$ & $\mathbf{0 . 1 1 3}$ \\
Std Dev. & & 0.005 & 0.65 & 0.004 \\
Variance & & 0.000 & 0.42 & 0.000 \\
\hline Test 2.2 & $\mathbf{0 . 0 2 4}$ & $\mathbf{0 . 1 4 1}$ & $\mathbf{3 . 1 5}$ & $\mathbf{0 . 1 1 5}$ \\
Std Dev. & & 0.005 & 0.56 & 0.004 \\
Variance & & 0.000 & 0.32 & 0.000 \\
\hline Test 2.3 & $\mathbf{0 . 0 2 4}$ & $\mathbf{0 . 1 3 5}$ & $\mathbf{2 . 5 2}$ & $\mathbf{0 . 1 1 9}$ \\
Std Dev. & & 0.009 & 0.62 & 0.008 \\
Variance & & 0.000 & 0.38 & 0.000 \\
\hline Test 2.4 & $\mathbf{0 . 0 2 4}$ & $\mathbf{0 . 1 4 0}$ & $\mathbf{2 . 5 6}$ & $\mathbf{0 . 1 2 2}$ \\
Std Dev. & & 0.006 & 0.49 & 0.007
\end{tabular}




\begin{tabular}{|l|llll|} 
Variance & & 0.000 & 0.24 & 0.000 \\
\hline Test 2.5 & $\mathbf{0 . 0 2 4}$ & $\mathbf{0 . 1 5 3}$ & $\mathbf{3 . 4 9}$ & $\mathbf{0 . 1 3 4}$ \\
Std Dev. & & 0.035 & 1.18 & 0.014 \\
Variance & & 0.001 & 1.38 & 0.000 \\
\hline Combined & & $\mathbf{0 . 1 4 2}$ & $\mathbf{2 . 9 1}$ & $\mathbf{0 . 1 2 1}$ \\
Std Dev. & & 0.017 & 0.79 & 0.011 \\
Variance & & 0.000 & 0.63 & 0.000 \\
\hline
\end{tabular}

Table 8. Overall Yield Stress and Modulus Confidence Intervals for FPA-02.

\begin{tabular}{|c|c|c|c|c|}
\hline & $\begin{array}{l}\text { Confidence } \\
\text { Interval }\end{array}$ & Mean & Error & $\%$ Error \\
\hline Yield Stress (MPa) & $\begin{array}{l}95 \% \\
90 \% \\
80 \% \\
75 \%\end{array}$ & $\begin{array}{l}0.142 \\
0.142 \\
0.142 \\
0.142\end{array}$ & $\begin{array}{l} \pm 0.005 \\
\pm 0.004 \\
\pm 0.003 \\
\pm 0.002\end{array}$ & $\begin{array}{l}3.30 \\
2.76 \\
2.15 \\
1.94\end{array}$ \\
\hline Modulus (MPa) & $\begin{array}{l}95 \% \\
90 \% \\
80 \% \\
75 \%\end{array}$ & $\begin{array}{l}2.91 \\
2.91 \\
2.91 \\
2.91\end{array}$ & $\begin{array}{l} \pm 0.22 \\
\pm 0.18 \\
\pm 0.14 \\
\pm 0.13\end{array}$ & $\begin{array}{l}7.55 \\
6.32 \\
4.93 \\
4.43\end{array}$ \\
\hline $\begin{array}{l}\text { Energy Absorption } \\
\left(\mathrm{MJ} / \mathrm{m}^{3}\right)\end{array}$ & $50 \%$ & \multicolumn{3}{|c|}{$\begin{array}{l}\text { Variance }\left(\mathrm{MJ} / \mathrm{m}^{3}\right)^{2} \\
0.00010=\sigma^{2}=0.00013\end{array}$} \\
\hline
\end{tabular}

These photos suggest that FPA-02 fails one layer at a time from the edges towards the center of the sample and that the cross-sectional area remains constant. Knowing this fact, energy absorption numbers can be obtained from both constrained and unconstrained tests. Therefore the results can be used to compare yield stress, modulus, and energy absorption for both unconstrained and constrained piston tests since the crosssectional area of the sample does not change during compression. 


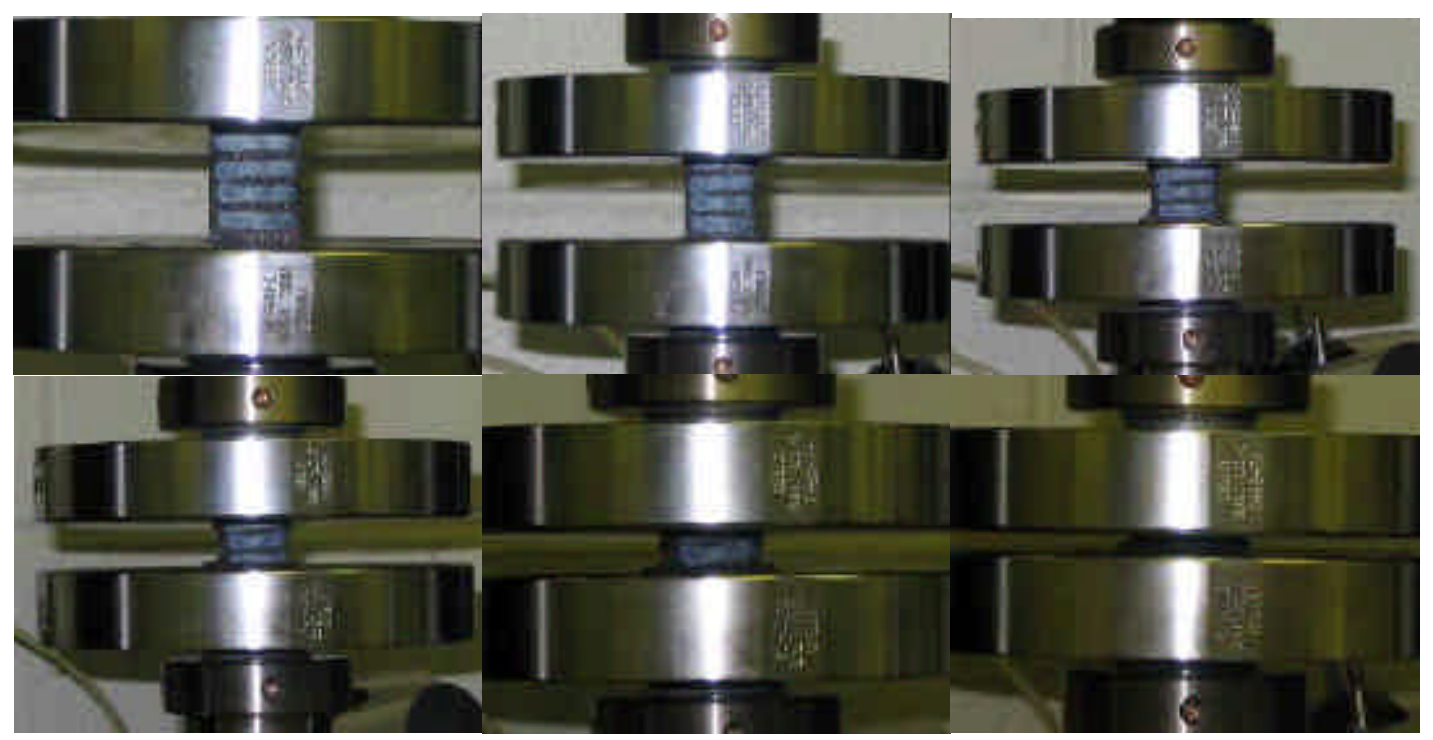

Figure 16. Photos taken at regular intervals (beginning at upper left) during an unconstrained compression test of FPA-02 carbon foam. (FPA-02 carbon foam courtesy of GrafTech International, Ltd.)

Comparing the micrograph in a Figure 14 with the compression results, it can be seen that this is the weakest foam of the group. The cell walls are extremely thin and thus, the yield stress is the lowest. Further investigation of the photo shows that the cells are open and interconnected, and the cell walls appear to contain smaller holes. These observations explain why FPA-02 is the weakest of the GrafTech foams tested.

The data presented in Table 7 shows other interesting results as well. There is very little to no difference in any of the results of Tests 2.1 and 2.3 (the constrained and unconstrained tests). This suggests that the piston assembly has no effect on the test. Moreover, all of the values for the all of the tests that contain a 1-inch tall sample have smaller standard deviations than Test 2.5 whose sample height is 2 inches. Thus 1 -inch sample heights produce a better cluster of data than 2 inch sample heights. It is also important to note that the yield stress and modulus values are not affected by the speed of the platen movement, at least over the speed range tested here.

GrafTech's $10-\mathrm{lb} / \mathrm{ft}^{3}\left(0.16 \mathrm{~g} / \mathrm{cm}^{3}\right)$ foam, known as FPA-10 was also evaluated for statistical analysis, however, only 30 samples were tested instead of 50. The same statistical techniques as described above for FPA-02 were used to analyze the data from FPA-10. It was found that the yield stress and modulus again followed a normal distribution. However, a student-t distribution was used since the number of samples was close to thirty. In general, when the number of samples is less than or equal to 30, a student-t distribution is used instead of the normal distribution in order to predict more accurately the amount of error associated with having a relatively small amount of data. FPA-10 can be seen in Figure 17.

The structure of FPA-10 varies slightly from FPA-02 in that the cell walls are thicker and the cells appear rounder. The cells are still open and interconnected, and the cell walls contain numerous smaller holes. 


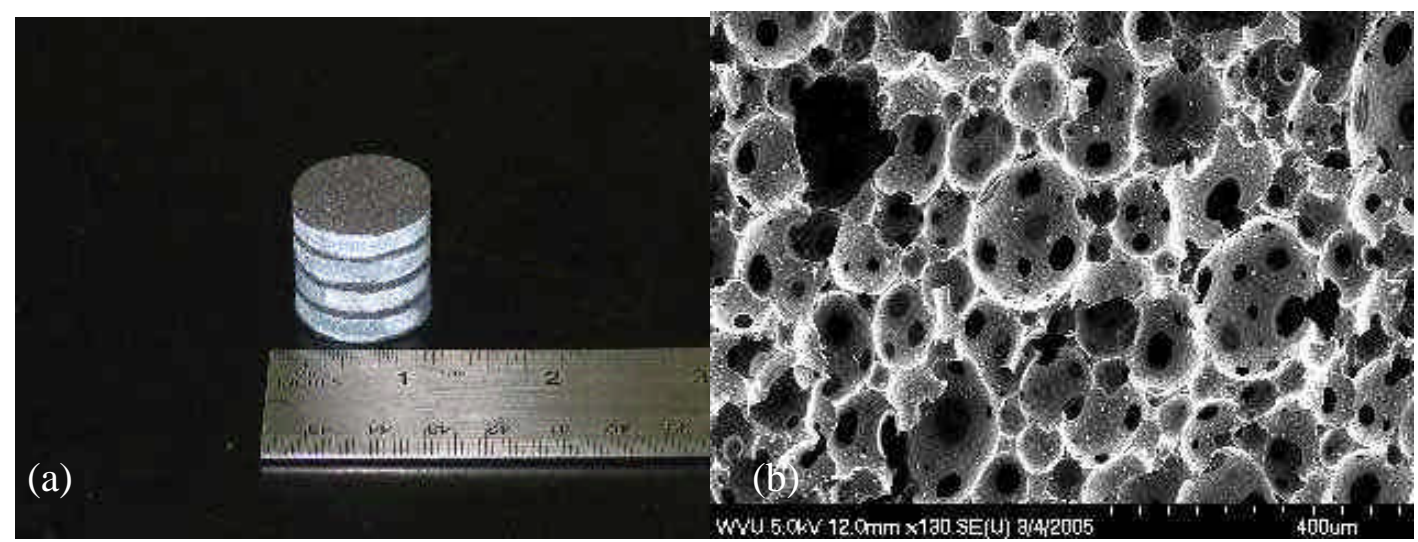

Figure 17. Image of FPA-10 with white lines drawn on for reference during testing (a), and (b) SEM micrograph of FPA-10.

The tests performed on FPA-10 are indicated in the table below. All tests were performed using the same platen speed of $2 \mathrm{~mm} / \mathrm{min}$ and all samples were kept at a height of 1 inch. One set of samples was compressed without the piston assembly and the results were compared to two identical sets of tests using the piston assembly. Therefore, one constrained test was compared to two separate tests to observe differences between the constrained and unconstrained techniques, and to observe any differences in the same test performed on two different occasions. The results from each test are shown in a later table.

The series of photos taken during an unconstrained compression test of FPA-10, illustrated in Figure 18, shows that the higher-density foam fails in slightly different manner than FPA-02. The FPA-10 foam fails by the breaking off of large pieces and not from the gradual degradation of the outer surfaces that are in contact with the compression device.

Table 9. Parameters for Compression Tests of FPA-10 Carbon Foam.

\begin{tabular}{|l|lll|}
\hline & $\begin{array}{l}\text { Test } \\
\text { Type }\end{array}$ & $\begin{array}{l}\text { Sample } \\
\text { Height }(\mathbf{c m})\end{array}$ & $\begin{array}{l}\text { Platen Speed } \\
(\mathbf{m m} / \mathbf{m i n})\end{array}$ \\
\hline Test 10.1 & Unconstrained & 2.54 & 2 \\
Test 10.2 & Constrained & 2.54 & 2 \\
Test 10.3 & Constrained & 2.54 & 2 \\
\hline
\end{tabular}

Table 10. Mean Results from Each Set of Compression Tests for FPA-10 Foam.

\begin{tabular}{|l|llll|}
\hline 10 samples/test & $\begin{array}{l}\text { Measured Bulk } \\
\text { Density }\left(\mathbf{g} / \mathbf{c m}^{\mathbf{3}}\right)\end{array}$ & $\begin{array}{l}\text { Yield } \\
\text { Stress }(\mathbf{M P a})\end{array}$ & $\begin{array}{l}\text { Modulus } \\
(\mathbf{M P a})\end{array}$ & $\begin{array}{l}\text { Energy } \\
\text { Absorption } \\
\left(\mathbf{M J} / \mathbf{m}^{\mathbf{3}}\right)\end{array}$ \\
\hline Test 10.1 & $\mathbf{0 . 1 6 9}$ & $\mathbf{6 . 4 6}$ & $\mathbf{1 8 2}$ & na \\
Std Dev. & & 0.23 & 15 & na \\
Variance & & 0.05 & 237 & na \\
\hline Test $\mathbf{1 0 . 2}$ & $\mathbf{0 . 1 7 0}$ & $\mathbf{6 . 5 9}$ & $\mathbf{1 7 9}$ & $\mathbf{4 . 0 2}$
\end{tabular}




\begin{tabular}{|c|c|c|c|c|}
\hline $\begin{array}{l}\text { Std Dev. } \\
\text { Variance }\end{array}$ & & $\begin{array}{l}0.35 \\
0.12\end{array}$ & $\begin{array}{l}28 \\
784\end{array}$ & $\begin{array}{l}0.29 \\
0.08\end{array}$ \\
\hline Test 10.3 & 0.166 & 6.24 & 155 & 3.82 \\
\hline Std Dev. & & 0.25 & 23 & 2.68 \\
\hline Variance & & 0.06 & 521 & 0.07 \\
\hline Combined & & 6.42 & 171 & 3.91 \\
\hline Std Dev. & & 0.30 & 23 & 0.29 \\
\hline Variance & & 0.09 & 620 & 0.08 \\
\hline
\end{tabular}

The photos show that the cross-sectional area of the foam sample is constantly changing. As the specimen in compressed, large pieces break off from the original sample. Thus the changing cross-sectional area does not allow for energy absorption results to be gathered from the unconstrained test. This is in contrast to the case of FPA02, which failed by a different mechanism. Therefore, no energy absorption results are reported for the unconstrained test of FPA-10 in Table 10. A student-t distribution was used to gather confidence intervals for the yield stress and modulus, while the energy absorption followed the chi-square distribution. The confidence intervals are shown in the Table 11.

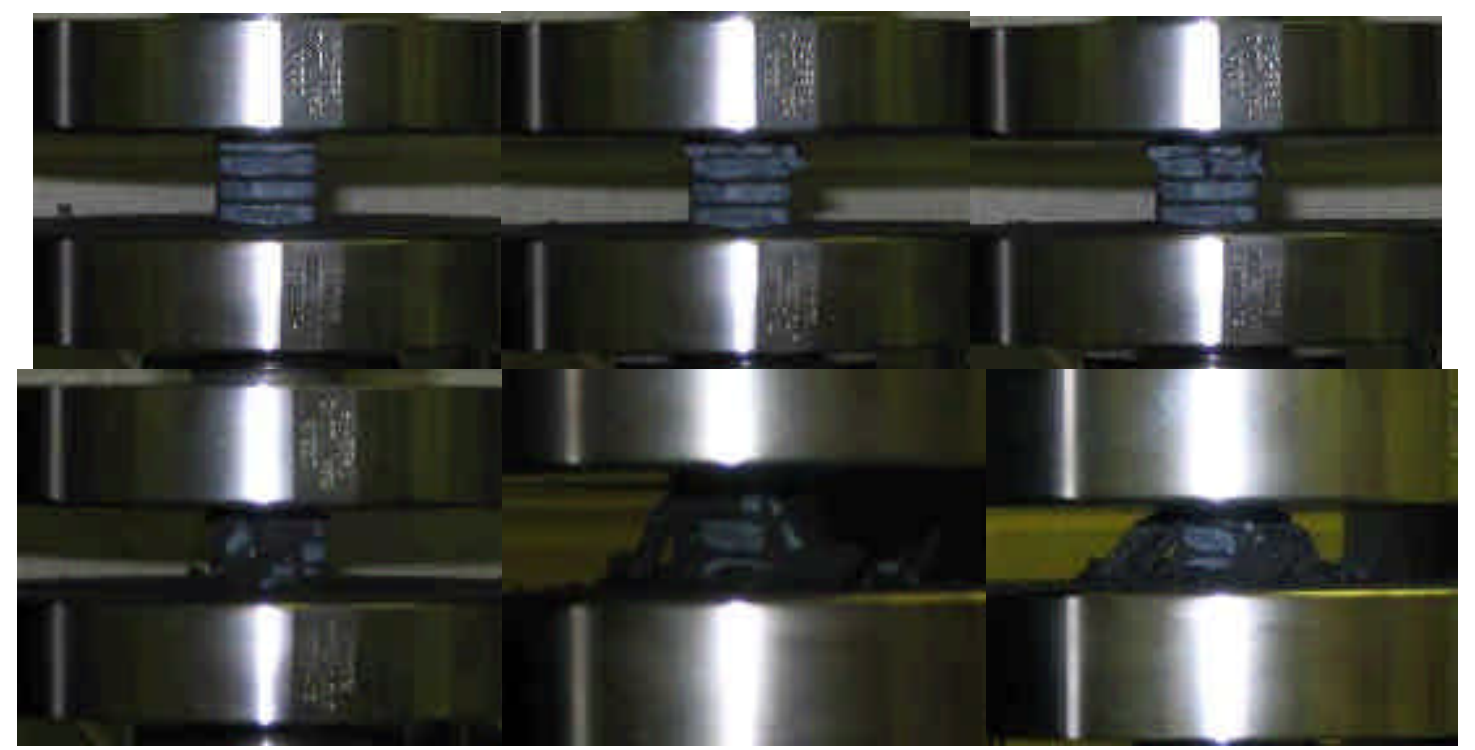

Figure 18. Photos taken at regular intervals (beginning at upper left) during an unconstrained compression test of FPA-10 carbon foam. (FPA-10 carbon foam courtesy of GrafTech International, Ltd.)

All three sets of data for yield stress and modulus are close to each other with the standard deviation of the yield stress being very low for all three. The two sets of data for energy absorption in the constrained test are also very similar with low standard deviation. Low standard deviations are desired because it means the data is more precise. Good precision is important because it defines how well data can be reproduced. 
Table 11. Overall Yield Stress and Modulus Confidence Intervals for FPA-10.

\begin{tabular}{|c|c|c|c|c|}
\hline & \begin{tabular}{|l} 
Confidence \\
Interval
\end{tabular} & Mean & Error & \% Error \\
\hline \multirow[t]{4}{*}{ Yield Stress (MPa) } & $95 \%$ & 6.42 & \pm 0.10 & 1.52 \\
\hline & $90 \%$ & 6.42 & \pm 0.08 & 1.17 \\
\hline & $80 \%$ & 6.42 & \pm 0.05 & 0.76 \\
\hline & $75 \%$ & 6.42 & \pm 0.04 & 0.61 \\
\hline \multirow[t]{4}{*}{ Modulus (MPa) } & $95 \%$ & 171 & \pm 7.99 & 4.66 \\
\hline & $90 \%$ & 171 & \pm 6.16 & 3.59 \\
\hline & $80 \%$ & 171 & \pm 4.02 & 2.35 \\
\hline & $75 \%$ & 171 & \pm 3.21 & 1.87 \\
\hline $\begin{array}{l}\text { Energy Absorption } \\
\left(\mathrm{MJ} / \mathrm{m}^{3}\right)\end{array}$ & $50 \%$ & \multicolumn{3}{|c|}{$\begin{array}{l}\text { Variance }\left(\mathrm{MJ} / \mathrm{m}^{3}\right)^{2} \\
0.06=\sigma^{2}=0.10\end{array}$} \\
\hline
\end{tabular}

Compression data for GrafTech's carbon foam, FPA-20, with bulk density of 20$\mathrm{lb} / \mathrm{ft}^{3}\left(0.32 \mathrm{~g} / \mathrm{cm}^{3}\right)$ were also evaluated for statistical analysis. The sample along with a photomicrograph of FPA-20 are shown in a Figure 19. It can be seen that for the higherdensity foam, the cells are much smaller and the walls are thicker with far less holes. The three sets of compression tests for FPA-20 are summarized in Table 12. Two initial tests were performed on FPA-20 in order to compare the results from the unconstrained and constrained techniques. The third test was performed with the intent of gathering better results with closer statistics, especially to reduce the standard deviation of the modulus data and to compare a different sample height. The mean results from the tests are in an Table 13. The confidence intervals were performed in a manner similar to those for FPA10 , in which the student-t distribution was used for yield stress and modulus, and the chisquare distribution was used for the energy absorption. These results are shown in Table 14. A comparison was performed after the Test 20.3 and better statistics were gathered due to the larger number of samples. The confidence intervals for the yield stress and modulus from Test 20.3 alone are shown in Table 15.

The structure of FPA-20 is similar to FPA-10. The main differences are that the cells are much smaller, the holes within those cell walls are much smaller, and the number of holes within the cell walls is much smaller. These observations suggest that there is more solid material in the foam matrix, which is indicated by the larger density of the foam. It should also be noted that the initial block of FPA-20 from which the samples were taken, was only 1.5 inches $(3.81 \mathrm{~cm})$ tall. The other GrafTech foams were 2 or more inches in height, allowing 2-inch tall samples to be used in the compression tests. 

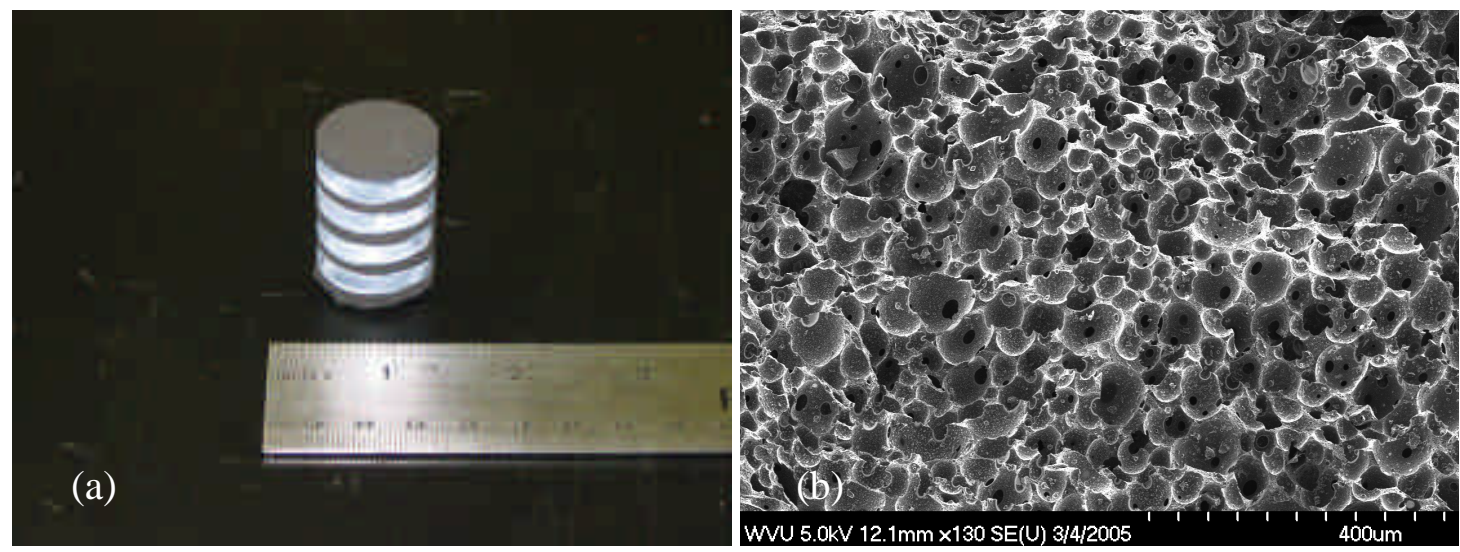

Figure 19. Image of FPA-20 with white lines drawn on for reference during testing (a), and (b) SEM micrograph of FPA-20.

Photos seen in Figure 20 were taken during an unconstrained compression test so that failure could be visually observed. The failure of FPA-20 was much more instantaneous than that of either FPA-02 or FPA-10. The foam sample fails by allowing large breaks and cracks to form throughout the foam matrix. Pieces large and small fall off of the original foam sample, drastically changing its cross-sectional area. Thus the energy absorption could not be calculated from the unconstrained compression test. However, yield stress and modulus, again can be compared between all three sets of compression tests. Photos, shown in Figure 21, were taken of a constrained test as well. The foam was placed inside a transparent Lexan ${ }^{\circledR}$ cylinder instead of the stainless steel cylinder and compressed in a manner similar to the other constrained compressive tests. This was done to visually observe the sample within the constrained piston assembly. The observation shows that the piston is always in contact with the sample faces, and that the piston assembly does not alter or interfere with the failure mechanism of the foam. The foam is allowed to fail normally, the cylinder simply maintains the cross-section of the sample constant.

Table 12. Parameters for Compression Tests of FPA-20 Carbon Foam.

\begin{tabular}{|l|lll|}
\hline & $\begin{array}{l}\text { Test } \\
\text { Type }\end{array}$ & $\begin{array}{l}\text { Sample } \\
\text { Height }(\mathbf{c m})\end{array}$ & $\begin{array}{l}\text { Platen Speed } \\
(\mathbf{m m} / \mathbf{m i n})\end{array}$ \\
\hline Test 20.1 & Unconstrained & 3.81 & 2 \\
Test 20.2 & Constrained & 3.81 & 2 \\
Test 20.3 & Constrained & 2.54 & 2 \\
\hline
\end{tabular}


Table 13. Mean Results from Each Set of Compression Tests for FPA-20 Foam.

\begin{tabular}{|l|llll|}
\hline & $\begin{array}{l}\text { Measured Bulk Yield } \\
\text { Density }\left(\mathbf{g} / \mathbf{c m}^{\mathbf{3}}\right)\end{array}$ & $\begin{array}{l}\text { Modulus } \\
\text { Stress }(\mathbf{M P a})\end{array}$ & $\begin{array}{l}\text { Energy } \\
\text { Absorption }\left(\mathbf{M J} / \mathbf{m}^{\mathbf{3}}\right)\end{array}$ \\
\hline Test 20.1 & $\mathbf{0 . 3 1 8}$ & $\mathbf{1 6 . 4}$ & $\mathbf{1 1 0 0}$ & $\mathbf{n a}$ \\
Std Dev. & & 2.8 & 141 & na \\
Variance & & 7.9 & 19881 & na \\
\hline Test 20.2 & $\mathbf{0 . 3 1 7}$ & $\mathbf{1 6 . 6}$ & $\mathbf{9 1 5}$ & $\mathbf{1 1 . 0 3}$ \\
Std Dev. & & 3.9 & 137 & 0.96 \\
Variance & & 15.2 & 18769 & 0.92 \\
\hline Test 20.3 & $\mathbf{0 . 3 1 5}$ & $\mathbf{1 6 . 5}$ & $\mathbf{6 9 8}$ & $\mathbf{9 . 1 5}$ \\
Std Dev. & & 1.3 & 45 & 0.78 \\
Variance & & 1.7 & 2025 & 0.62 \\
\hline Combined & & $\mathbf{1 6 . 5}$ & $\mathbf{9 0 3}$ & $\mathbf{1 0 . 0 5}$ \\
Std Dev. & & 2.7 & 203 & 1.29 \\
Variance & & 7.4 & 41209 & 1.65 \\
\hline
\end{tabular}

Table 14. Overall Yield Stress and Modulus Confidence Intervals for FPA-20.

\begin{tabular}{|l|l|l|l|l|}
\hline & $\begin{array}{l}\text { Confidence } \\
\text { Interval }\end{array}$ & \multicolumn{1}{l|}{ Mean } & \multicolumn{1}{l|}{ Error } & \% Error \\
\hline Yield Stress (MPa) & $95 \%$ & 16.5 & \pm 0.87 & 5.27 \\
& $90 \%$ & 16.5 & \pm 0.67 & 4.06 \\
& $80 \%$ & 16.5 & \pm 0.44 & 2.66 \\
& $75 \%$ & 16.5 & \pm 0.35 & 2.12 \\
\hline Modulus (MPa) & $95 \%$ & 903 & \pm 65.1 & 7.21 \\
& $90 \%$ & 903 & \pm 50.2 & 5.56 \\
& $80 \%$ & 903 & \pm 32.7 & 3.63 \\
& $75 \%$ & 903 & \pm 26.2 & 2.90 \\
\hline & & Variance $\left(\mathrm{MJ} / \mathrm{m}^{3}\right)^{2}$ & \\
\hline Energy Absorption & $50 \%$ & $1.30=\sigma^{2}=2.03$ & \\
$\left(\mathrm{MJ} / \mathrm{m}^{3}\right)$ & & &
\end{tabular}



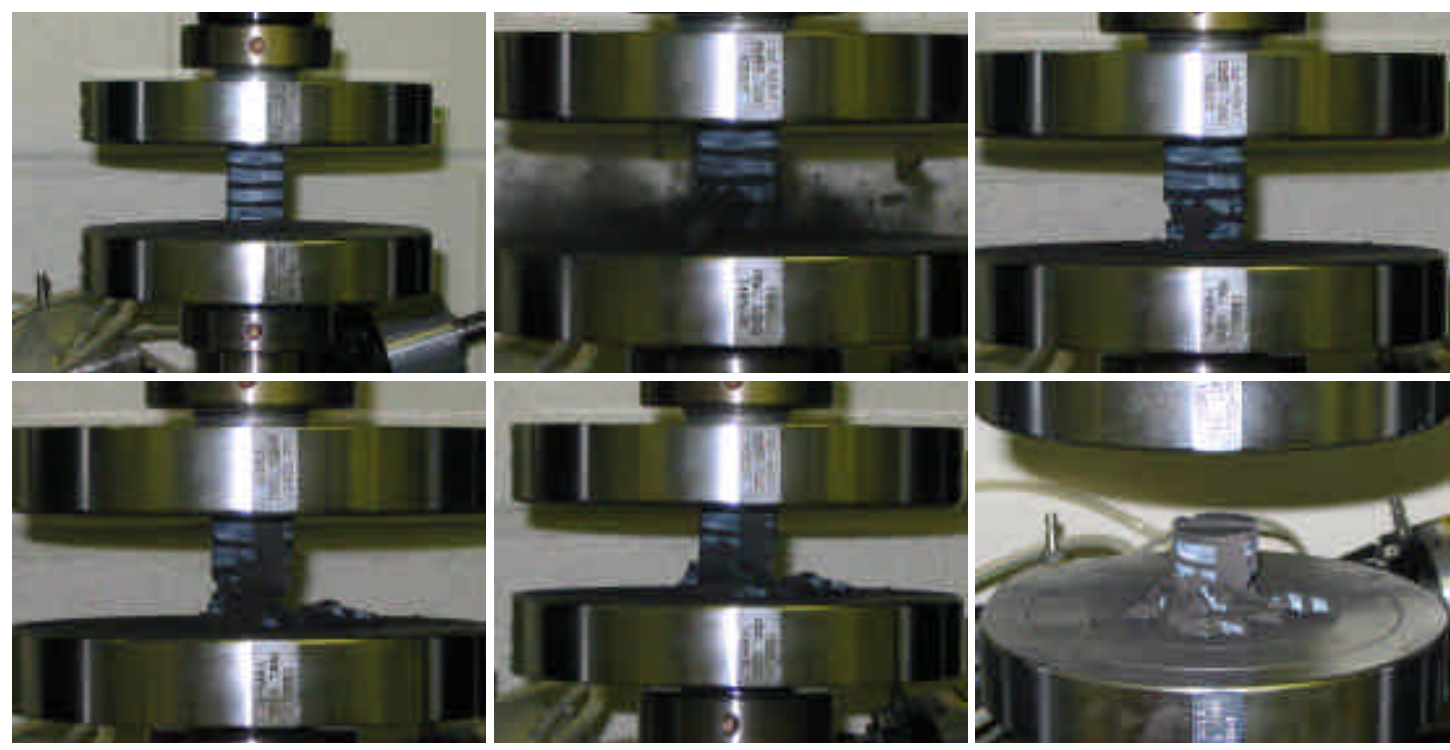

Figure 20. Photos taken at regular intervals beginning at upper left during an unconstrained compression test of FPA-20 carbon foam (FPA-20 carbon foam courtesy of GrafTech International, Ltd.).

\begin{tabular}{|c|c|c|c|c|}
\hline & \multicolumn{4}{|c|}{ Confidence } \\
\hline & Interval & Mean & Error & \% Error \\
\hline \multirow[t]{4}{*}{ Yield Stress (MPa) } & $95 \%$ & 16.5 & \pm 0.74 & 4.48 \\
\hline & $90 \%$ & 16.5 & \pm 0.57 & 3.45 \\
\hline & $80 \%$ & 16.5 & \pm 0.37 & 2.24 \\
\hline & $75 \%$ & 16.5 & \pm 0.30 & 1.81 \\
\hline \multirow[t]{4}{*}{ Modulus (MPa) } & $95 \%$ & 698 & \pm 27.1 & 3.88 \\
\hline & $90 \%$ & 698 & \pm 20.5 & 2.94 \\
\hline & $80 \%$ & 698 & \pm 13.2 & 1.89 \\
\hline & $75 \%$ & 698 & \pm 10.5 & 1.50 \\
\hline
\end{tabular}



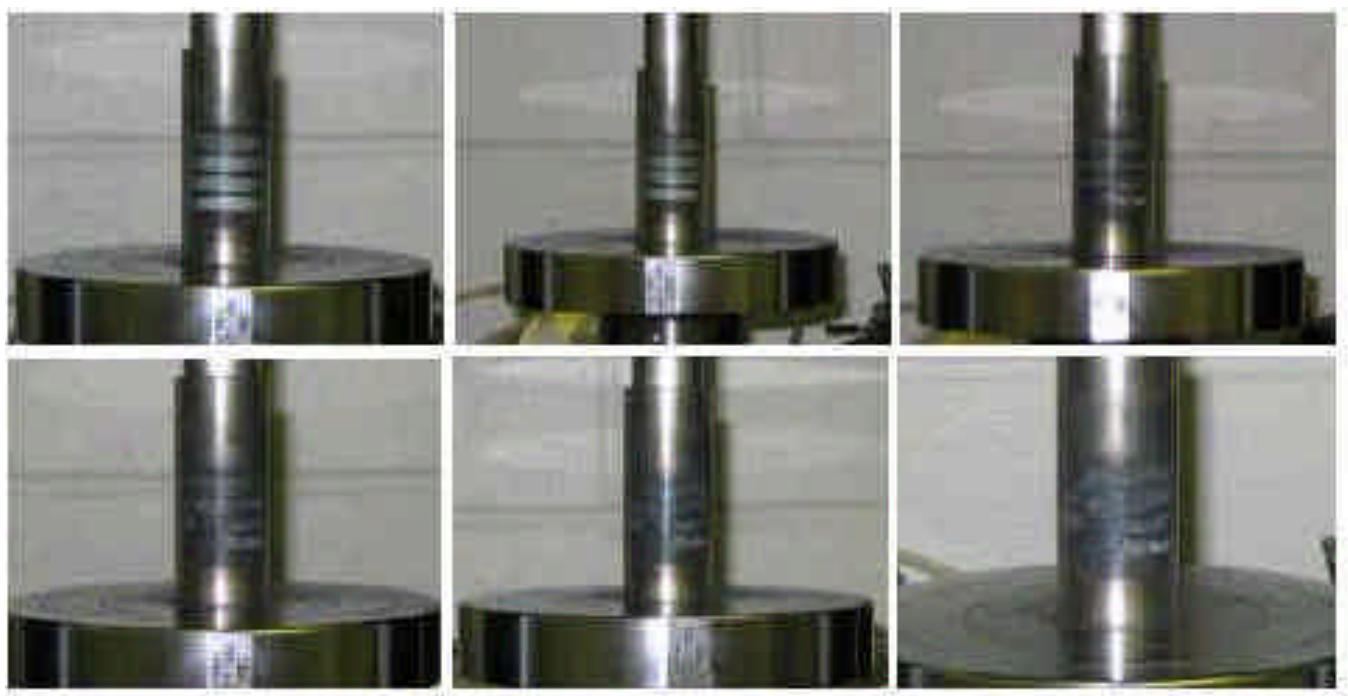

Figure 21. Photos taken at regular intervals beginning at upper left during a constrained compression test of FPA-20 carbon foam (FPA-20 carbon foam courtesy of GrafTech International, Ltd.).

Results from testing three grades of carbon foam manufactured by GrafTech International Ltd. were evaluated for compression behavior in order to perform statistical analysis and verify the operation of the constrained method of testing. The experimental protocol for the GrafTech foams was designed so as to gather as much data as possible while controlling certain parameters that could affect the testing results.

FPA-02 was used most frequently because of it was the lightest, easiest foam to work with and because it was provided in the largest quantity. It is also noted that FPA02 fails in a manner different than FPA-10 or FPA-20. This failure mechanism allows for easier observation and comparison with the unconstrained test.

The constrained piston test and the unconstrained compression tests were performed to determine if the piston assembly influenced the values of the yield stress or modulus. The main reason for utilizing the piston assembly is to ensure a onedimensional volume change over the entire compression of the carbon foam sample so that energy absorption values can be gathered. The piston assembly should not influence the yield stress or the modulus. Unconstrained tests give results easily for yield stress and modulus, however, the changing cross-section (as is the case with FPA-10 and FPA20) causes the stress calculations to be flawed after the initial failure occurs. Therefore, the area under the curve is meaningless if the cross-section of the sample changes and the absorption energy can not be determined. The yield stress and modulus for the constrained technique are compared to those from the unconstrained technique to ensure that the initial portion of the stress vs. strain plots is not altered by the chosen technique. The constrained piston technique is shown to be more beneficial since it has the added capability of gathering energy absorption data regardless of the failure mode of the sample.

FPA-02 is extremely beneficial in this study because its failure mechanism allows its cross-sectional area to remain constant even during unconstrained testing. Therefore, the energy absorption results from the unconstrained tests can be compared directly with the constrained results in addition to the comparisons of yield stress and modulus. Indeed 
the results herein indicate a very favorable agreement between the two techniques provided the sample fails in a well-defined manner.

The results from each set of compression tests for the FPA-02 foam were compared together to determine if the differences between constrained and unconstrained testing, sample height, and platen speed affected the results. The yield stress data between Tests 2.1 and 2.2 are nearly identical. This indicates that there is little to no effect on results between platen movement of $1 \mathrm{~mm} / \mathrm{min}$ and $2 \mathrm{~mm} / \mathrm{min}$. Therefore tests can be performed in half the time originally expected by setting the platen speed at $2 \mathrm{~mm} / \mathrm{min}$. The overall platen movement is still restricted to lower rates, however, in order to allow air to escape from the piston assembly without pressurizing the inside of the chamber. It is important to note that air resistance has no affect whatsoever on these tests at these low strain rates. Low platen speeds are maintained to eliminate any type of effects from dynamic compression and air resistance.

Yield stress numbers from Test 2.4 also show that the same results at $2 \mathrm{~mm} / \mathrm{min}$ can be achieved with the piston assembly. Test 2.5 results are actually closer than the mean value show. One particular sample in Test 2.5 provided a high value for yield stress, which drove the mean value above 1.40. Otherwise, yield stress results from Test 2.5 are extremely close to those from Tests 2.1, 2.2, and 2.4. Most of the mean yield stress values from the 5 sets of tests fall within the $95 \%$ confidence interval for yield stress, and most of the energy absorption variances are better than the calculated 50\% confidence interval. However, nearly all mean modulus values fall just outside the $95 \%$ confidence interval. (This observation is probably due to Test 2.5 having larger mean values.) The confidence interval for the yield stress claims there is a $95 \%$ chance that the yield stress of FPA-02 is between 0.137 and $0.147 \mathrm{MPa}(0.142 \pm 0.005 \mathrm{MPa})$. The modulus results and confidence interval suggest that the mean modulus values of Tests 2.1-2.5 have been shifted.

Table 15. Results of Compression Test 2.5 of FPA-02.

\begin{tabular}{|l|l|l|l|l|}
\hline Sample Number & $\begin{array}{l}\text { Measured Bulk } \\
\text { Density }\left(\mathbf{g} / \mathbf{c m}^{\mathbf{3}}\right)\end{array}$ & $\begin{array}{l}\text { Yield } \\
\text { Stress }(\mathbf{M P a})\end{array}$ & $\begin{array}{l}\text { Modulus } \\
(\mathbf{M P a})\end{array}$ & $\begin{array}{l}\text { Energy } \\
\text { Absorption }\left(\mathbf{M J} / \mathbf{m}^{\mathbf{3}}\right)\end{array}$ \\
\hline 2.5 .1 & 0.024 & 0.227 & 3.45 & 0.161 \\
\hline 2.5 .2 & 0.025 & 0.206 & 3.18 & 0.153 \\
\hline 2.5 .3 & 0.024 & 0.124 & 1.60 & 0.124 \\
\hline 2.5 .4 & 0.024 & 0.134 & 2.82 & 0.127 \\
\hline 2.5 .5 & 0.025 & 0.140 & 2.24 & 0.133 \\
\hline 2.5 .6 & 0.024 & 0.159 & 3.02 & 0.142 \\
\hline 2.5 .7 & 0.024 & 0.140 & 4.87 & 0.125 \\
\hline 2.5 .8 & 0.024 & 0.127 & 4.07 & 0.118 \\
\hline 2.5 .9 & 0.025 & 0.130 & 4.21 & 0.124 \\
\hline 2.5 .10 & 0.025 & 0.138 & 5.44 & 0.137 \\
\hline Mean & $\mathbf{0 . 0 2 4}$ & $\mathbf{0 . 1 5 3}$ & $\mathbf{3 . 4 9}$ & $\mathbf{0 . 1 3 4}$ \\
\hline Std Dev & $\mathbf{0 . 0 0 0}$ & $\mathbf{0 . 0 3 5}$ & $\mathbf{1 . 1 8}$ & $\mathbf{0 . 0 1 4}$ \\
\hline Variance & $\mathbf{0 . 0 0 0}$ & $\mathbf{0 . 0 0 1}$ & $\mathbf{1 . 3 9}$ & $\mathbf{0 . 0 0 0}$ \\
\hline
\end{tabular}


A closer comparison of specific testing sets can give a better idea on how variables may affect the test. Comparison of the data suggests that the piston assembly does not increase the yield stress nor the modulus, but it may slightly increase the energy absorption results. The height difference between 1 and 2 inches $(2.54$ and $5.08 \mathrm{~cm})$ in Tests 2.4 and 2.5 appears to affect all three parameters, inflating the results for yield stress $(0.140$ to $0.153 \mathrm{MPa})$, modulus $(2.56$ to $3.49 \mathrm{MPa})$, and energy absorption $(0.122$ to $0.134 \mathrm{MJ} / \mathrm{m}^{3}$ ) when the sample height is increased to 2 inches. However, considering the fact that Sample 2.5.1 provided a yield stress result that was higher than all others in the FPA-02 series of tests, this observed difference in the mean values of Test 2.5 might not be significant. Although the differences in the mean values may not real, it is significant that Test 2.5 has the largest standard deviations for yield stress, modulus, and energy absorption (regardless of the values provided by Sample 2.5.1). This suggests that the 2-inch tall samples have the largest range of values, and thus are less repeatable than the other four tests. Finally, the platen speed does not seem to have a significant affect on any of the measured quantities. The platen speed was limited to $2 \mathrm{~mm} / \mathrm{min}$ in order to ensure than no air resistance would be a factor as air escapes from the sample chamber between the piston and the cylinder. The data presented in a previous table suggests that Test 2.4 provides results that have the lowest standard deviation for modulus, a yield stress result that falls within the $95 \%$ confidence interval, and a fairly low variance for energy absorption with an average value very close to the rough population mean.

A comparison of Test 10.1 and Test 10.2 indicates that the piston assembly has no affect on the yield stress or modulus. In Test 10.2 the yield stress and modulus are larger than in the unconstrained test. However, these values for Test 10.3 are lower. The mean bulk density of the samples in Test 10.3 was actually a bit lower than the bulk densities in Tests 10.1 and 10.2. This explains why the results are the lowest. Despite this finding, the yield stress results are still very close to each other suggesting that the piston has little to no effect on the results of the compression tests.

Looking at confidence intervals, the range of the yield stress is quite good. In the $95 \%$ confidence interval, the error of nearly $\pm 1.5 \%$ is the best of any other value in any set of data. The individual sample standard deviations for each set of samples are low and are very comparable to that of the unbiased standard deviation calculated for all combined data. However, the range of the modulus confidence interval is a little larger at just over $\pm 4.5 \%$, and the standard deviations are higher than anticipated. This suggests that the range of modulus readings has the highest spread compared to the results of yield stress and energy absorption. This problem can be the result of operator error, sample preparation, or equipment failure and will be addressed in the next section.

FPA-20 was tested in the same way as FPA-02 and FPA-10 in the fact that constrained and unconstrained results were compared for yield stress and modulus. Again, between the three sets of tests, there seems to be little to no effect from the piston assembly on the yield stress values. However, after Test 20.2, the sample standard deviations of the modulus data were, again, quite high. Noticing that the modulus standard deviations were becoming larger and larger with the increase in density of the foams, an effort was made to gather results with a lower standard deviation. Since a similar trend was not observed from the yield stress or energy absorption, it was assumed that the problem was not due to equipment issues or the testing technique itself. 
Therefore, sample preparation issues were addressed as a possible cause for the large spread of modulus results.

Test 20.3 is the result of that effort. It was discovered that modulus is highly dependant on the surface structure of the samples being compressed. All previous samples were cut using everyday machinery with the best precision possible at the time. However, it was noted that the surfaces in contact with the compression device (whether the piston assembly or the platens directly) were not always parallel. Therefore, the faces of the samples were not always fully in contact with the faces of the compression devices. Since the modulus is calculated using the part of the stress vs. strain plot before the sample fails, the initial dimensions and shape of the sample greatly influence the results. Thus, Test 20.3 was performed with the sole purpose of reducing the sample standard deviation of the modulus values of the set of data.

Samples for Test 20.3 were cut out using the same 1.25 in OD hole-saw as all other samples. However, the ends were cut with the aid of a jig that was not previously available. This jig was clamped to the saw's table and used as a straightedge guide to allow all 10 samples to be cut identically with better precision. During the previous tests, samples were cut as precisely as possible by hand without the help of a guide because there was not one available. However, this test shows that the use of the guide greatly improves the repeatability of the results, and lowers the scatter of the data.

This test was performed successfully. The standard deviation of the yield stress was reduced from 3.9 down to 1.3, and more impressively, the standard deviation of the modulus was reduced from over 136 down to just below 45. This result shows that more precise machining of the sample can reduce these deviations, giving results that are very reproducible as has been shown by the difference between Test 20.2 and Test 20.3.

The photos from the constrained test were taken for observation. The stainless steel cylinder prohibits visual observation of the samples during compression and so very little was known about the physical interaction between the piston and the sample contained within the assembly during such a test. Therefore, the Lexan ${ }^{\circledR}$ cylinder was employed to allow such an observation. The photos using the Lexan ${ }^{\circledR}$ cylinder show that the piston remains in constant contact with the sample surface. They also show that the piston assembly does not prohibit the samples from failing normally as shown in the unconstrained testing photos, yet it does prohibit the sample's cross-sectional area from changing. The foam was cracked through the middle, as was the case during the unconstrained test. However, instead of breaking and falling apart into several pieces, the foam sample's initial cross-section was retained. It can then be said that the piston does not negatively interfere with the failure mechanism of the sample during the compression test, while keeping the cross-section of the sample constant. Maintaining a constant cross-section throughout the compression test allows the energy absorption result to be attained.

The MER foam and WVU foam are denser than FPA-20, and the Ultramet foam has a much different internal structure than any of the other foams. There was not enough material to perform statistical analysis on any of these foams, other than a mean value with standard deviation. There was not enough material to make any type of changes to the tests or samples after the initial tests were performed, so the standard deviations are not as low as those from the GrafTech series. In spite of this fact, this series of tests were still successful because the main goal of them was to show that the 
compression test described here can successfully be performed on any foam with any density.

\subsubsection{MER Carbon Foam}

The tests on MER foam were performed because it was the foam with the highest density tested for this report measured at $37-1 \mathrm{~b} / \mathrm{ft}^{3}\left(0.59 \mathrm{~g} / \mathrm{cm}^{3}\right)$. The main intent was to show that foams much denser than FPA-02 or foams with different bulk structure could be successfully tested using this method. There was very little material to test so only two sets of three samples were run for this particular study. However, successful tests did return results for yield stress, modulus, and energy absorption (for the constrained technique only). The tests performed are described in the Table 17 and the results are shown in Table 18.

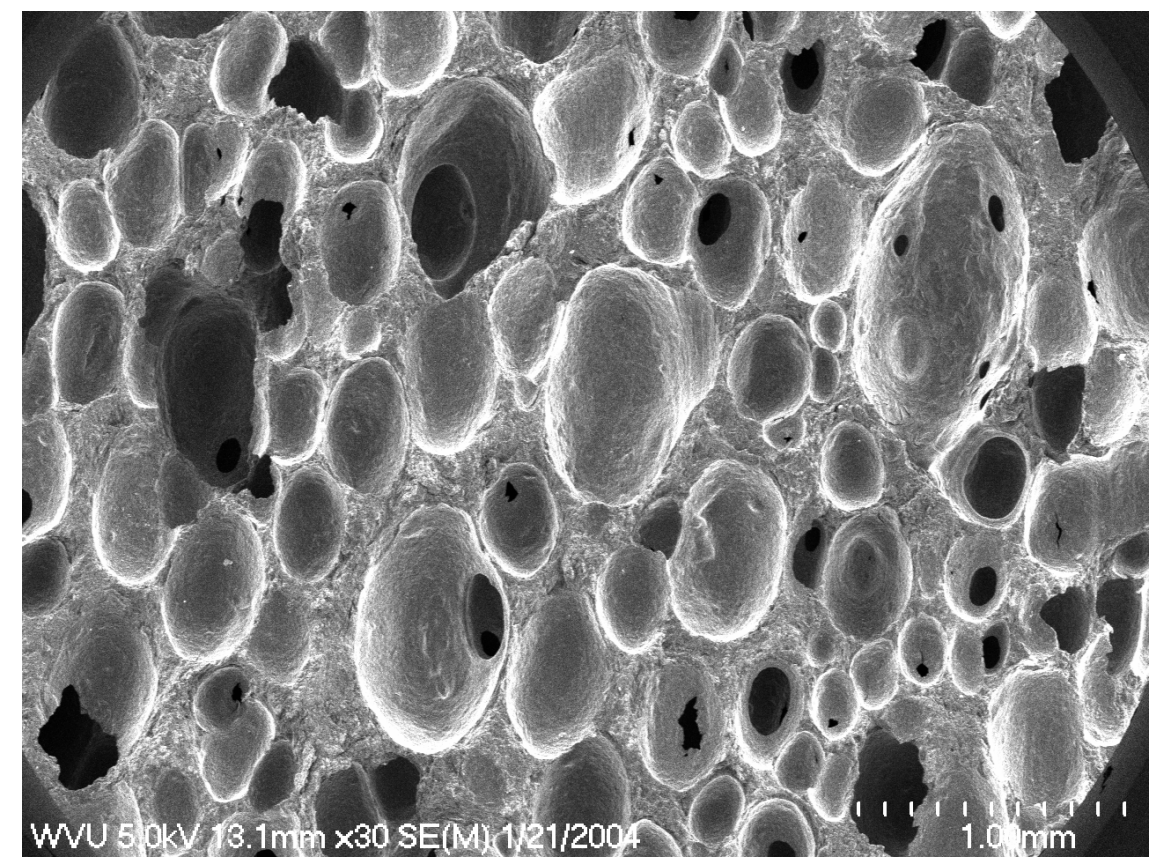

Figure 22. SEM Micrograph of MER Carbon Foam.

Table 16. Parameters for Compression Tests of Carbon Foam from MER Corp.

\begin{tabular}{|l|lll|}
\hline & $\begin{array}{l}\text { Test } \\
\text { Type }\end{array}$ & $\begin{array}{l}\text { Sample } \\
\text { Height }(\mathbf{c m})\end{array}$ & $\begin{array}{l}\text { Platen Speed } \\
(\mathbf{m m} / \mathbf{m i n})\end{array}$ \\
\hline Test MER.1 & Unconstrained & 2.54 & 1 \\
Test MER.2 & Constrained & 2.54 & 1 \\
\hline
\end{tabular}


Table 17. Mean Results from Each Set of Compression Tests for MER Foam.

\begin{tabular}{|c|c|c|c|c|}
\hline 3 samples/test & $\begin{array}{l}\text { Measured Bulk } \\
\text { Density }\left(\mathrm{g} / \mathrm{cm}^{3}\right)\end{array}$ & $\begin{array}{l}\text { Yield } \\
\text { Stress (MPa) }\end{array}$ & $\begin{array}{l}\text { Modulus } \\
\text { (MPa) }\end{array}$ & $\begin{array}{l}\text { Energy } \\
\text { Absorption }\left(\mathrm{MJ} / \mathrm{m}^{3}\right)\end{array}$ \\
\hline \begin{tabular}{|l|} 
Test MER.1 \\
\end{tabular} & 0.591 & 22.8 & 1160 & na \\
\hline Std Dev. & & 3.4 & 522 & na \\
\hline Variance & & 11.5 & 272484 & na \\
\hline Test MER.2 & 0.596 & 20.8 & 910 & 12.3 \\
\hline Std Dev. & & 2.0 & 20 & 0.5 \\
\hline Variance & & 4.1 & 400 & 0.3 \\
\hline
\end{tabular}

\subsubsection{WVU Carbon Foams}

The foam produced at West Virginia University is a coal-based carbon foam, so the foam in general is slightly different from the others with respect to the bulk matrix, precursor material, and the manufacturing process. The foam from WVU also has a larger bulk density of $34 \mathrm{lb} / \mathrm{ft}^{3}\left(0.54 \mathrm{~g} / \mathrm{cm}^{3}\right)$ than those foams from GrafTech. Therefore, because of these differences, the foam from WVU was tested, much like the MER foam, to show that this technique can successfully be used on any type of carbon foam, regardless of bulk density, precursor material, or manufacturing process. The tests are outlined in the Table 19 and results are shown in a Table 20. The initial foam piece, like that of FPA-20, was not 2 inches in height initially. Therefore, sample heights of 1.5 inches $(3.81 \mathrm{~cm})$ were tested instead of 2-inch samples.

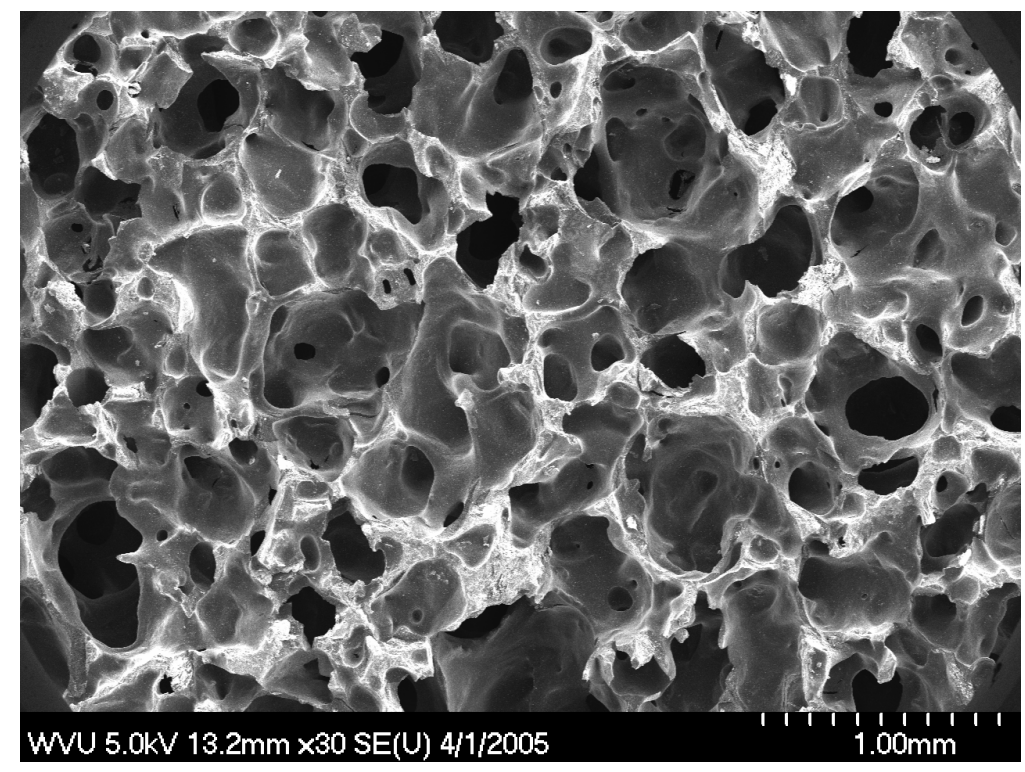

Figure 23. SEM Micrograph of Carbon Foam from WVU. 
Table 18. Parameters for Compression Tests of Carbon Foam from WVU.

\begin{tabular}{|l|lll|}
\hline & $\begin{array}{l}\text { Test } \\
\text { Type }\end{array}$ & $\begin{array}{l}\text { Sample } \\
\text { Height }(\mathbf{c m})\end{array}$ & $\begin{array}{l}\text { Platen Speed } \\
(\mathbf{m m} / \mathbf{m i n})\end{array}$ \\
\hline Test WVU.1 & Unconstrained & 3.81 & 1 \\
Test WVU.2 & Constrained & 3.81 & 1 \\
\hline
\end{tabular}

Table 19. Mean Results from Each Set of Compression Tests for WVU Foam.

\begin{tabular}{|l|llll|}
\hline 5 samples/test & $\begin{array}{l}\text { Measured Bulk } \\
\text { Density }\left(\mathbf{g} / \mathbf{c m}^{\mathbf{3}}\right)\end{array}$ & $\begin{array}{l}\text { Yield } \\
\text { Stress }(\mathbf{M P a})\end{array}$ & $\begin{array}{l}\text { Modulus } \\
(\mathbf{M P a})\end{array}$ & $\begin{array}{l}\text { Energy } \\
\text { Absorption }\left(\mathbf{M J} / \mathbf{m}^{\mathbf{3}}\right)\end{array}$ \\
\hline Test WVU.1 & $\mathbf{0 . 5 5 8}$ & $\mathbf{8 . 8 8}$ & $\mathbf{3 4 7}$ & $\mathbf{n a}$ \\
Std Dev. & & 0.14 & 36 & na \\
Variance & & 0.02 & 12.96 & na \\
\hline Test WVU.2 & $\mathbf{0 . 5 3 6}$ & $\mathbf{6 . 0 8}$ & $\mathbf{3 5 0}$ & $\mathbf{6 . 0 8}$ \\
Std Dev. & & 0.36 & 49 & 0.36 \\
Variance & & 0.13 & 2401 & 0.13 \\
\hline
\end{tabular}

\subsubsection{Ultramet Inc. Carbon Foam}

A foam from Ultramet was also evaluated. This particular foam fails much like FPA-02. The cross-sectional area of this lightweight foam $\left(3.87 \mathrm{lb} / \mathrm{ft}^{3}, 0.062 \mathrm{~g} / \mathrm{cm}^{3}\right)$ does not change during compression, which allows energy absorption to be calculated for both constrained and unconstrained tests. The amount of material allowed for more sets of tests to be performed, but since there were only five samples per test, statistical analysis was not performed. However, the standard deviation and the mean were calculated and compared between all the tests to compare differences in sample height and to observe any differences that the piston assembly may have had on the compression results. The tests are outlined in the Table 21 below and the results are shown in a Table 22. 


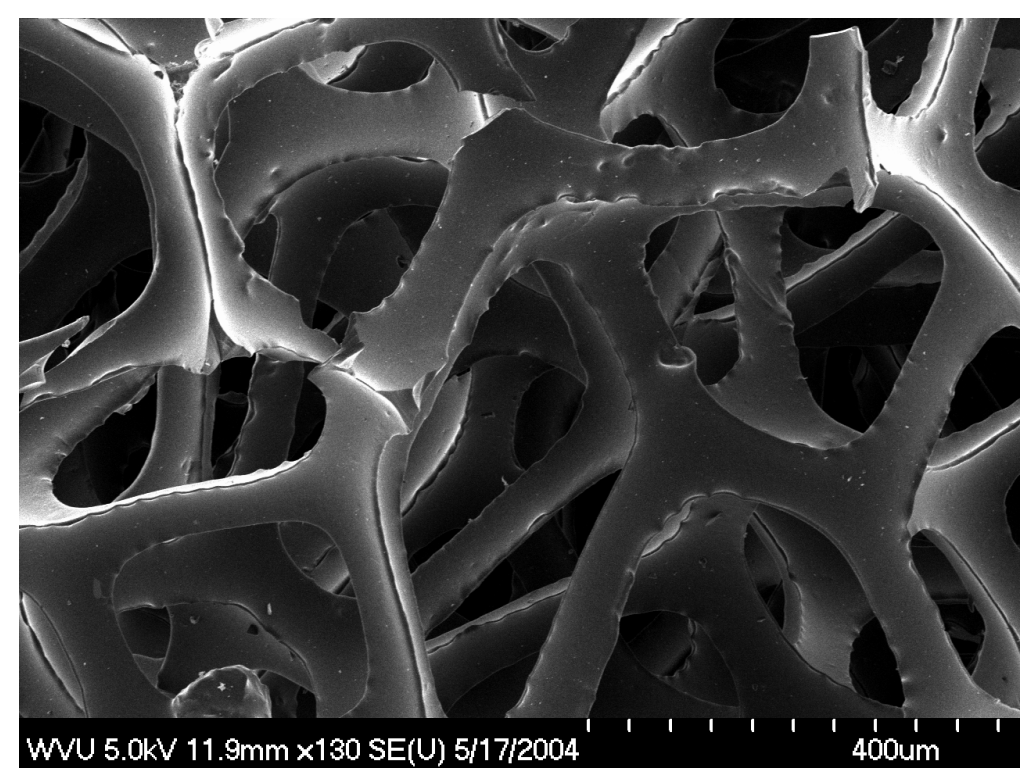

Figure 24. SEM micrograph of Carbon Foam from Ultramet.

Table 20. Parameters for Compression Tests of Carbon Foam from Ultramet.

\begin{tabular}{|l|lll|}
\hline & Test & $\begin{array}{l}\text { Sample } \\
\text { Type }\end{array}$ & $\begin{array}{l}\text { Platen Speed } \\
\text { Height }(\mathbf{c m})\end{array}$ \\
\hline Test U.1 & Unconstrained & 5.08 & 1 \\
Test U.2 & Unconstrained & 2.54 & 1 \\
Test U.3 & Constrained & 5.08 & 1 \\
Test U.4 & Constrained & 2.54 & 1 \\
\hline
\end{tabular}

Table 21. Mean Results from Each Set of Compression Tests for Ultramet Foam.

\begin{tabular}{|c|c|c|c|c|}
\hline 5 samples/test & $\begin{array}{l}\text { Measured Bulk } \\
\text { Density }\left(\mathrm{g} / \mathrm{cm}^{3}\right)\end{array}$ & $\begin{array}{l}\text { Yield } \\
\text { Stress (MPa) }\end{array}$ & $\begin{array}{l}\text { Modulus } \\
\text { (MPa) }\end{array}$ & $\begin{array}{l}\text { Energy } \\
\text { Absorption }\left(\mathrm{MJ} / \mathrm{m}^{3}\right)\end{array}$ \\
\hline Test U.1 & - & 0.316 & 31.5 & 0.222 \\
\hline Std Dev. & & 0.021 & 2.81 & 0.040 \\
\hline Variance & & 0.000 & 7.90 & 0.002 \\
\hline Test U.2 & 0.062 & 0.342 & 21.0 & 0.255 \\
\hline Std Dev. & & 0.058 & 8.31 & 0.057 \\
\hline
\end{tabular}




\begin{tabular}{|l|llll|} 
Variance & & 0.003 & 69.1 & 0.003 \\
\hline Test U.3 & $\mathbf{0 . 0 5 2}$ & $\mathbf{0 . 3 5 1}$ & $\mathbf{2 8 . 8}$ & $\mathbf{0 . 2 6 9}$ \\
Std Dev. & & 0.033 & 2.77 & 0.071 \\
Variance & & 0.001 & 7.67 & 0.005 \\
\hline Test U.4 & $\mathbf{0 . 0 6 3}$ & $\mathbf{0 . 3 4 4}$ & $\mathbf{1 4 . 3}$ & $\mathbf{0 . 3 0 6}$ \\
Std Dev. & & 0.019 & 1.99 & 0.040 \\
Variance & & 0.000 & 3.96 & 0.002 \\
\hline
\end{tabular}

\subsubsection{Discussion of Results}

The different foams described above were tested to show that the constrained piston compression test developed herein could successfully be performed on any carbon foam of any bulk density, precursor material, or manufacturing process. The small amount of material from each foam limited the number of samples and therefore statistical analysis could not be performed. However, the mean values for the constrained and unconstrained tests for each individual foam were compared. Despite the small number of samples for each set of tests, the results for yield stress are relatively close together regardless of constrained or unconstrained testing and the associated standard deviations are fairly low.

The results from MER foam were surprisingly close considering only six total samples were tested. SEMs show the anisotropy of the matrix of the foam, with elongated cells of different dimensions. Despite this fact, the results were still quite close to each other. The direct effect of anisotropy of the cell shapes was not part of the focus of this study and thus, was not investigated. The foam community, in general, agrees that foams are strongest in the foaming direction (the direction of the cell elongation) and so all of these foams were tested in this direction.

The piston assembly does not seem to have any effect as far as altering the values of the yield stress and modulus. It is important to note that the relation between modulus and sample preparation (as described for Test 20.3) was made after these tests (as well as Ultramet and WVU) were performed. The initial sample heights were just below 1 inch, therefore it was quite difficult and unsafe to handle the samples so close to the saw-blade in order to cut the edges and ensure they were parallel. Therefore the large standard deviations of the unconstrained test are most likely due to poor sample preparation, not the actual compression test itself. In addition, only three samples were available for each set of tests, which also will increase standard deviation. However, the constrained technique successfully gathered yield stress values that were in good agreement with those of the unconstrained test, the cluster of results for the modulus is much closer for the constrained test, and energy absorption was successfully calculated with a standard deviation below 0.5 .

The foam from West Virginia University is similar to MER in that the amount of data that could be gathered was small and yet the results were extremely close to each other. The average values of yield stress and modulus changed very little between the constrained and unconstrained test. Due to the small amount of data gathered, it is not possible to say with any certainty that the piston assembly added any resistance to cause 
the constrained values to slightly increase. In fact, the data from all other foams vary slightly up and down, seemingly independent of whether or not the test was constrained or unconstrained.

The foam from Ultramet behaved very much like FPA-02 in the sense that energy absorption could be gathered using both the unconstrained test as well as the piston assembly. This type of failure allows the energy absorption values of the constrained tests to be compared directly to those from the unconstrained tests. The same is true for the yield stress and modulus so that any effect of the piston assembly can be observed. The difference between 1 and 2 inch sample heights does not seem to affect the results. All yield stress and energy absorption values are nearly within standard deviation limits of each other which implies that value differences are not significant. It does appear that the constrained test increases all of the results, however, when this trend is compared to the other tests (from GrafTech, WVU, MER foams), there does not seem to be any similar tendencies to support this theory. That is to say, none of the other results from this study seem to provide adequate evidence to suggest that the constrained technique increases the testing results. Since there were only five samples per set of tests, it is difficult to make any absolute conclusions in this regard.

Based on the results from all of the compression tests performed in this study, a few general observations can be made. One observation is based on the density relation with yield stress. Studying the SEM micrographs and comparing them with the bulk densities of the foams, it is apparent that, in general, if a foam has a higher bulk density, the yield stress, modulus, and energy absorption are higher. This is as expected because the higher the density of the foam, the more solid material it will contain. It was also observed that density is not the only determining factor for foam strength. MER foam is nearly twice as dense as FPA-20, but the yield stress results are slightly higher for FPA20. The SEM micrographs show that the two foams have vastly different structure. For example, the cell sizes are different, the distribution of the cell sizes is different, and the cell walls have different thicknesses. Hence, the physical structure of the foam also has some effect on foam strength.

Several further observations can be made from the test results. The data show that the speed of the platen can be increased from 1 to $2 \mathrm{~mm} / \mathrm{min}$. The speed of the test is kept low for a few reasons. Dynamic crushing drives the resulting yield stress upwards due to localization of deformation and densification. These results drive up local strain rates and do not allow force to be evenly displaced over the entire volume of the sample. Other speeds were not tested (such as $3 \mathrm{~mm} / \mathrm{min}$ or $5 \mathrm{~mm} / \mathrm{min}$ ) due to an overall lack of material. Testing was limited to 1 and $2 \mathrm{~mm} / \mathrm{min}$ in order to gain more data from these two speeds so that useful comparisons could be made. Another reason is to completely avoid any influence on results from air resistance as air escapes the piston assembly. It is observed that the weight of the piston pushes out the air from the sample chamber if there is no foam sample in the piston assembly. The piston falls much faster than $2 \mathrm{~mm} / \mathrm{min}$. Therefore, it is determined that, in the platen speed range of 1 to $2 \mathrm{~mm} / \mathrm{min}$, air resistance is not a factor in the constrained piston assembly compression test.

The piston itself may also have its own effect on the values of the tests. The piston weighs $343 \mathrm{~g}(0.756 \mathrm{lb})$ and has a cross-sectional area of $79.7 \mathrm{~mm}^{2}\left(0.124 \mathrm{in}^{2}\right)$. This results in an additional stress of $0.04 \mathrm{MPa}$ on the testing values. Since this value is so small compared to the yield stresses for most of the foams tested (FPA-10, FPA-20, 
MER, WVU), it has been ignored. It probably has some effect on FPA-02 and the Ultramet foam, however, none of the recorded differences between constrained and unconstrained (with and without piston) are $0.04 \mathrm{MPa}$. For example, the yield stress for Test U.2 (unconstrained) is $0.342 \mathrm{MPa}$ while the value for Test U.4 (constrained) is 0.344 $\mathrm{MPa}$, a difference of $0.002 \mathrm{MPa}$. Therefore, the stress addition due to the weight of the piston was ignored for these foams.

The results also allowed comparison of 1, 1.5, and 2-inch $(2.54,3.81$, and 5.08 $\mathrm{cm})$ sample height. The results, in general, show that 1-inch tall samples yield results with much lower standard deviation than the 2-inch tall samples. If more material is trapped within the piston assembly during testing, there is a better chance that dust and particles will be available to interfere with the interaction between the piston face and the sample itself, therefore, a 1-inch tall sample is preferred.

Most importantly, the constrained tests provided results that were entirely consistent with those from the unconstrained test. There was very little to no statistically significant difference between any constrained or unconstrained test in any of the testing groups (FPA-02, FPA-10, MER, WVU, etc.). The yield stress and modulus values were all very comparable as expected, and the energy absorption data for FPA-02 and Ultramet showed very little change between the two testing techniques. This suggests that the constrained technique is a more preferred way to gather yield stress, modulus, and volumetric energy absorption in one test.

Due to the anisotropic structure of the foams, it is expected that there will be error in the results of any set of tests. No two pieces of the same foam will yield the exact same results because these foams do not have ideal perfect structures. Therefore, differences in mean values, standard deviations, and confidence intervals are expected. The $95 \%$ confidence intervals calculated for the three GrafTech samples have errors as low as $1.5 \%$ up to about $7.5 \%$. However, it has been shown that the error can be reduced with more precise sample preparation with the completion of Test 20.3 (of FPA-20). It is imperative that the sample surfaces are parallel to each other and to the compression faces. These surfaces must also be perpendicular to the sides to ensure that the forces applied to the sample are kept at a $90^{\circ}$ angle to the compression faces.

Currently, there are no theoretical values to which the experimental results of these tests can be compared. For this reason, the standard deviation of the data and the percent error of the confidence intervals are even more important to display the precision of this testing method. It has been shown herein that the newly-proposed constrained technique can consistently return reproducible results that are not only comparable to the conventional technique, but also include the energy absorption data.

\subsubsection{Protocol}

Several types of carbon foam were successfully tested using the proposed constrained piston method for compression of carbon foams. In addition to validating the technique for a wide variety of foam, several other parameters were investigated, including the platen speed (increased from 1 to $2 \mathrm{~mm} / \mathrm{min}$ ), and the defined sample height of 1 inch $(2.54 \mathrm{~cm})$. Statistical analysis was performed on the data from FPA-02, FPA-10, and FPA-20 in order to gather confidence intervals. It was noted that improved 
sample preparation in the machining and measurement of the samples decreases the error in the confidence interval and the standard deviation of the data. Therefore it is imperative that the faces of the sample be parallel to each other and parallel to the face of the piston assembly. The entire area of the samples must be in complete contact with the compression faces of the piston assembly during the entire compression test. These faces must also be perpendicular to the circular sides in order to make sure that the forces exerted on the samples are not being diverted away from the center of the samples. Finally, the technique was successfully demonstrated on carbon foams from Ultramet, MER, and WVU. These foams have various densities up to two times that of FPA-20. Statistical analysis was not performed on these foams due to the small amount of samples that were available for testing.

This study has shown that the constrained piston technique can successfully be used to gather compression data from carbon foams. Yield stress, modulus, and energy absorption can all be gathered in one testing session. It has been shown that the constrained test gives similar values of both yield stress and modulus compared to those from the unconstrained test. Thus it is a distinct improvement over the conventional unconstrained tests in which energy absorption data may not always be accessible.

These tests were performed to gather statistical analysis and information on the proposed constrained compression testing method for carbon foam. In order to gather the most reliable data with the smallest confidence intervals, more samples (well over 100) of each individual foam specimen should be tested.

Theoretical studies should be done on the foams tested in this study. There are no ideal, or preferred values at this time with which to compare absolute values of yield stress, modulus, or energy absorption. Therefore, modeling should be done in order to gain mathematical information with which to compare the experimental values.

The test method is described in Appendix A. 


\section{APPENDIX A. Proposed Test Protocol.}

\section{A.1 Sample Dimensions}

Specimens shall be a right cylinder. The faces of the right cylinder must be parallel to each other and perpendicular to the cylindrical sides. The diameter of each cylinder shall be $25 \mathrm{~mm}$ ( 1 inch) and the height shall be $25 \mathrm{~mm}$ ( 1 inch).

\section{A.2 Sample Preparation}

The specimens should be conditioned in the room in which the test shall be performed for 24 hours.

\section{A.3 Testing Apparatus}

Compression tests on the carbon foam have been successfully performed using an Instron 5869 load frame fitted with a $50 \mathrm{kN}$ load cell (any other comparably-equipped apparatus should be suitable). In order to control the sample cross-section during compression testing, a piston assembly has been constructed out of stainless steel.

A hollow, stainless steel cylinder has been turned on a lathe with an inside diameter of $25.42 \mathrm{~mm} \pm 0.0254 \mathrm{~mm}(1.001 \pm 0.001 \mathrm{in})$. An $88.9 \mathrm{~mm}$ (3.50in) long solid plunger and a $12.7 \mathrm{~mm}$ (0.50in) long solid plug were also constructed with an outside diameter of $25.37 \mathrm{~mm} \pm 0.0254 \mathrm{~mm}(0.999 \pm 0.001 \mathrm{in})$. The plug is employed as a false bottom for the sample chamber cavity to provide a stable base for the specimen and to ensure that the crushed specimen can be removed. The foam is compressed between the solid plunger and the solid plug to ensure a one-dimensional volume change between two parallel surfaces.

\section{A.4 Procedure}

The height and diameter of each specimen are recorded as an average of 3 different measurements using a caliper to the nearest \pm 0.001 in $( \pm 0.0254 \mathrm{~mm})$. The measurement shall be taken when the faces of the caliper first come into contact with the specimen and there should be no force from the caliper applied to the specimen. The specimen weight $( \pm 0.01 \mathrm{~g})$ shall also be taken so that bulk density can be calculated. The specimen shall be placed in the piston assembly, assuring that the loaded ends are parallel and no binding can occur between the piston and the cylinder. The piston assembly is placed between the platens, being sure that the assembly is centered on the lower platen. 
The platens shall compress at $2 \mathrm{~mm} / \mathrm{min}$ to assure that there is no air resistace being recorded as air escapes the cylinder.

\section{A.5 Calculations}

The yield strength (or compressive strength) $C(\mathrm{MPa})$ is defined as the maximum load $F_{m}(\mathrm{~N})$ of the initial linear portion of the stress-strain curve divided by the apparent cross-sectional area $A_{c}\left(\mathrm{~mm}^{2}\right)$ of the foam sample being tested.

$$
C=\frac{F_{m}}{A_{c}}
$$

The Young's Modulus $E_{c}(\mathrm{MPa})$ is the slope of the linear portion of the plot and is defined as the change in stress divided by the change in strain.

$$
E_{c}=\frac{y_{1}-y_{2}}{\left(\frac{x_{1}-x_{2}}{100}\right)}
$$

where $x_{1}, y_{1}$ is a set of data for strain and stress at an instant, and $x_{2}, y_{2}$ is a set of data for strain and stress at another instant (both are on the linear portion of the curve).

The total energy absorbed per unit volume is found by integrating the area under the Stress vs. Strain plot. Integration can be carried out using the Newton-Cotes closed integration formula where:

$$
\begin{gathered}
x_{i}=\frac{x_{n+1}-x_{n}}{100} \\
y_{i}=\frac{y_{n}+y_{n+1}}{2} \\
A=\sum_{1}^{i} x_{i} y_{i}
\end{gathered}
$$

The total area $A$ under the stress-strain plot, which is the total energy absorbed by the foam, is calculated by the summation of the products of each individual piece of area. The individual pieces are defined as the product of $x_{i}$ and $y_{i}$. The term, $x_{i}$, is defined as the difference between two consecutive data points of strain (\%), where the $y_{i}$ term is the arithmetic mean of two consecutive data points of stress (MPa). The area under the plot is the total energy absorbed per unit volume expressed in $\mathrm{MJ} / \mathrm{m}^{3}$. Dividing the total energy by the sample density results in specific energy $(\mathrm{kJ} / \mathrm{kg})$. 


\section{Appendix B. Stress-Strain Plots}

Notes: Plot Titles are named according to:

$\begin{array}{ll}\text { 1. } & \text { Foam Sample } \\ \text { 2. } & \text { Testing Set Number } \\ \text { 3. } & \text { Sample Number }\end{array}$

Foam Sample Codes:

2. -FPA-02

10. -FPA-10

20. -FPA-20

MER. -MER Foam

WVU. -WVU Foam

U. -Ultramet Foam

ex. Plot 2.1.5 represents

1. FPA-02 (GrafTech Foam)

2. Testing Set 1 (therefore representing Test 2.1)

3. Sample Number 5 
2.1.1

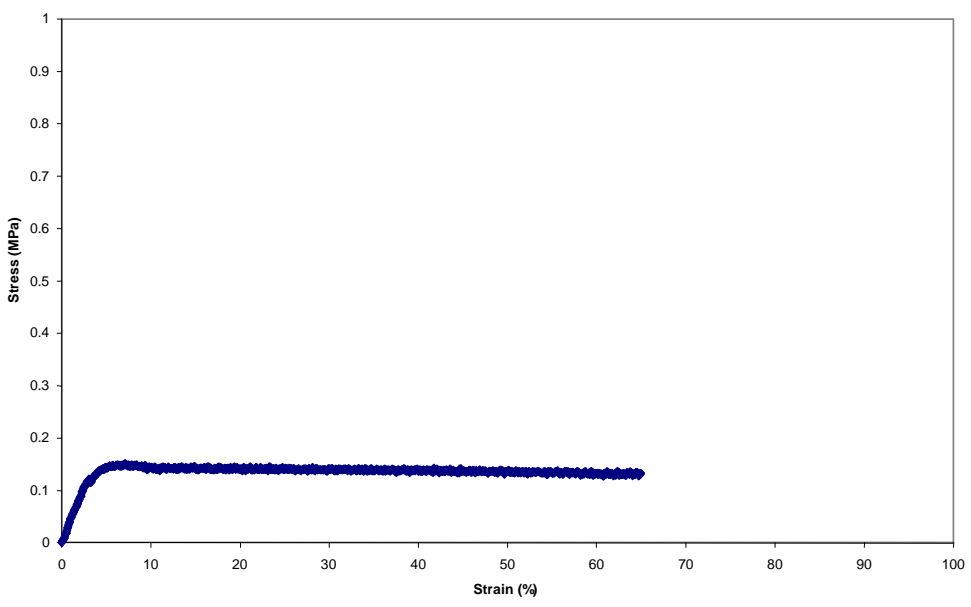

Figure 25. Stress Strain Plot, Sample 2.1.1.

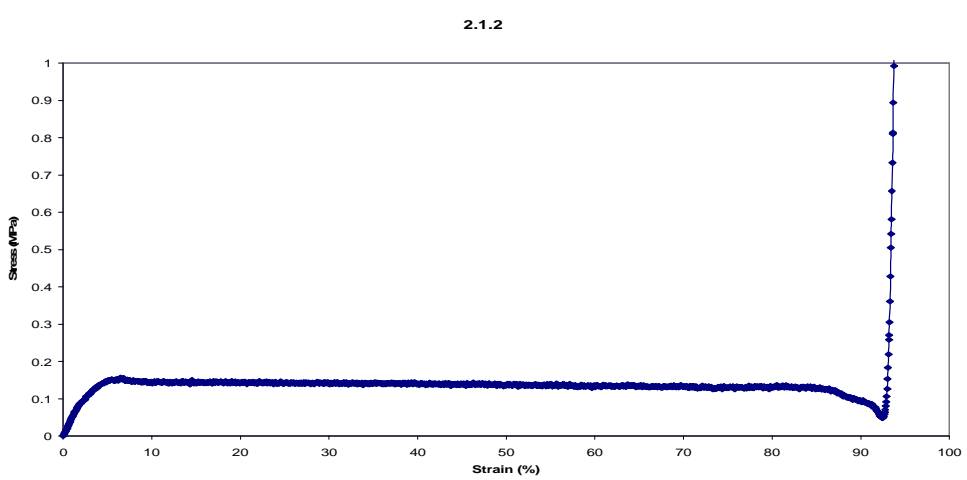

Figure 26. Stress Strain Plot, Sample 2.1.2.

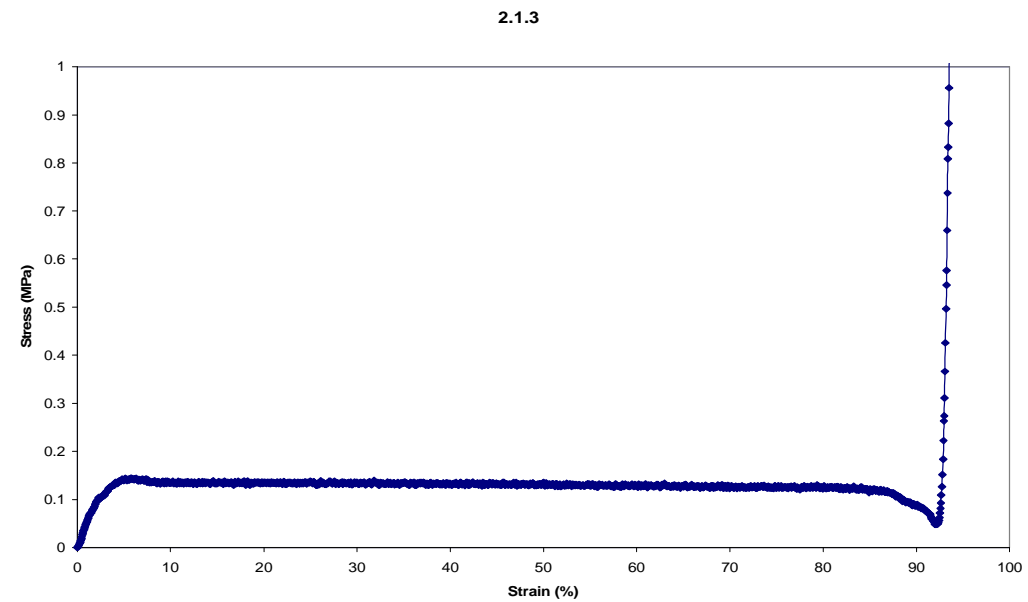

Figure 27. Stress Strain Plot, Sample 2.1.3. 


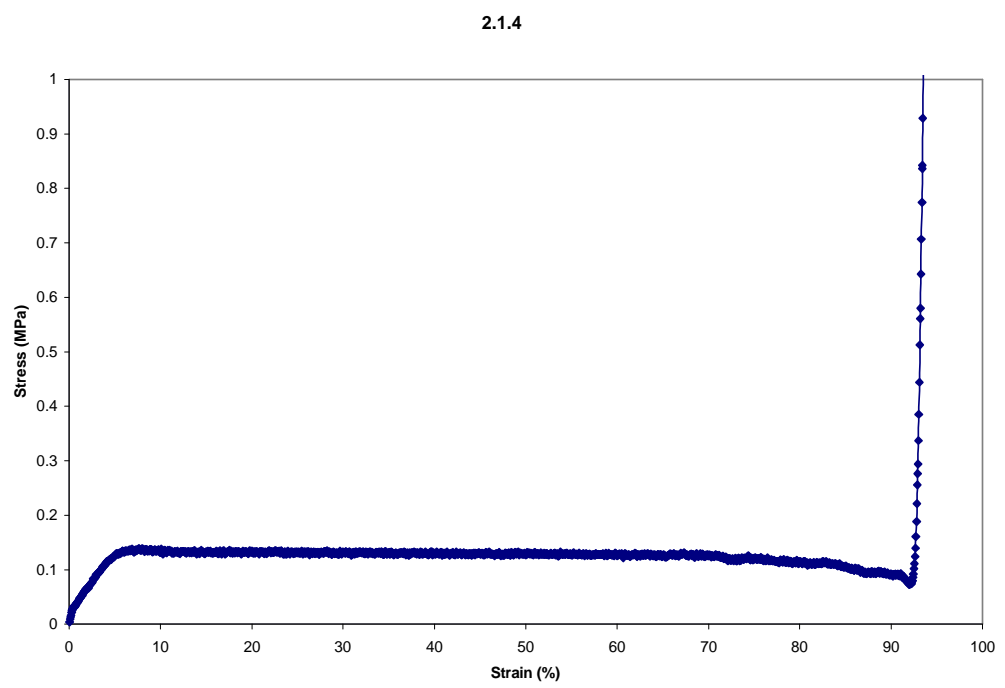

Figure 28. Stress Strain Plot, Sample 2.1.4.

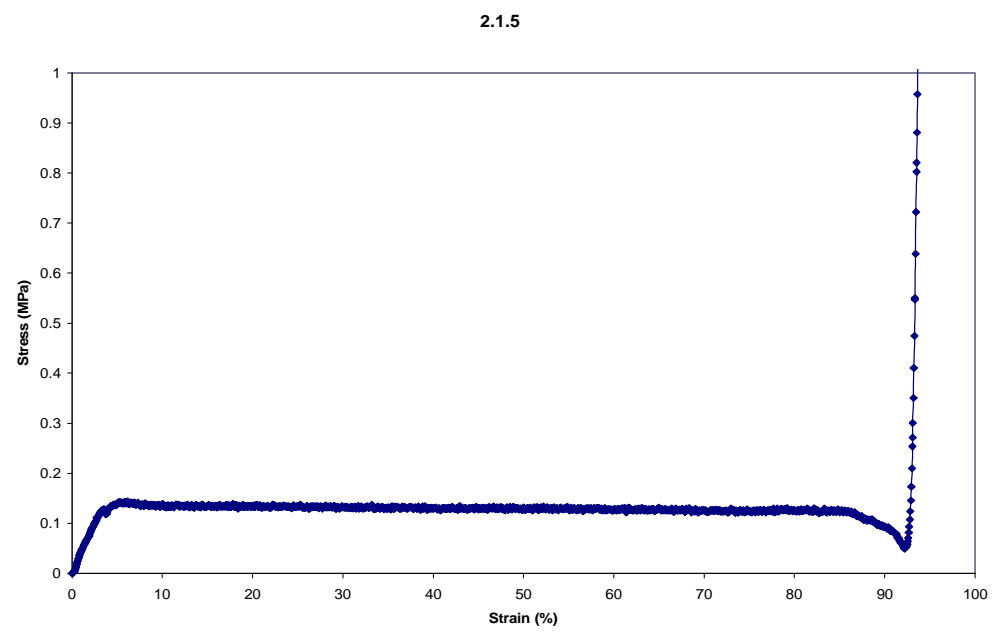

Figure 29. Stress Strain Plot, Sample 2.1.5.

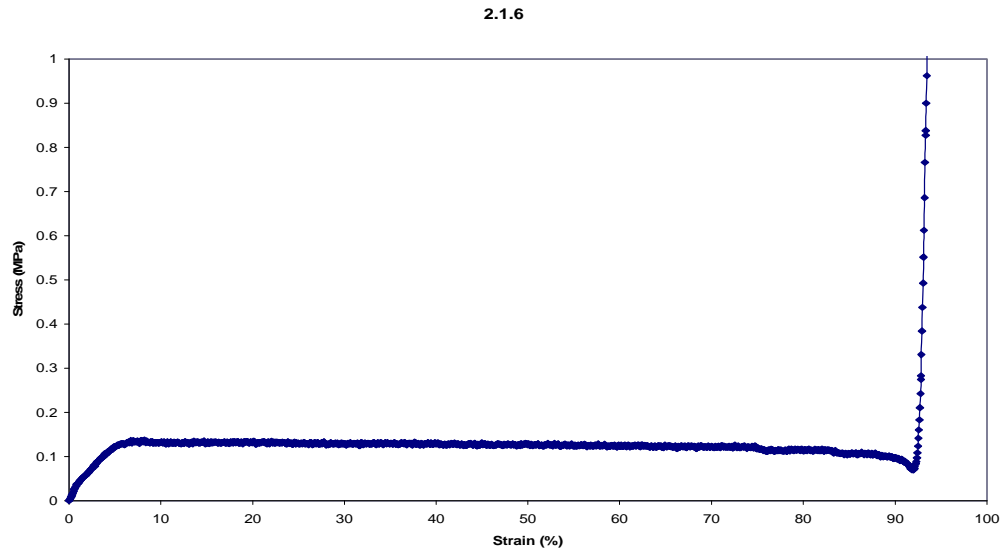

Figure 30. Stress Strain Plot, Sample 2.1.6. 


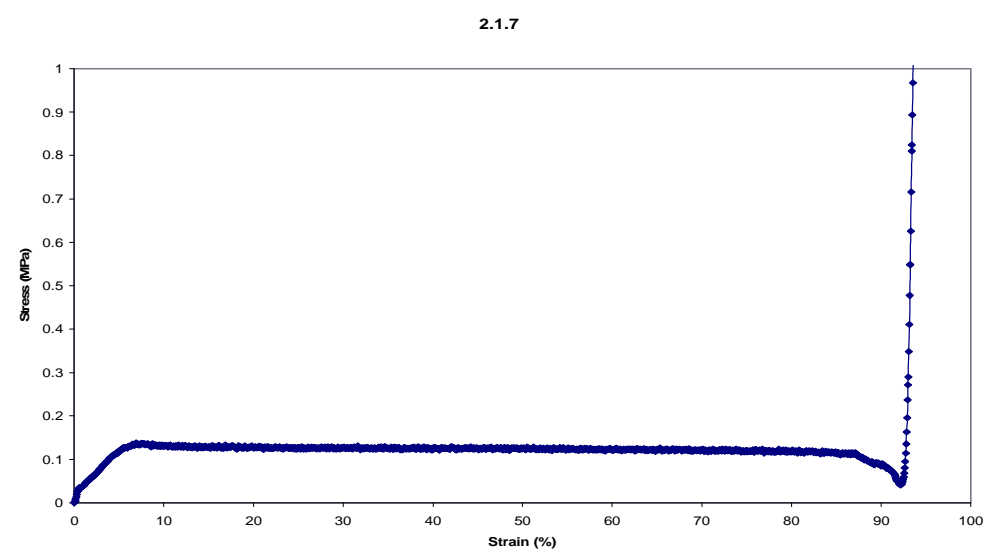

Figure 31. Stress Strain Plot, Sample 2.1.7.

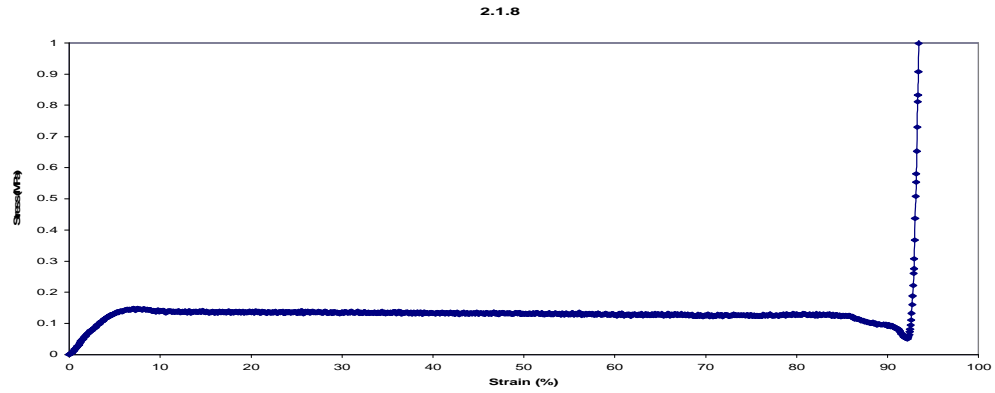

Figure 32. Stress Strain Plot, Sample 2.1.8.

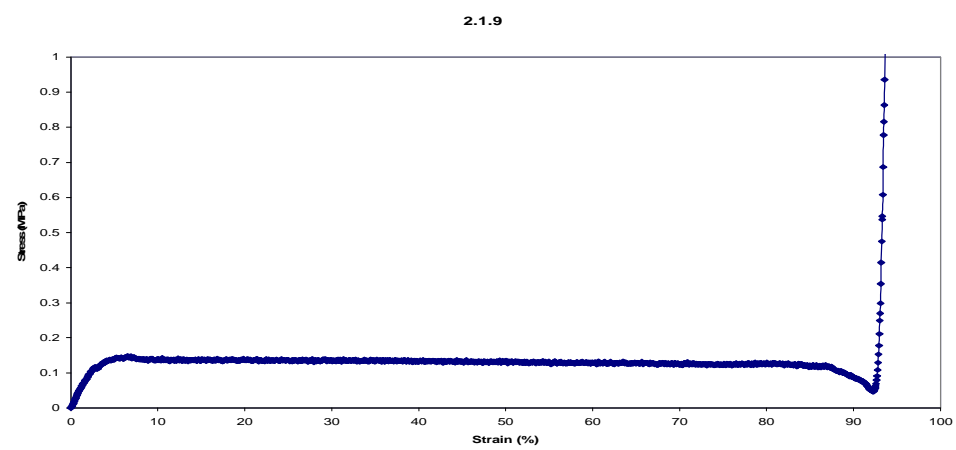

Figure 33. Stress Strain Plot, Sample 2.1.9. 


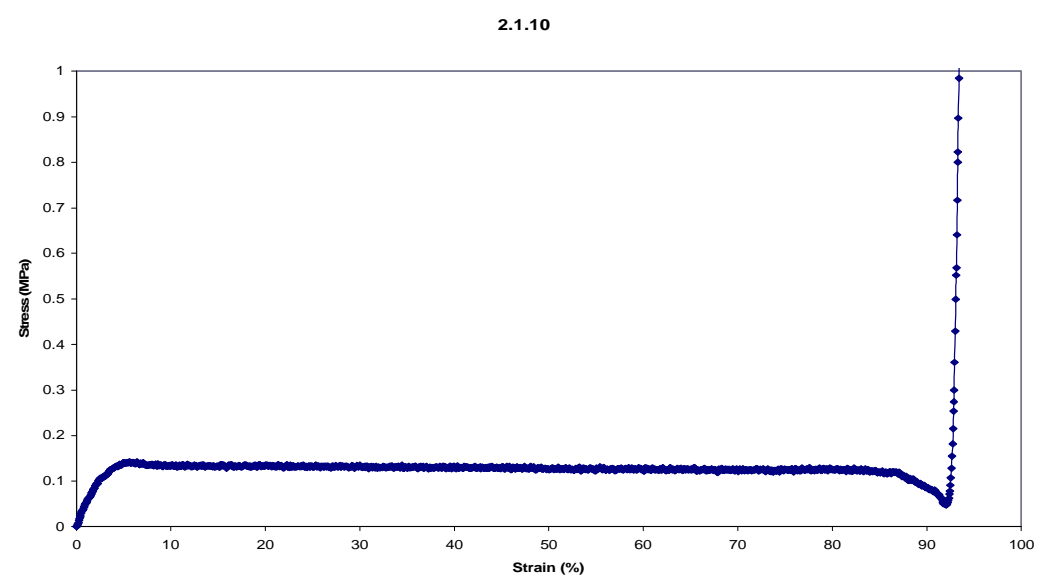

Figure 34. Stress Strain Plot, Sample 2.1.10.

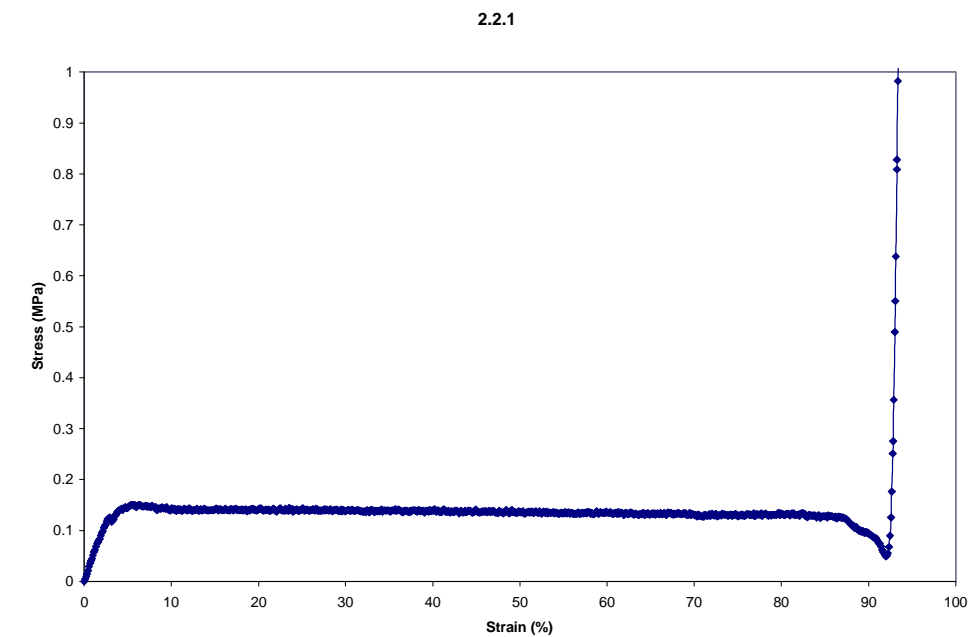

Figure 35. Stress Strain Plot, Sample 2.2.1.

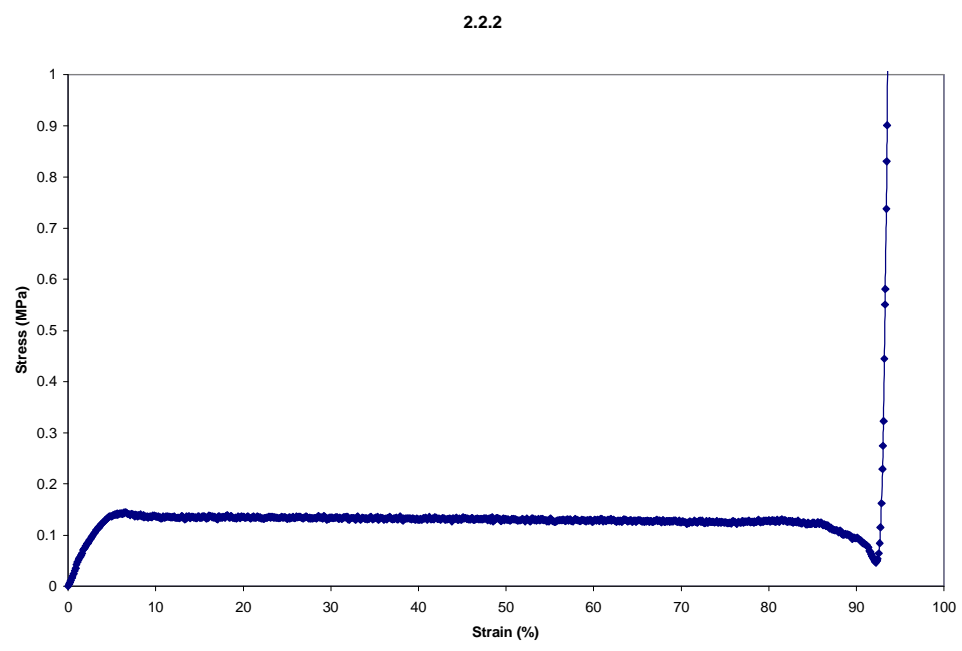

Figure 36. Stress Strain Plot, Sample 2.2.2. 
2.2 .3

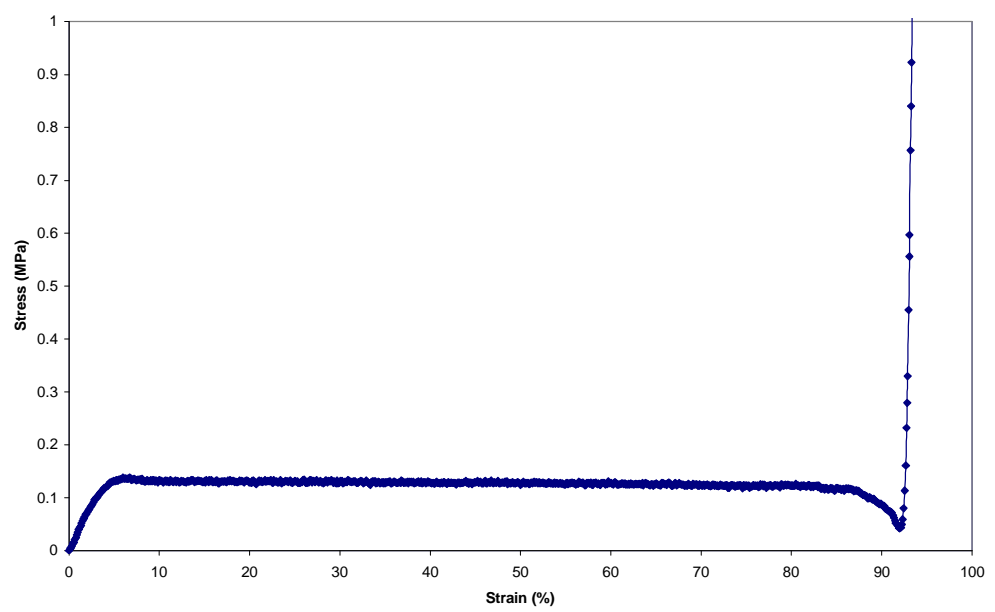

Figure 37. Stress Strain Plot, Sample 2.2.3.

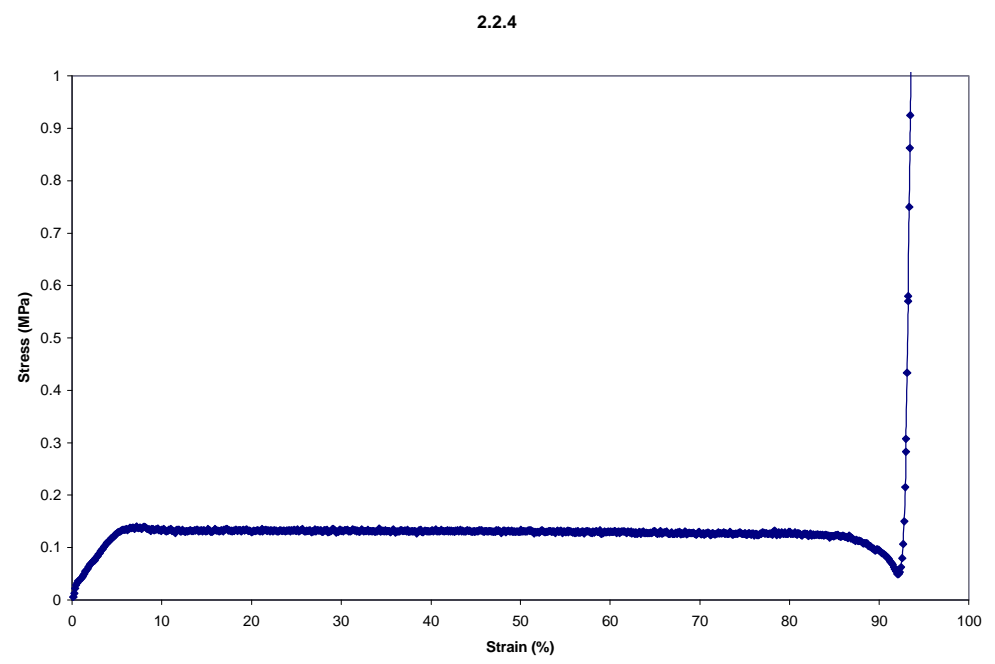

Figure 38. Stress Strain Plot, Sample 2.2.4. 


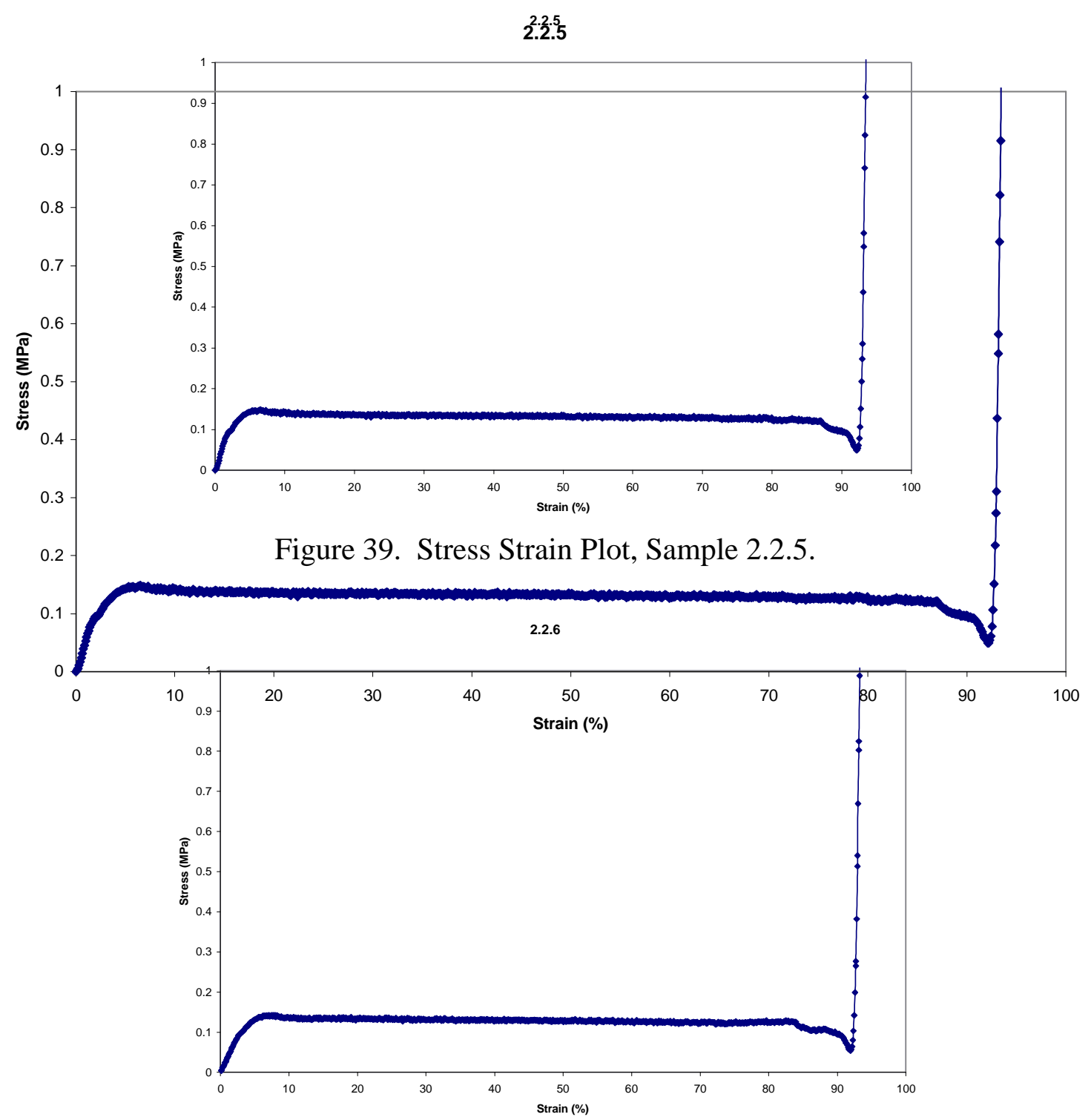

Figure 40. Stress Strain Plot, Sample 2.2.6. 


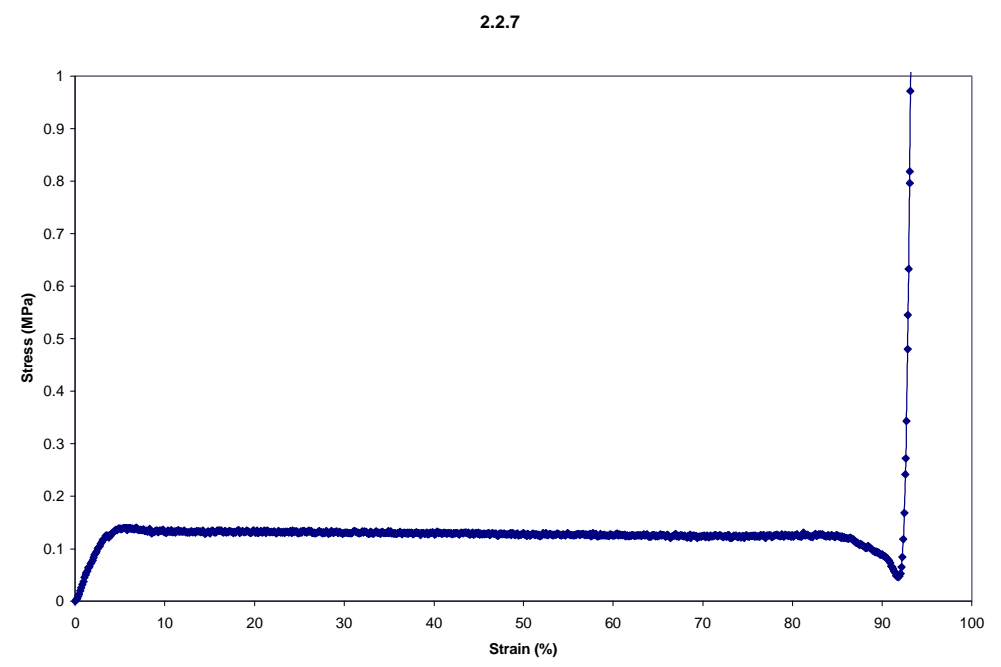

Figure 41. Stress Strain Plot, Sample 2.2.7.

2.2.8

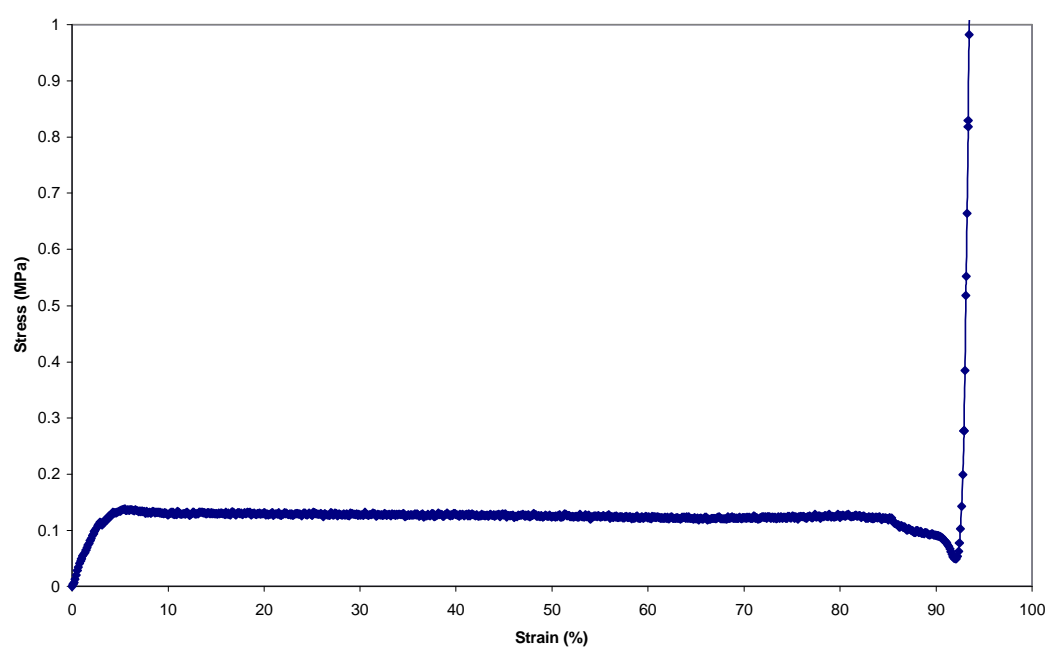

Figure 42. Stress Strain Plot, Sample 2.2.8. 


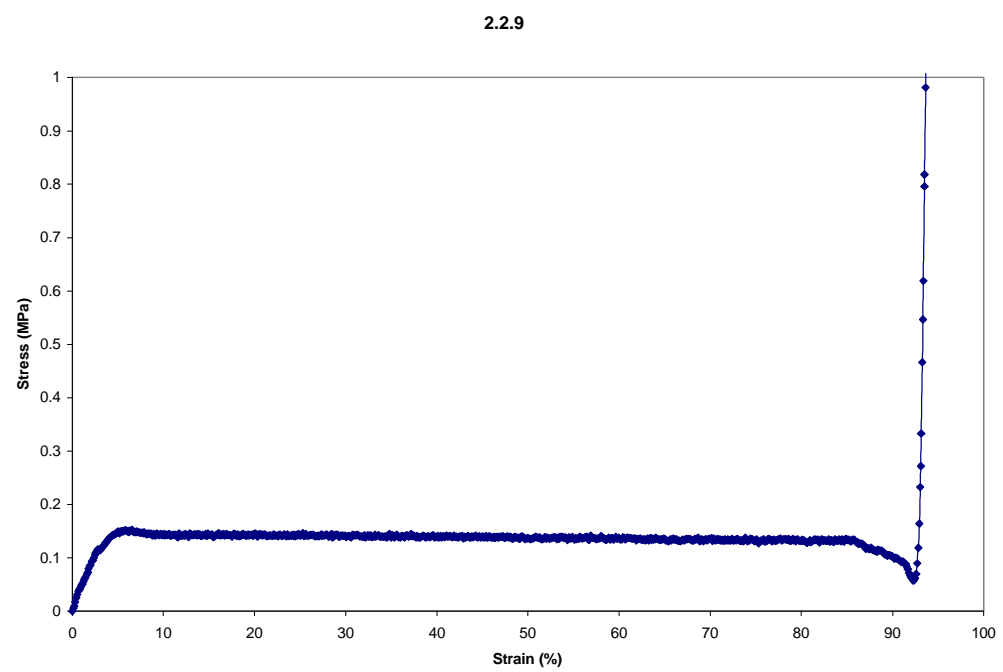

Figure 43. Stress Strain Plot, Sample 2.2.9.

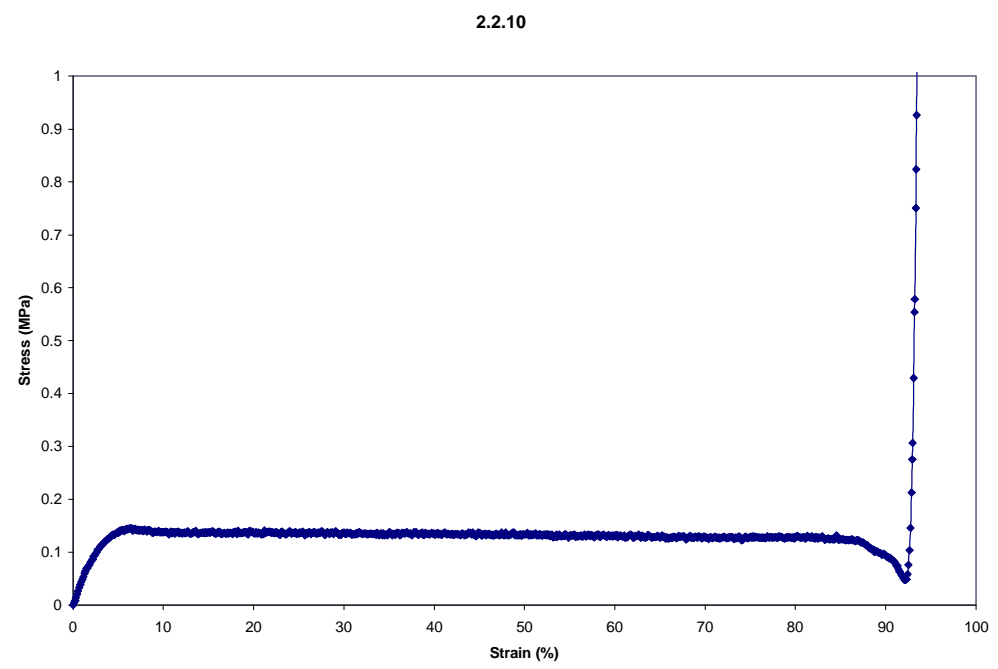

Figure 44. Stress Strain Plot, Sample 2.2.10. 


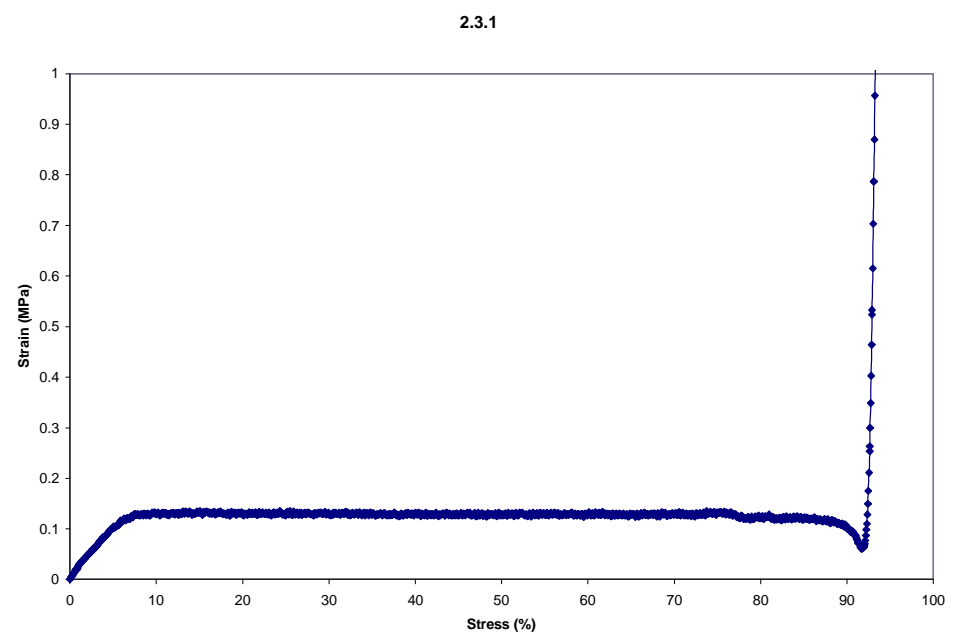

Figure 45. Stress Strain Plot, Sample 2.3.1.

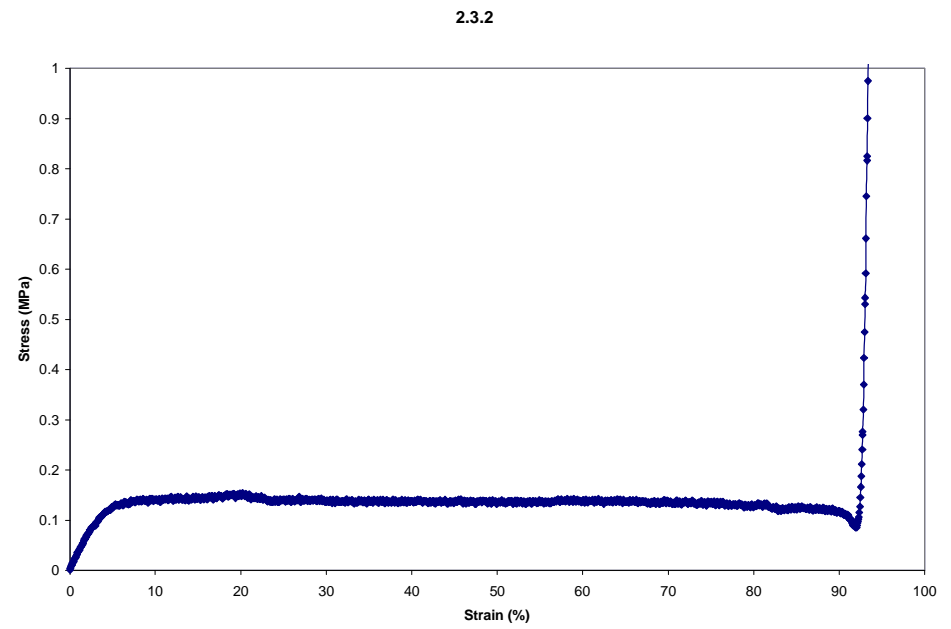

Figure 46. Stress Strain Plot, Sample 2.3.2.

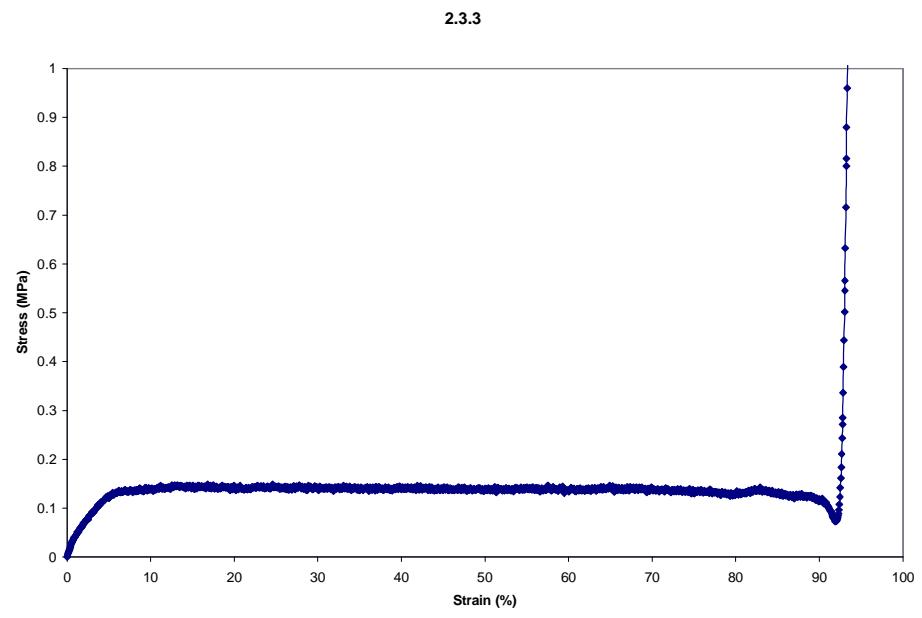

Figure 47. Stress Strain Plot, Sample 2.3.4. 


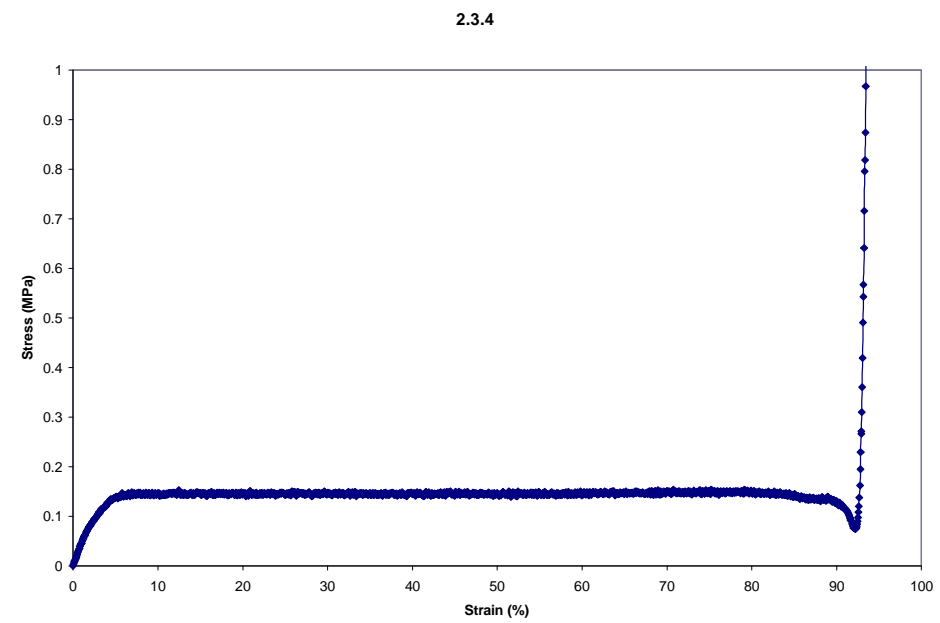

Figure 48. Stress Strain Plot, Sample 2.3.4.

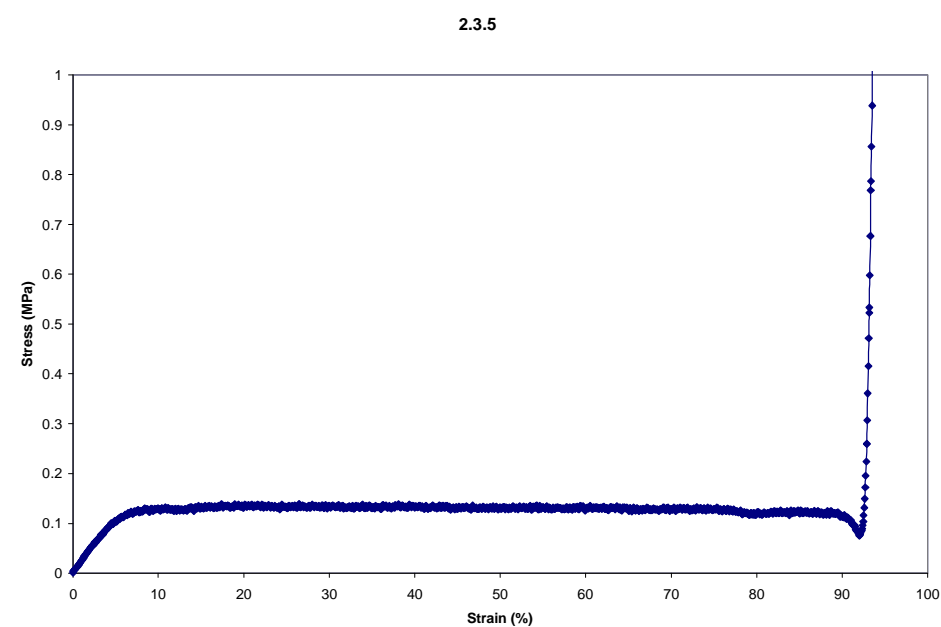

Figure 49. Stress Strain Plot, Sample 2.3.6.

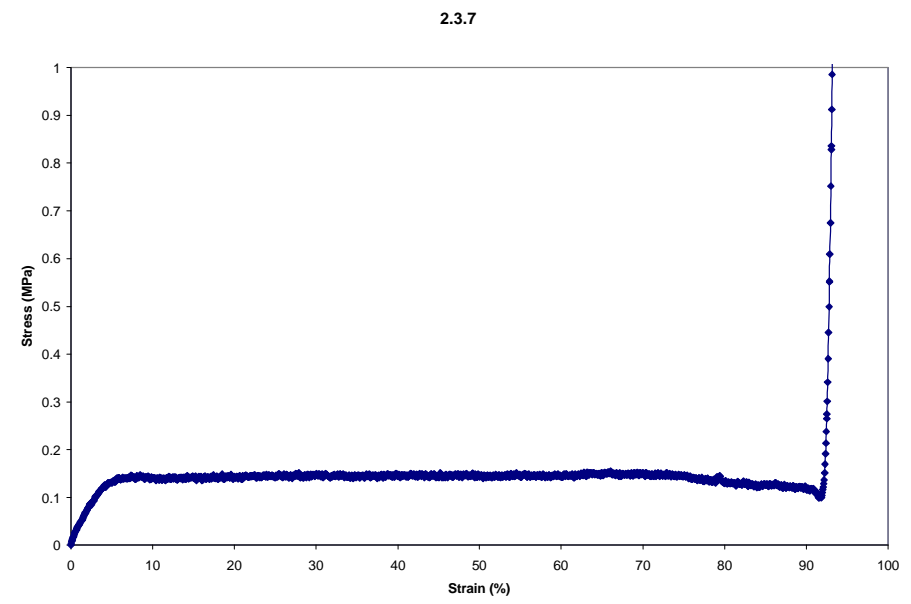

Figure 50. Stress Strain Plot, Sample 2.3.7. 


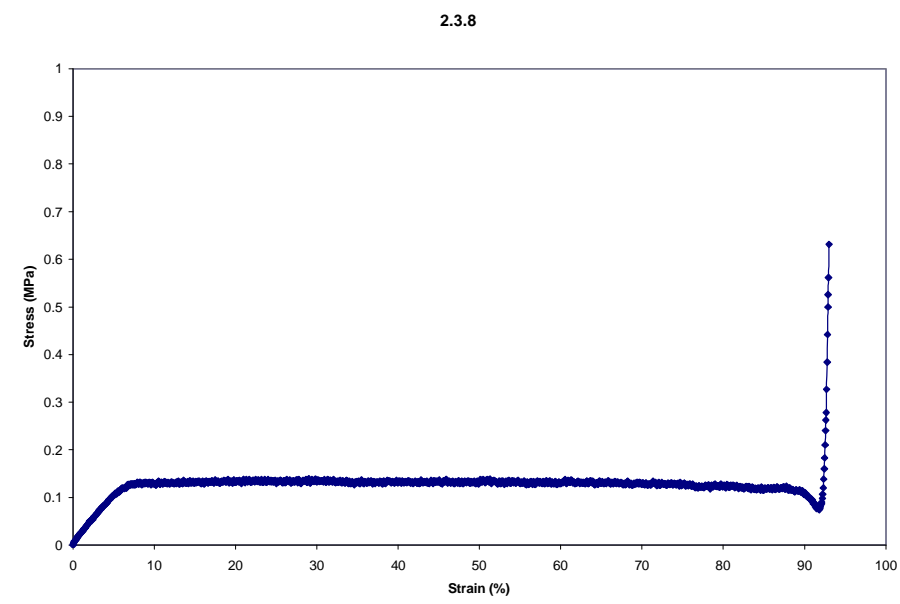

Figure 51. Stress Strain Plot, Sample 2.3.8.

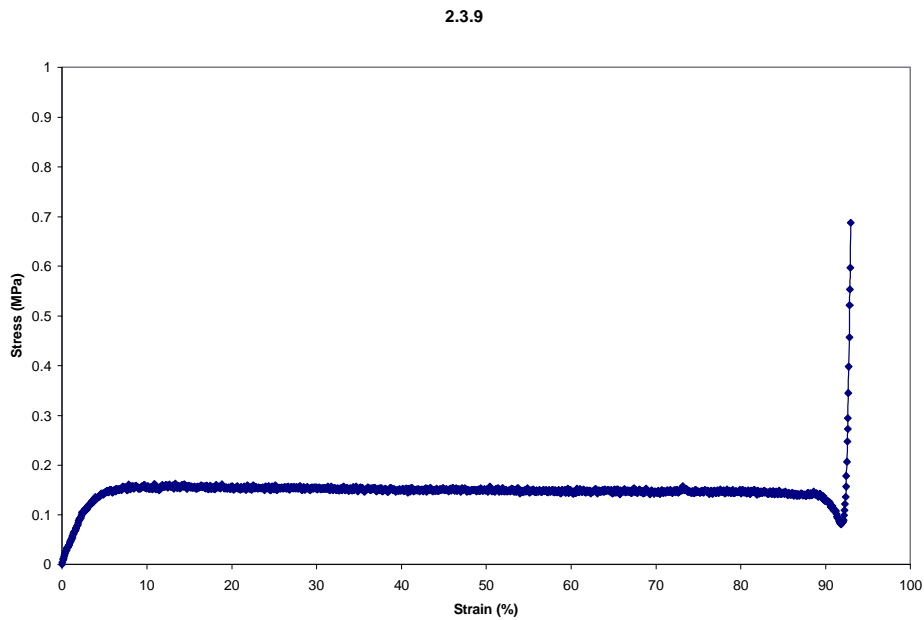

Figure 52. Stress Strain Plot, Sample 2.3.9.

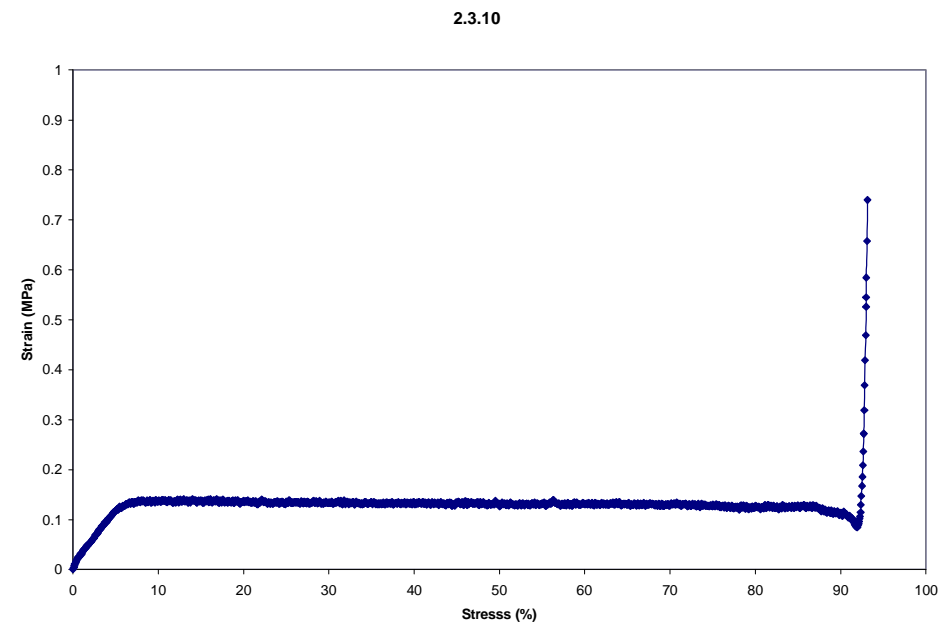

Figure 53. Stress Strain Plot, Sample 2.3.10. 


\section{Appendix C. References}

\footnotetext{
${ }^{1}$ M. Katakdaunde, MS Thesis, June 2004.

${ }^{2}$ A University, Industry, Government Cooperative Research Partnership. "Non-Fuel Use of Coal: CoalDerived Carbon Materials". Nov. 12, 1993. The National Research Center for Coal and Energy (NRCCE), West Virginia University, P. O. Box 6064, Morgantown, WV 26505-6064.

3 "Final Technical Report" Coal Based Nuclear Graphites for the New Production Gas Cooled Reactor. Task 1: Development of Coal-Derived Isotropic Coke and Nuclear Graphite, West Virginia University, 1994.
}

${ }^{4}$ ASTM C67-99a, Standard Test Methods for Sampling and Testing Brick and Structural Clay Tile. Annual Book of ASTM Standards, 2000; Section 4 Construction Vol. 04.05.

${ }^{5}$ ASTM C695-91(95), Standard Test Method for Compressive Strength of Carbon and Graphite. Annual Book of ASTM Standards, 2000; Section 5 Petroleum Products, Lubricants, and Fossil Fuels Vol. 05.05.

${ }^{6}$ ASTM D1621-00, Standard Test Method for Compressive Properties of Rigid Cellular Plastics. Annual Book of ASTM Standards, 2000; Section 8 Plastics Vol. 08.01.

${ }^{7}$ ASTM D1621-00, Standard Test Method for Compressive Properties of Rigid Cellular Plastics. Annual Book of ASTM Standards, 2000; Section 8 Plastics Vol. 08.01

8 F 414-96 Standard Test Method for Energy Absorbed by a Tire When Deformed by a Slow-Moving Plunger. 